\title{
INVESTIGATING THE ANNUAL WATER BALANCE OF A HIGH-ALTITUDE WATERSHED USING NEAR-REAL TIME LIDAR DATA INTEGRATION INTO A PHYSICALLY BASED SNOWMELT MODEL
}

by

Andrew R. Hedrick

\author{
A dissertation \\ submitted in partial fulfillment \\ of the requirements for the degree of \\ Doctor of Philosophy in Geophysics \\ Boise State University
}

December 2018 
(c) 2018

Andrew R. Hedrick

\section{ALL RIGHTS RESERVED}


BOISE STATE UNIVERSITY GRADUATE COLLEGE

\section{DEFENSE COMMITTEE AND FINAL READING APPROVALS}

of the dissertation submitted by

Andrew R. Hedrick

Dissertation Title: Investigating the Annual Water Balance of a High-Altitude Watershed Using Near-Real Time Lidar Data Integration Into a Physically Based Snowmelt Model

Date of Final Oral Examination: 19 October 2018

The following individuals read and discussed the dissertation submitted by student Andrew R. Hedrick, and they evaluated the student's presentation and response to questions during the final oral examination. They found that the student passed the final oral examination.

Hans-Peter Marshall Ph.D. Chair, Supervisory Committee

Danny Marks Ph.D. Member, Supervisory Committee

James P. McNamara Ph.D. Member, Supervisory Committee

Thomas H. Painter Ph.D. External Examiner

The final reading approval of the dissertation was granted by Hans-Peter Marshall Ph.D., Chair of the Supervisory Committee. The dissertation was approved by the Graduate College. 


\begin{abstract}
Knowledge of the amount of water stored in the mountain snowpack is crucial for flood prevention, drought mitigation, and energy production in the Western United States. In modeling terms, the most important component of the hydrologic water balance is the precipitation input to the system. Determining where and how much precipitation falls in mountain catchments, however, is the most difficult problem with regards to closing the water balance. The work presented in this dissertation details the modeling portion of the NASA Airborne Snow Observatory (ASO) using the iSnobal physically based snow model. This combination of remote sensing and modeling at $50 \mathrm{~m}$ resolution provides the most accurate quasi-operational estimates of snow distribution ever produced over a mountain basin. The first chapter supplies the background and motivation for undertaking this dissertation and presents a brief introduction to the following chapters. Chapter 2 describes the methods used for periodically inserting the ASO-derived snow depths into iSnobal over a consecutive four-year period (2013-2016) in the Tuolumne River Basin in California's Sierra Nevada. Chapter 3 provides a background for how the forcing data for our modeling approach was derived in near-real time and addresses the problem of reproducibility in the hydrologic sciences. Chapter 4 examines the water balance over the Tuolumne Basin using ASO-derived snow depth updates to iSnobal in three very dissimilar water years (2015-2017). For validation of the modeled evapotranspiration using the
\end{abstract}


water balance approach, we use an independent satellite-derived estimate of annual evapotranspiration and show that the basin runoff efficiency is related to total precipitation input for each year. Finally, Chapter 5 presents a summary of the previous chapters and provides a direction for moving the research detailed in this dissertation forward. The combined results of these studies will help usher in a shift toward more wide-spread use of physics-based models for operational predictions of water storage and runoff. 


\section{TABLE OF CONTENTS}

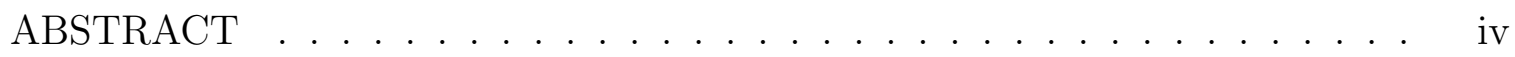

LIST OF FIGURES ..................... . ix

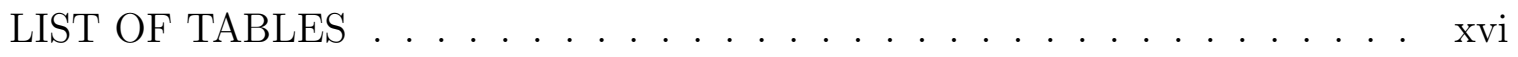

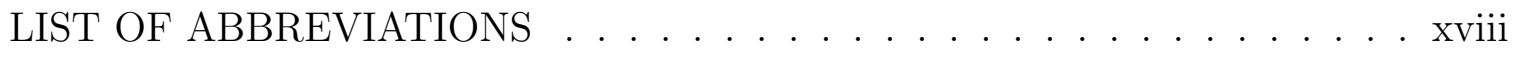

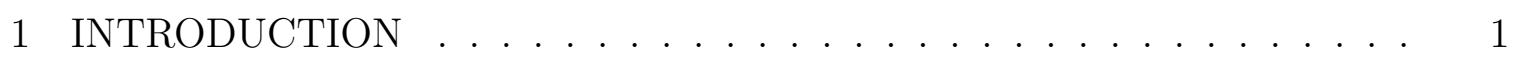

2 DIRECT INSERTION OF NASA AIRBORNE SNOW OBSERVATORY-DERIVED SNOW DEPTH TIME-SERIES INTO THE ISNOBAL ENERGY BALANCE

SNOW MODEL $\ldots \ldots \ldots \ldots \ldots \ldots \ldots \ldots \ldots \ldots \ldots \ldots \ldots \ldots \ldots \ldots$

2.1 Introduction . . . . . . . . . . . . . . . 6

2.2 Study Area . . . . . . . . . . . . . . . . . . . 8

2.3 Background and Methodology . . . . . . . . . . . . . 10

2.3.1 The Airborne Snow Observatory . . . . . . . . . . . . . 10

2.3 .2 iSnobal. . . . . . . . . . . . . . . . . . . . 12

2.3 .3 Modeling and Direct Insertion . . . . . . . . . . . . . . 22

2.4 Results . . . . . . . . . . . . . . . . . . . . . . . . 24

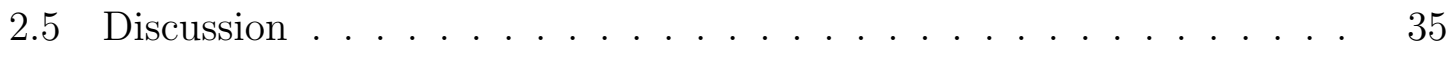




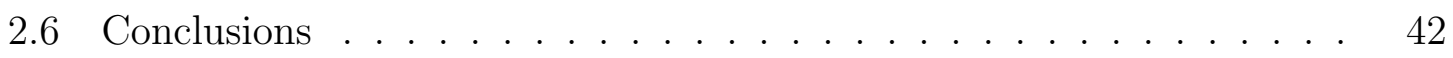

3 REPRODUCIBLE GRIDDED FORCING DATA FOR A PHYSICALLY BASED SNOW MODEL THROUGHOUT HISTORIC DROUGHT CONDITIONS IN

CALIFORNIA $(2013-2016) \ldots \ldots \ldots \ldots \ldots \ldots$

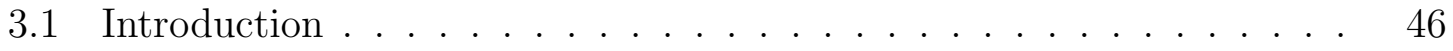

3.2 Site Description . . . . . . . . . . . . . . . . . 50

3.3 Meteorological Data . . . . . . . . . . . . . . . . . . 52

3.3 .1 Air Temperature and Humidity $\ldots \ldots \ldots \ldots$

3.3 .2 Wind . . . . . . . . . . . . . . . 57

3.3 .3 Incoming Shortwave Irradiance . . . . . . . . . . . 58

3.3 .4 Precipitation . . . . . . . . . . . . . 60

3.4 Snow / Streamflow Data . . . . . . . . . . . . . . . . 62

3.5 Example Application . . . . . . . . . . . . . . . . 63

3.6 Data Availability . . . . . . . . . . . . . . . 65

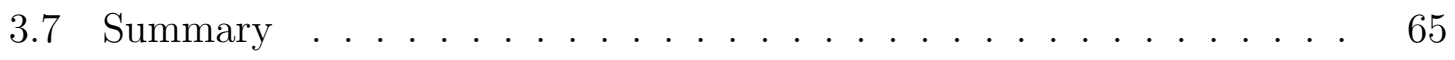

4 FROM DROUGHT TO FLOOD: EVALUATING EVAPOTRANSPIRATION IN A HIGH-ALTITUDE BASIN DURING EXTREME CONDITIONS . . 67

4.1 Introduction . . . . . . . . . . . . . . 68

4.2 Study Area \& Model Application . . . . . . . . . . . . . . . 71

4.2.1 iSnobal \& the Airborne Snow Observatory . . . . . . . . . 73

4.3 Background \& Methods . . . . . . . . . . . . . . . . . . . 74

4.3.1 Evapotranspiration in the Sierra Nevada . . . . . . . . . 76

4.3 .2 Precipitation $\ldots \ldots \ldots \ldots \ldots \ldots \ldots \ldots \ldots$ 
4.3 .3 Streamflow . . . . . . . . . . . . . . . . 78

4.3.4 Snow Surface Evaporation and Sublimation . . . . . . . . . 78

4.3.5 Uncertainty Considerations . . . . . . . . . . . . . . 80

4.4 Results \& Discussion . . . . . . . . . . . . . . . . . . . . . . . 81

4.4.1 Evapotranspiration Validation . . . . . . . . . . . . 86

4.4.2 Estimating Runoff Efficiency from the Water Balance . . . . . 89

4.5 Conclusions . . . . . . . . . . . . . . . . . . . . . . . . . . . 91

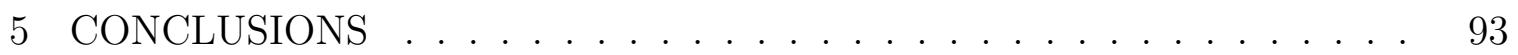

ACKNOWLEDGMENT . . . . . . . . . . . . . . . . . . . 96

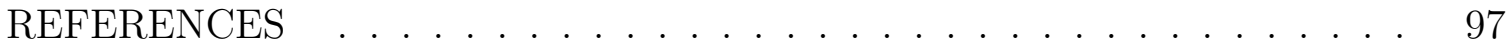




\section{LIST OF FIGURES}

2.1 Location and relief map of the Tuolumne River Basin above Hetch Hetchy Reservoir within the U.S. State of California. Locations of various measurement stations used to force iSnobal in water year 2013 are depicted as red circles. . . . . . . . . . . . . . .

2.2 Exploded view of the workflow for the iSnobal modeling progression from initiation to delivery of model products to the Airborne Snow Observatory (ASO) compute team. This chart includes the process of updating the iSnobal model state using the ASO light detection and ranging (lidar)-derived snow depths. . . . . . . . . . . .

2.3 Basin-averaged iSnobal snow water equivalent (snow water equivalent (SWE)) and surface water input (surface water input $(S W I)$ ) over three elevation bands for both the unmodified and ASO-updated predictions. The three bands, delineated by area, reveal elevations most sensitive to direct insertion of the lidar-derived snow depths. From the initial ASO update SWE is added at upper elevations for all four years, while complete melt out occurs earlier at mid to lower elevations. . . 
2.4 Spatial iSnobal SWE distribution both without the lidar update (i) and with (ii) the update applied for two surveys from water years 2014 and 2015, and the change in SWE resulting from the direct insertion of snow depths into the model. Inset areas $(5.0$ by $7.5 \mathrm{~km})$ reveal the enhanced detail of the change in modeled SWE distribution from the ASO updates. The spatial distribution is most refined for the first update of the year (update \#1, top row) and results in a much larger change in SWE than the updates later in the ablation season (update \#2, bottom row) which benefit from prior snow depth updates. Updates correspond to those also shown in Figure 2.5. . . . . . . .

2.5 iSnobal change in SWE from two ASO updates delineated by equalarea elevation bands. Each band (area $\approx 118 \mathrm{~km}^{2}$ ) makes up $10 \%$ of the total basin area. The y-axis of the box plot is the total change in basin SWE resulting from the update, while the elevation bands depicted at top are on the x-axis. Red circles show the mean $\triangle \mathrm{SWE}$ contribution per band, while box plots display $\triangle \mathrm{SWE}$ distributions within bands. Note the significant scale difference on the box plot vertical axes. .

2.6 Scatter plot of ASO snow depths and both iSnobal snow depths with and without prior ASO updates for the 7th update of the 2015 water year. With previous updates, the spatial distribution is accurately defined and model estimates are highly statistically correlated to the ASO-derived snow depths. . . . . . . . . . . . . . . . 
2.7 Coefficients of determination for each of the ASO-derived snow depth products with respect to iSnobal predicted snow depths on the day of the lidar acquisitions for both the previously updated (blue) and ordinary estimates without ASO (red). Once the spatial distribution is defined by the first update the correlation to subsequent updates drastically increases. . . . . . . . . . . . . . . . .

2.8 Basin-averaged iSnobal model results for both the unmodified predictions and the ASO-derived snow depth updates to the model state. The blue line is SWE and red line is the cumulative SWI from either the base of the snowpack or rain on bare ground. The solid black line is the estimated cumulative inflow to Hetch Hetchy Reservoir (courtesy of the San Francisco Public Utilities Commission (SFPUC)). The dashed vertical lines represent the timing of each lidar survey used to update the model. . . . . . . . . . . . . . . .

3.1 Location and relief map of the Tuolumne River Basin above Hetch Hetchy Reservoir within the U.S. State of California. Locations of the stations with measurements presented in this dataset are depicted, along with their site codes according to the California Data Exchange Center (CDEC). The lowest elevation within the basin boundary is 1150 m.a.s.l. at Hetch Hetchy Reservoir just adjacent to the HEM weather station. To the right is the basin hypsometric curve and elevations of all 23 stations included in this dataset. . . . . . . . . . 
3.2 Station names, identification codes (according to the CDEC), locations, and elevations in the WGS84 datum for all 23 stations used in the Tuolumne Basin modeling domain. Also shown are the timings of available individual measurements included in this dataset over the period of record. Types of measurements available are denoted by color. 54

3.3 Level 1 (L-1) data and smoothed level 2 (L-2) results at the Crane Flat Lookout weather station for the five basic weather measurements plus the derived cloud factor variable over a 20-day period in early 2015. These measurements include a) air temperature, b) relative humidity (back-calculated from vapor pressure), c) wind speed and direction, d) incoming shortwave radiation, e) derived cloud factor, and $\mathbf{f}$ ) precipitation. This time period depicts a warm, wet mid-winter precipitation event moving across the Tuolumne Basin. . . . . . . . 
3.4 Reported precipitation from three stations in the same vicinity for a 16-day period in February 2016. An approximately 32-hour storm began on February 18th and was captured across all three sites. In a), the DDM site experienced significant noise after the storm due to large diurnal fluctuations that were not adequately filtered by the chosen parameters in the Automated Precipitation Correction Program (APCP). The precipitation gauge at the LVT site (b) was likely capped from the snowfall event, and melted into the gauge two days afterwards. The LVM site (c) reported acceptable measurements throughout the time period. The capped measurements in (b) give a false depiction of the storm characteristics, and should be removed to limit bias in the resulting distributed precipitation grid. . . . . . . . . . . . . .

4.1 Location and relief map of the Tuolumne River Basin above Hetch Hetchy Reservoir within the U.S. State of California. Locations of various measurement stations used to force iSnobal in water year 2015 are depicted as yellow circles. . . . . . . . . . . . . . .

4.2 Cumulative estimated daily full natural flow (FNF) into Hetch Hetchy Reservoir from daily measurements that began in 1970. From 19191970 mean inflow estimates were kept by hand and the mean inflow since the dam construction is shown as the dash-dotted horizontal line. Lundquist et al. (2016) estimated the uncertainty in these daily estimates to be approximately $\pm 10 \%$. . . . . . . . . . . . 
4.3 Cumulative precipitation from (a) station measurements of precipitation interpolated to a $50 \mathrm{~m}$ grid using detrended kriging (DK) and (b) the $4 \mathrm{~km}$ Precipitation-elevation Regressions on Independent Slopes Model (PRISM) product for water year 2016. Locations of stations used by the DK method are depicted as circles in (a) . . . . . . . .

4.4 Basin-averaged products for the Tuolumne Basin (2015-2017). Solid lines represent iSnobal estimated SWE (blue), SWI (red), cumulative evaporative losses $\left.\left(E_{s}\right)\right)$ from the snow surface (green), as well as the estimated FNF at the outlet at Hetch Hetchy Reservoir (black). Dotted lines show the ASO-updated iSnobal results for each variable. The grey shaded area is the $\pm 10 \%$ uncertainty in the FNF estimates (Lundquist

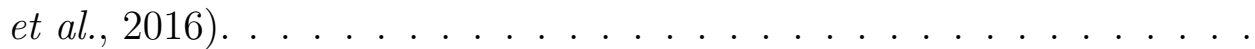

4.5 Basin-averaged evapotranspiration (ET) losses estimated by the cloud and snow-cover corrected MOD16 $500 \mathrm{~m}$ gridded product for water years 2015-2017 over the Tuolumne River Basin. The left-hand side $\mathrm{y}$-axis and the black curves represent cumulative totals over each year, while the right-hand side y-axis and the red curves are the 8-day sum totals. Evaporative losses (e.g. sublimation) from snow-covered surfaces are not considered in this MOD16 product and are instead accounted for by iSnobal. . . . . . . . . . . . . . . . 
4.6 Basin-averaged daily SWE storage (blue) and cumulative SWI (red) estimated by the ASO-updated iSnobal model. The dashed grey line is the previously reported cumulative estimated FNF (i.e. basin discharge). The black line is the sum of the cumulative discharge $(Q)$, $E T_{M O D}$ from the MOD16 product, and the $i$ Snobal estimated evaporation $\left(E_{s}\right)$ from the snow surface. The error bounds on the losses are derived from the $\pm 10 \%$ streamflow uncertainty. . . . . . . . . . . . 90 


\section{LIST OF TABLES}

2.1 By water year, number of ASO lidar survey updates and meteorological measurements by variable required as input to iSnobal. The numbers represent all stations that reported data for any length of time throughout the year. In addition, the specifics of the point measurement to regular grid interpolation for each variable are listed. (IDW $=$ Inverse Distance Weighting, DK $=$ Detrended Kriging) . . . . . . . . .

2.2 a) Hourly energy input forcing grids required by iSnobal. b) Hourly mass input forcing grids that are only required when precipitation is measured by one or more meteorological stations within the modeling domain. c) Output grids of snow mass and temperature (energetics are written into a separate file not shown here) from the time step prior to the ASO snow depth update. d) Initialization grids for the iSnobal restart. Highlighted variables in c) and d) indicate parameters that must be adjusted when incorporating the new snow depth measurements from the ASO . . . . . . . . . . . . . .

2.3 Hydrologic metrics derived from the precipitation model forcing grids and the ASO-updated $i$ Snobal SWE estimates. . . . . . . . . . . 
4.1 End of year cumulative sums for water balance terms. $P$ is the basin input term, $E_{s}$ is the modeled evaporative loss from the snow surface to the atmosphere, and $Q$ is the basin discharge. ET is computed from the water balance equation 4.7 and $E T_{M O D}$ is the evapotranspiration estimate from the MOD16 algorithm. The final column is the annual estimated total sum of the loss terms in the Tuolumne Basin. . . . . . 


\section{LIST OF ABBREVIATIONS}

ET evapotranspiration

$R E$ runoff efficiency

SWI surface water input

APCP Automated Precipitation Correction Program

AR atmospheric river

ARS Agricultural Research Service

ASO Airborne Snow Observatory

Caltech California Institute of Technology

CDEC California Data Exchange Center

CRAE Complementary Relationship Areal Evapotranspiration

DA data assimilation

DEM digital elevation model

DK detrended kriging 
EOS Earth Observing System

FNF full natural flow

HRRR High-Resolution Rapid Refresh

IDW inverse distance weighting

JPL Jet Propulsion Laboratory

LAI leaf area index

lidar light detection and ranging

LPDAAC Land Processes Distributed Active Archive Center

MAXUS MAXimum Upwind Slope

MERRA Modern-Era Retrospective Analysis for Research and Application

MODIS MODerate resolution Imaging Spectrometer

NASA National Aeronautics and Space Administration

NLCD National Land Cover Database

NLDAS North American Land Data Assimilation System

NRCS Natural Resources Conservation Service

NWRC Northwest Watershed Research Center

PRISM Precipitation-elevation Regressions on Independent Slopes Model 
QC quality control

RMSE root-mean square error

SFPUC San Francisco Public Utilities Commission

SMRF Spatial Modeling for Resources Framework

SNOTEL SNOw TELemetry

SQL Structured Query Language

SWE snow water equivalent

TEP total error propagation

USDA United States Department of Agriculture 
CHAPTER 1: INTRODUCTION

Over 2 billion people in the Northern Hemisphere rely on fresh water runoff that begins as snow in mountain catchments (Mankin et al., 2015). Mountain snowpacks are becoming more and more sensitive to increasing demands, yet mountain hydrologic processes remain the least understood of the terrestrial cryosphere.

A better understanding of the magnitude and timing of snowmelt runoff from mountain watersheds is hampered by the complex interactions between many different physical processes. Correlations between point measurements of snowfall and streamflow, developed over long time periods, can provide glimpses of how a basin responds to hydrometeorological conditions and is the primary streamflow forecasting technique used by operational water managers (Pagano et al., 2009). However, to more fully comprehend the entire snow-to-flow system, we must accurately account for each process affecting the hydrology.

Physically based models that attempt to resolve the energy and mass balances of snow have been under development for over 50 years (Anderson, 1976; Colbeck, 1974; Yen, 1962). Until recently, such models were considered to be too computationally intensive for real time operational applications. Simpler conceptual approaches became abundant during this time period because they performed reasonably well at predicting runoff in gauged basins (Day, 1990; Franz et al., 2008). The major 
assumption for those stochastic models is that the system is unchanging (i.e. stationary); whereas models based upon equations derived from physics are less susceptible to non-stationarity.

Feedbacks due to warming temperatures are now being observed in the hydroclimatic system (Groisman et al., 1999). For instance, land energy fluxes have been found to exhibit feedbacks from water management policies (Ferguson \& Maxwell, 2012), and increases in summer ET have cascading effects on water availability (Foster et al., 2016). These feedbacks cannot be explained by legacy statistically based models since there is no prior record of their occurrences.

This dissertation details the implementation of a high-resolution, physically based iSnobal snow model (Marks et al., 1999) in near-real time over a large mountain basin. Remote sensing measurements of snow depth from multitemporal ASO lidar surveys over five years were periodically inserted into the model, updating the snowpack distribution (Hedrick et al., 2018a). These ASO updates provided more accurate simulations of SWE in the upper elevations of the basin.

Chapter 2 pertains to the specific methodology of incorporating the updates into the snow model in near-real time. Results show that the modeled precipitation distribution does not completely capture elevational gradients and is more uniform than the ASO-derived distribution. In addition, the first update of the year was found to be more important than subsequent updates, yet those late season updates help maintain an accurate spatial distribution when modeled melt patterns begin to drift from reality.

Chapter 3 elaborates on the ASO updating procedure by describing the groundbased weather station data that was used to create the necessary hourly model forcing 
grids. A major conclusion is that implementing the model in near-real time over a sparsely instrumented basin requires significant human interaction for ensuring serially complete model estimates. A secondary result from this chapter, though no less important, is that the entire modeling approach used in this Dissertation is entirely reproducible. This was accomplished using a novel approach to using a combination of data repositories, Operating-System-Level Virtualization, and version controlled software.

A scientific application of the combination of remote sensing and the physically based modeling approach is presented in Chapter 4. Using the monitored reservoir inflow to the Hetch Hetchy Reservoir at the terminus of the basin, and the iSnobal-estimated SWI constrained by the ASO updates, the annual evapotranspiration throughout the basin was determined for three very dissimilar water years (2015-2017) using a water balance approach. With the groundwater loss component of the water balance approximated as negligible, the residual can be represented by losses to other sources in the form of evaporation, transpiration, and sublimation. In maritime snowpacks such as that found in the Tuolumne, sublimation losses are much lower than those found in continental snowpacks, but they are still considered by $i$ Snobal as a separate loss term. The remaining dominant term, ET, has been the focus of a few other studies in the Sierra Nevada. Our approach here is to validate the iSnobal-estimated residual using an independent gridded approximation of ET over the basin. The approximation is from the MODerate resolution Imaging Spectrometer (MODIS) Global Evapotranspiration Product (MOD16) (Mu et al., 2011), which is based on the Penman-Monteith concept (Monteith, 1965). Results showed that the modeled residual was within the bounds of the measured product. Additionally, the 
runoff efficiency of the basin, or the ratio of runoff to precipitation, increased as precipitation increased through all three years. Finally, the addition of ASO updates to the $i$ Snobal modeling stream increased the accuracy of the precipitation inputs to the basin by a factor of three, resulting in higher accuracy estimates of evapotranspiration and runoff efficiency. 


\title{
CHAPTER 2:
}

\section{DIRECT INSERTION OF NASA AIRBORNE SNOW OBSERVATORY-DERIVED SNOW DEPTH TIME-SERIES INTO THE ISNOBAL ENERGY BALANCE SNOW MODEL}

\begin{abstract}
Accurately simulating the spatiotemporal distribution of mountain SWE improves estimates of available melt water and benefits the water resource management community. In this paper we present the first integration of lidar-derived distributed snow depth data into a physics-based snow model using direct insertion. Over four winter seasons (2013-2016) the National Aeronautics and Space Administration (NASA)/California Institute of Technology (Caltech) Jet Propulsion Laboratory (JPL) ASO performed near-weekly lidar surveys throughout the snow melt season to measure snow depth at high-resolution over the Tuolumne River Basin above Hetch Hetchy Reservoir in the Sierra Nevada Mountains of California. The modeling component of the ASO program implements the iSnobal model to estimate snow density for converting measured depths to SWE, and to provide temporally complete snow cover mass and thermal states between flights. Over the four years considered in
\end{abstract}


this study, snow depths from 36 individual lidar flights were directly inserted into the model to provide updates of snow depth and distribution. Considering all updates to the model, the correlation between ASO depths and modeled depths with and without previous updates was on average $r^{2}=0.899(R M S E=12.5 \mathrm{~cm})$ and $r^{2}=0.162(R M S E=41.5 \mathrm{~cm})$, respectively. The precise definition of the snow depth distribution integrated with the iSnobal model demonstrates how the ASO program represents a new paradigm for the measurement and modeling of mountain snowpacks and reveals the potential benefits for managing water in the region.

\subsection{Introduction}

In the Western United States, mountain snowmelt is the primary source of water supply for domestic, agricultural and ecosystem use, provides hydropower electricity to millions of people, and replenishes groundwater. In the state of California, the Sierra Nevada seasonal snowpack on average provides an additional $70 \%$ of water storage to the existing manmade reservoir system (Dettinger \& Anderson, 2015). For most of the 20th century, the relative stability of the relationship between point measurements of streamflow and SWE at index sites allowed the use of empirical relationships for making decisions that affect downstream consumers and stakeholders,

albeit with seasonal forecast errors of $20 \%$ to greater than $40 \%$ (Dozier, 2011). However, a warming climate shortens the duration of seasonal snow cover in the Northern hemisphere, decreasing snowfall and subsequently the naturally stored water supply (Derksen \& Brown, 2012; Vaughan et al., 2013). With ever increasing demand, low precipitation totals, abnormally higher temperatures, and a reduced snowpack (Griffin \& Anchukaitis, 2014; Henn et al., 2018b; Margulis et al., 2016; Wilson et al., 2016), water supply forecasting is proving to be more important than ever before. The re- 
cent 2012-2015 California drought has reiterated the need to identify new methods to quantify water storage in mountain snowpacks.

Changes in the timing of snow cover accumulation and ablation alter the relationship between streamflow and SWE at index sites and drive the need for new approaches to better inform water resource management (Vano et al., 2012). To further complicate matters, snowpack mass (SWE) can change drastically over small distances in mountain basins because of the combined effects of highly variable wind fields, solar and thermal radiation, and topographic and vegetation structure (Anderton et al., 2004; Conway \& Abrahamson, 1984; Grünewald et al., 2010). The timing of melt and delivery of water to the soil surface is never uniform, following high energy locations across the landscape as solar zenith angles and temperatures increase (Essery \& Pomeroy, 2004; Luce et al., 1999). The physically based modeling and remote sensing assimilation approach presented here aims to address the source of greatest uncertainty for reservoir managers by more explicitly defining the quantity of water entering the mountain hydrologic system.

The NASA ASO launched during the winter of 2013 to provide distributed SWE and albedo estimates over large mountain basins. The ASO program provides more detailed estimates of basin snowpack storage for water managers and researchers through a unique coupling of multitemporal remote sensing and physically based snow modeling (Painter et al., 2016). To accomplish this, ASO performs airborne surveys every few weeks during accumulation and weekly intervals from peak SWE onward, deriving snow depths by differencing snow-free from snow-covered elevation surfaces obtained by its lidar scanner. The ASO-derived snow depth products are combined with iSnobal simulated snow density fields to produce $50 \mathrm{~m}$ spatial resolution daily 
images of SWE distribution and volume. iSnobal (Marks et al., 1999) is a distributed, physically based energy and mass balance snow model that explicitly solves for a number of snowpack properties including snow depth, density, and SWE.

Vögeli et al. (2016) demonstrated the value of redefining the spatial snow depth distribution of a physically based model using snow depths derived from a single lidar survey. Brauchli et al. (2017) took that approach a step further by demonstrating how streamflow responded to the more accurate snow distribution. Following those efforts, this paper describes how the ASO-derived snow depths were integrated into the iSnobal snow model in near-real time over the Tuolumne Basin in the central Sierra Nevada for the first four years of the ASO program (2013-2016). This approach is providing water managers with periodic spot checks of how existing legacy models have been performing throughout the season and establishing the foundation for a new modeling paradigm.

\section{$2.2 \quad$ Study Area}

The Tuolumne River and its tributaries provide the fresh water supply for over 2 million people in the San Francisco Bay Area through a combination of winter snow storage in the upper elevations and careful water management of the system's reservoirs. The Tuolumne extends from just above the Central Valley floor to the Sierra crest and includes much of Yosemite National Park. Elevations within the $1180 \mathrm{~km}^{2}$ basin above the Hetch Hetchy Reservoir (Figure 2.1) range from 1150-3999 m.a.s.l., with slightly less than half of the basin below timberline. Tree line occurs at approximately $2900 \mathrm{~m}$ and the majority of the alpine terrain is comprised of exposed granite bedrock. Historically, the lowest elevations (1150-1600 m, 4\% of basin area) are rain-

dominated where approximately $60 \%$ of the precipitation falls as rain. The region 


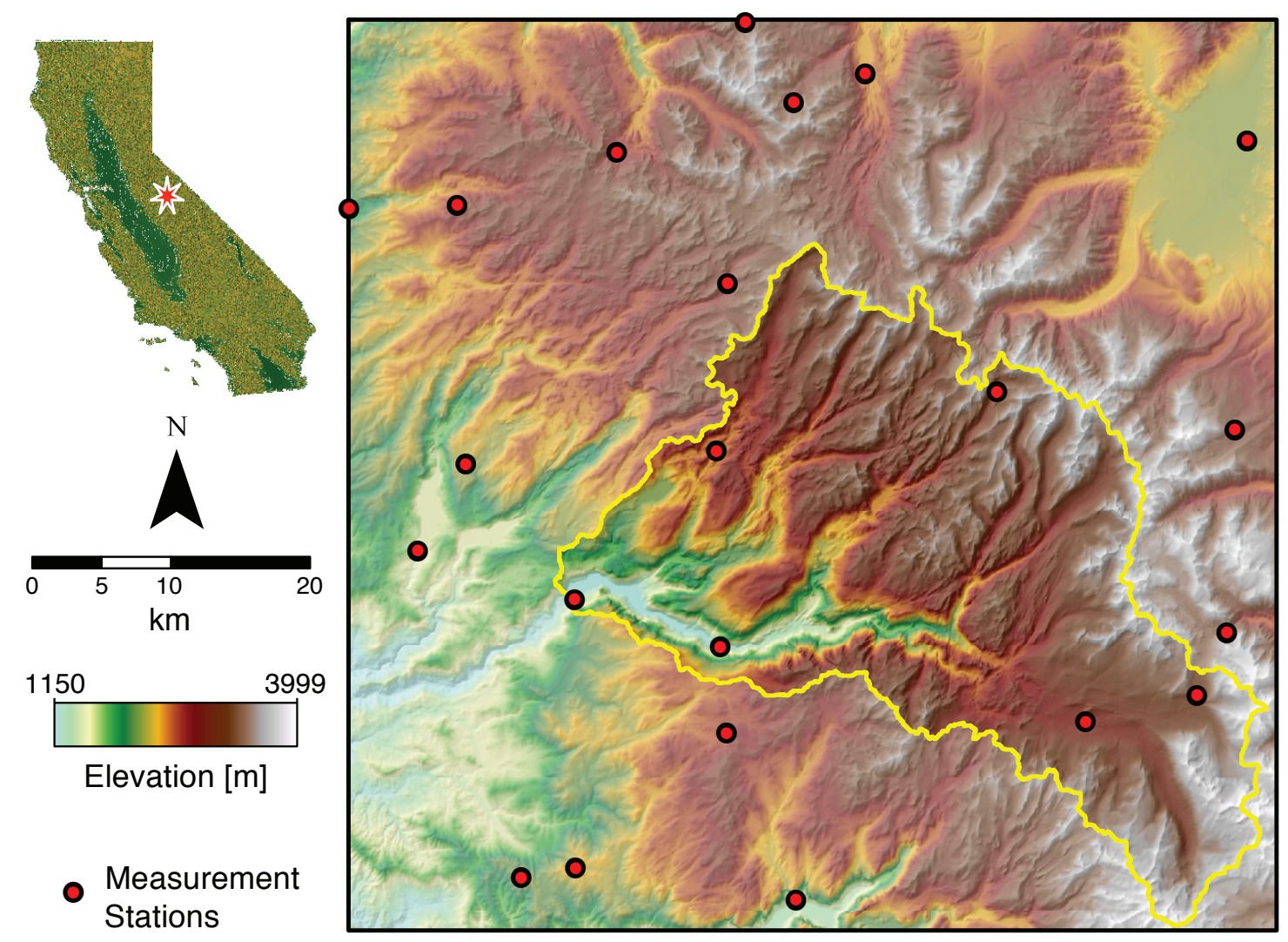

Figure 2.1: Location and relief map of the Tuolumne River Basin above Hetch Hetchy Reservoir within the U.S. State of California. Locations of various measurement stations used to force iSnobal in water year 2013 are depicted as red circles.

between $1600-2000 \mathrm{~m}$ ( $6 \%$ of basin area) is the rain-snow transition zone where most storms are a mix of rain and snow. The region above $2000 \mathrm{~m}$ ( $90 \%$ of basin area) is snow-dominated where more than $70 \%$ of precipitation falls as snow (Lundquist et al., 2016). However, it is possible for rain to fall at the highest elevations of the basin, and for snowfall to occur at the lowest. Two relatively small receding glaciers (Lyell and Maclure) are found in the southwest portion of the basin, but this work does not treat them separately from non-glaciated terrain. 
Owing to the basin's location within the Yosemite National Park Wilderness Area, establishment and maintenance of weather monitoring stations is limited and therefore the measurement network used for the modeling work presented here is sparse (Figure 2.1). Additionally, scheduled routine site maintenance is generally difficult or impossible since sites positioned in remote locations can only be accessed on foot or by horseback in the short summer snow-free season.

\subsection{Background and Methodology}

\subsubsection{The Airborne Snow Observatory}

Light detection and ranging (lidar) has been demonstrated to be an accurate tool for observing the spatial variability of snow depths in complex terrain (Deems et al., 2006, 2013; Prokop, 2008; Tinkham et al., 2014; Trujillo et al., 2007). ASO is the first operational campaign to use airborne lidar coupled with imaging spectrometry for hydrological forecasting applications (Painter et al., 2016). Its 24-hour turnaround time from the moment of aircraft landing to delivery of SWE products is crucial to the ASO mission objective due to the dynamic nature of the mountain snowpack.

Snow depths were measured by differencing a baseline snow-free surface from snowon surfaces, obtained using ASO's Riegl Q1560 dual scanning lidar, combined with geographical analysis and constrained by classification from the visible-near infrared spectrometer analysis and lidar return intensity (Painter et al., 2016). SWE, the primary concern for water managers and decision makers, can be estimated spatially from the product of the lidar-derived snow depths and modeled snow density fields. In its first two years, ASO planned to begin surveying at approximately peak SWE and continue flying weekly until complete melt out. As the ASO program began to 
characterize the dynamic nature of snow cover distribution, the decision was made to fly earlier to capture accumulation processes in the following years. This resulted in 6 surveys during the 2013 snow season (early April to early June), 9 surveys during the 2014 snow season (mid-March to early June), 9 surveys during the 2015 snow season (mid-February to early June) and 12 surveys during the near-average 2016 snow season (late March to early July) (see Table 2.1).

\begin{tabular}{|c|c|c|c|c|c|c|}
\hline \multirow{2}{*}{ Year } & \multirow{2}{*}{$\begin{array}{l}\text { \# ASO } \\
\text { Updates }\end{array}$} & \multicolumn{5}{|c|}{ \# of Available Meteorological Stations } \\
\hline & & $\mathbf{T}_{a}$ & $\mathbf{R H} / \mathbf{e}_{a}$ & $\mathbf{u} / \mathbf{u}_{d i r}$ & $\mathbf{m}_{p p}$ & $\mathbf{S}_{\text {in }} / \mathbf{c c}_{\text {frac }}$ \\
\hline 2013 & 6 & 20 & 8 & 7 & 12 & 6 \\
\hline 2014 & 9 & 23 & 10 & 7 & 15 & 5 \\
\hline 2015 & 9 & 23 & 12 & 8 & 15 & 7 \\
\hline 2016 & 12 & 21 & 10 & 7 & 14 & 7 \\
\hline & $\begin{array}{r}\text { erpolation } \\
\text { Method }\end{array}$ & IDW & IDW & IDW & DK & IDW \\
\hline
\end{tabular}

Table 2.1: By water year, number of ASO lidar survey updates and meteorological measurements by variable required as input to iSnobal. The numbers represent all stations that reported data for any length of time throughout the year. In addition, the specifics of the point measurement to regular grid interpolation for each variable are listed. (IDW $=$ Inverse Distance Weighting, DK = Detrended Kriging)

Coincidentally, ASO captured the extreme California drought of 2012-2015, which brought the program to the attention of California water supply forecasters and stakeholders in a way that would not have been expected had these been typical or nearaverage snow years. Fortunately, the 2016 snow season was closer to the long-term average, so the analysis presented herein also includes a non-drought year. 


\subsection{2 iSnobal}

The snow density modeling component of ASO was carried out over the winter/spring seasons concurrent with the airborne surveys (2013-2016). The initial task for the modeling component was only to provide distributed estimates of snow density in order to produce spatially distributed SWE products for downstream stakeholders, water managers, and forecasters. By the beginning of 2014 it became clear that the ASO program needed to more effectively integrate the iSnobal modeling components into developed products because users of the ASO products desired more than basin distributed and total SWE storage volumes. iSnobal is able to separate rain from snow while simultaneously providing detailed information on the distribution of SWE volume, snow cover thermal state, melt, and the delivery of melt-water or rain to the soil surface. However, due to the sparse meteorological network at higher elevations and the inherent spatial variability of mountain snow covers, the modeled snow distribution is consistently more uniform with less spatial variability than the distribution measured by the ASO surveys.

The ASO surveys provide periodic measurements of snow depth that define the true distribution of snow across large mountain basins. Additionally, iSnobal fills in the periods between ASO flights to provide a complete time series of snowpack evolution. We hypothesize that the integration of the ASO lidar-derived snow depth field into the iSnobal state variable data stream defines the true snow distribution and therefore improves the ability of the snow model to predict the energy and mass fluxes of the snowpack, similar to the findings of Brauchli et al. (2017) and Vögeli et al. (2016). Though touched on in this methodological study, future work will test this hypothesis in a more rigorous fashion. 


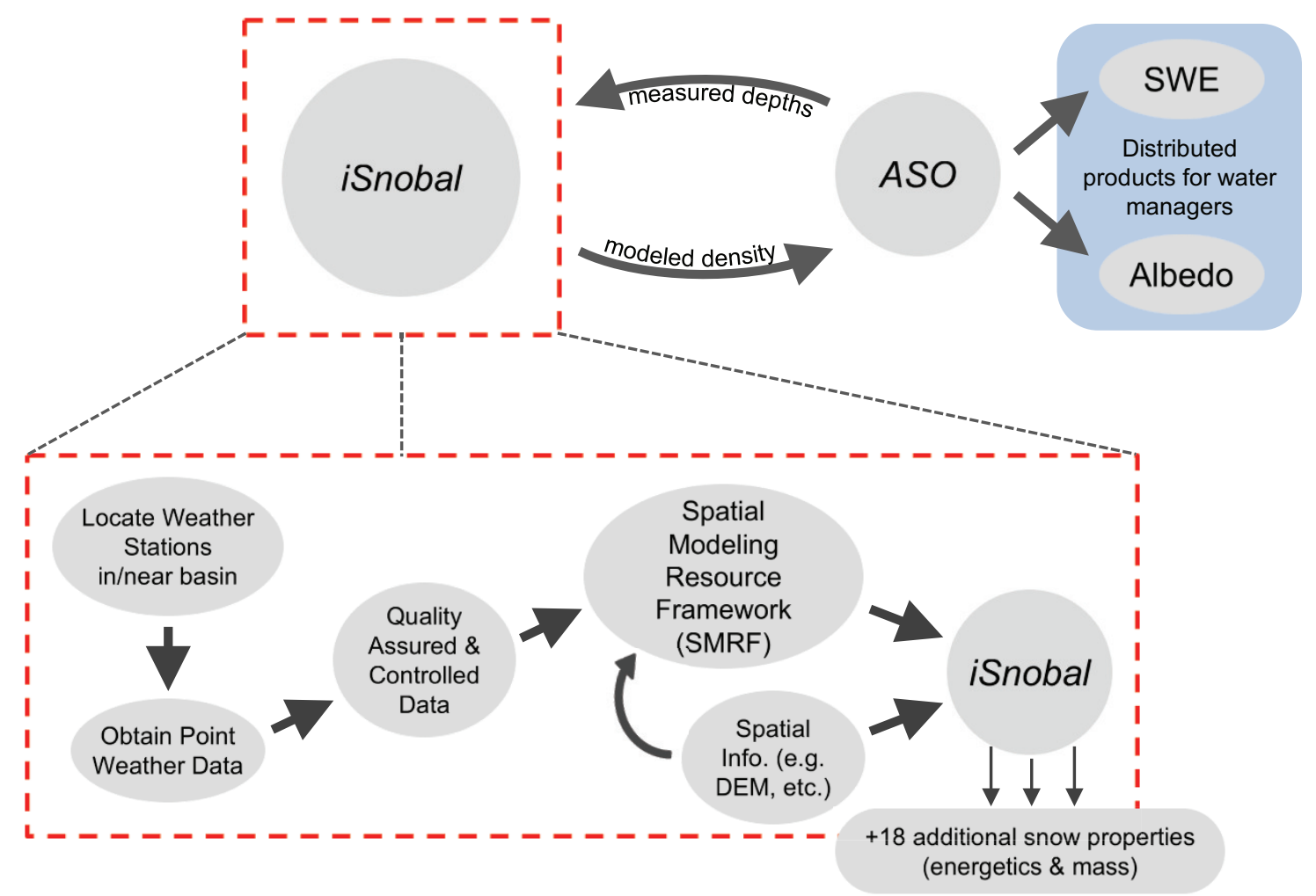

Figure 2.2: Exploded view of the workflow for the iSnobal modeling progression from initiation to delivery of model products to the ASO compute team. This chart includes the process of updating the iSnobal model state using the ASO lidar-derived snow depths.

In 2014, the United States Department of Agriculture (USDA)-Agricultural Research Service (ARS) Northwest Watershed Research Center (NWRC) in Boise, Idaho began assimilating the ASO snow depth fields as a model state variable update to iSnobal in near-real time. Figure 2.2 depicts the typical process for the initial model setup and the subsequent re-initializations when the ASO snow depth measurements become available. To the knowledge of the authors, this is the first near-real time incorporation of high-resolution snow depths into the data stream of an energy balance snow model. 
As a physically based, gridded snow model, iSnobal estimates snowpack properties given particular spatial and temporal meteorological forcing data (Marks et al., 1999). Designed to be computationally efficient while maintaining maximum portability, $i S$ nobal explicitly solves the energy and mass balances at each grid cell over a digital elevation model (DEM) grid, and therefore does not require site-specific calibration within the model itself. All meteorological forcing surfaces are assembled outside the model and adjustments are performed at the user's discretion when producing the spatial forcings required by the model. The original iSnobal design concept was that the model should not make adjustments for limitations in available forcing data (Marks \& Dozier, 1992). Instead of being built into the snow model, the methods used to develop the distributed forcing data surfaces are determined by any available weather station measurements, remote sensing data, or output from numerical weather models.

iSnobal was originally designed to accommodate periodic inputs from satellite or aircraft remote sensing data in the NASA Earth Observing System (EOS) era (Dozier, 1990). This design feature allows the model to be run forward to a time when model initialization or state data are available, stopped and updated, and then restarted. The ASO surveys provide unprecedented detail for the snow depth state variable, which can be reset mid-year for a more accurate, updated estimate of snow distribution, resulting in improved model predictions.

Studies assessing iSnobal across a range of snow environments and snow-dominated basins are numerous in the literature. The temporal and spatial scales of various studies range from $0.015 \mathrm{~km}^{2}$ over a $2.5 \mathrm{~m}$ grid (Kormos et al., 2014a), $460 \mathrm{~km}^{2}$ over a $75 \mathrm{~m}$ grid (Marks et al., 1999), 2150km² over a 250m grid (Garen et al., 2001; Garen \& 
Marks, 2005), $1180 \mathrm{~km}^{2}$ over a $50 \mathrm{~m}$ grid (this study), to $7000 \mathrm{~km}^{2}$ over a $100 \mathrm{mgrid}$ (Havens et al., 2015). Each of these assessment studies generated the required forcing parameter grids using different methods and at different spatial resolutions determined by available computational resources and study objectives. From the above listed studies, the increase in computational resources over the last 15 years is evident. By streamlining source code and taking advantage of multiprocessor computing power, the recent upgrades to the modeling system represent a $200 x$ increase in computational efficiency. This boost in efficiency allows the model to be run in near-real time and errors in forcing data to be diagnosed in real time.

iSnobal can be implemented at any temporal resolution that can be supported by the available spatial forcings, though Garen \& Marks (2005) point out that the selected temporal resolution must account for the diurnal cycle. In this work, hourly meteorological station measurements are the basis for the forcing grids and, accordingly, iSnobal is run at an hourly resolution onward from the onset of each water year (October 1st). As input, iSnobal requires spatially gridded interpolants derived from point measurements of basic meteorological variables that are available from most standard mountain weather stations in the Western U.S (Table 2.1). In addition, indirect forcing grids of vapor pressure, net shortwave radiation, percent cloud cover, and incoming longwave radiation are computed through empirical relationships (described in Section 2.3.2).

While iSnobal does not simulate below-ground hydrologic processes or streamflow, it does explicitly deal with both rain and snowfall as input precipitation. SWI is defined as either rain on bare ground or melt/rain that exceeds the liquid water holding capacity of the snowpack and drains through the snow to the ground sur- 
face. Percolation processes within the snowpack are not explicitly considered. The results presented here represent simulations for complete water years (October 1 to the following September 30), including both the wet and dry seasons.

\section{Station Data}

The six meteorological variables of air temperature $\left(\mathbf{T}_{a}\right)$, wind speed $(\mathbf{u})$ and direction $\left(\mathbf{u}_{\text {dir }}\right)$, relative humidity $(\mathbf{R H})$, incoming solar radiation $\left(\mathbf{S}_{i n}\right)$, and accumulated precipitation $\left(\mathbf{m}_{p p}\right)$ are measured within or adjacent to the Tuolumne modeling domain at hourly temporal resolution (refer to Section 2.2). In California, weather stations are maintained by various cooperative agencies, and the data are collected and assembled by both the CDEC (http://cdec.water.ca.gov) and MesoWest (Horel et al., 2002) (http://mesowest.utah.edu/). Table 2.1 lists the number of stations that measured these six meteorological variables throughout each of the four years presented in this study. Since many stations occasionally went offline at various times throughout the simulation years, the reported number of stations represent the maximum used throughout each complete water year. For instance, incoming solar radiation measurements were only available at four stations over the latter half of water year 2016. The quality of iSnobal model results are directly influenced by the quality of the point meteorological data used to create the spatial forcing grids. Additional in-house quality assurance and control (QA/QC) is non-trivial and paramount for preparing the most accurate possible forcing dataset over the model domain.

Hourly measurements of all variables from every available station are automatically downloaded each day to a local database maintained at the NWRC. Manual and semi-automated QA/QC is performed on raw downloaded data to interpolate across small data gaps and remove spikes. Precipitation data are adjusted using the APCP 
(Nayak et al., 2008), which fills gaps and removes spikes using a bias-limiting noise reduction algorithm. The precipitation measurements are then adjusted for wind undercatch using standardized equations for either shielded or unshielded gauges according to Yang et al. (1998), depending on each individual sensor. Methods for dealing with raw station data are described in both Chapter 3 and Havens et al. (2017). Agencies that manage stations in the Western United States often report coordinates only to the tenth of a degree in latitude and longitude precision. Since accurate station locations are crucial for producing forcing grids at $50 \mathrm{~m}$ resolution over complex terrain, care has been taken to determine more precise coordinates.

In addition to the six available variables measured by automated weather stations, two additional point variables must first be calculated using those available measurements. Vapor pressure $\left(\mathbf{e}_{a}\right)$ is determined from the Clausius-Clapeyron empirical relationship at stations with measurements of air temperature and relative humidity. Fractional cloud cover $\left(\mathbf{c c}_{\text {frac }}\right)$ is estimated from the ratio of measured incoming shortwave radiation to calculated clear-sky irradiance at locations where incident solar radiation is measured, similar to the method presented by Susong et al. (1999). A description of these data and the methods used in the creation of model forcing inputs is available in an accompanying dataset (Hedrick et al., 2018b).

Table 2.2 details all of the generated snow properties and processes along with the energy and mass inputs and outputs for a typical model time step. The fundamental principles that iSnobal uses for calculating the snowcover energy and mass balance are based upon relatively straightforward and thoroughly validated physical relationships. Therefore, when model estimates differ significantly from in situ measurements, then all adjustments and corrections must be performed on the forcing data provided 
to the model. Any necessary adjustment or correction to spatially distributed forcing data (e.g. estimated cloud cover, incoming thermal radiation, the approximated precipitation distribution, etc.) must occur prior to model initialization. Poor or missing measurements may cause iSnobal to crash, so occasionally adjustments must be made to interpolate over a span of hours during a simulation cycle.

\section{Spatial Forcing Grids}

The Spatial Modeling for Resources Framework (SMRF) is a tool for distributing various point measurements over a regular grid for near real-time applications (Havens et al., 2017). SMRF was developed in-house at the NWRC and the latest stable release can be found at https://github.com/USDA-ARS-NWRC/smrf. The source code used for this study (SMRF v0.3.0) can be found in a Zenodo software repository Hedrick et al. (2018c).

Various methods exist for distributing point measurements of meteorological variables over large areas and complex terrain (Garen et al., 1994; Goovaerts, 2000; Livneh et al., 2014; Luo et al., 2008). As a modular framework, SMRF permits the user to decide which method is appropriate for distributing each particular parameter. For instance, measured accumulated precipitation can be distributed in SMRF using either the DK or inverse distance weighting (IDW) methodologies.

Table 2.1 summarizes the various distributing methods that were used throughout all four water years. The most suitable interpolation method depends on the meteorological variable being distributed. For instance, precipitation during storms is often spatially inconsistent over large mountain basins and generally exhibits a positive local elevation gradient (Lundquist et al., 2010). On the other hand, temperature typically displays a negative elevation lapse rate and is spatially continuous. 


\begin{tabular}{|c|c|c|c|}
\hline File type & Variable & Description & Units \\
\hline $\begin{array}{l}\text { (a) Energy } \\
\text { inputs (all time } \\
\text { steps) }\end{array}$ & $\begin{array}{l}\mathbf{I}_{l w} \\
\mathbf{T}_{a} \\
\mathbf{e}_{a} \\
\mathbf{u} \\
\mathbf{T}_{g} \\
\mathbf{S}_{n}\end{array}$ & $\begin{array}{c}\text { incoming longwave radiation } \\
\text { air temperature } \\
\text { vapor pressure } \\
\text { wind speed } \\
\text { soil temperature } \\
\text { net shortwave radiation }\end{array}$ & $\begin{array}{c}\mathrm{W} / \mathrm{m}^{2} \\
{ }^{\circ} \mathrm{C} \\
\mathrm{Pa} \\
\mathrm{m} / \mathrm{s} \\
{ }^{\circ} \mathrm{C} \\
\mathrm{W} / \mathrm{m}^{2}\end{array}$ \\
\hline $\begin{array}{l}\text { (b) Precipitation } \\
\text { inputs (only during } \\
\text { storms) }\end{array}$ & $\begin{array}{c}\mathbf{m}_{p p} \\
\mathbf{P}_{\text {snow }} \\
\boldsymbol{\rho}_{n s} \\
\mathbf{T}_{p p} \\
\end{array}$ & $\begin{array}{c}\text { total precipitation mass } \\
\text { percent mass that fell as snow } \\
\text { new snow density } \\
\text { average precipitation temperature }\end{array}$ & $\begin{array}{l}\mathrm{kg} / \mathrm{m}^{2} \\
0-1.0 \\
\mathrm{~kg} / \mathrm{m}^{3} \\
{ }^{\circ} \mathrm{C}\end{array}$ \\
\hline \multirow{8}{*}{$\begin{array}{l}\text { (c) iSnobal outputs } \\
\text { (previous time step) }\end{array}$} & $\mathbf{z}_{s}$ & predicted snow depth & $\mathrm{m}$ \\
\hline & $\rho$ & predicted average snow density & $\mathrm{kg} / \mathrm{m}^{3}$ \\
\hline & $\begin{array}{l}\mathbf{m}_{s} \\
\mathbf{h}_{2} \mathbf{O}\end{array}$ & $\begin{array}{l}\text { predicted specific mass of snow } \\
\text { predicted liquid water in snow }\end{array}$ & $\begin{array}{l}\mathrm{kg} / \mathrm{m}^{2} \\
\mathrm{~kg} / \mathrm{m}^{2}\end{array}$ \\
\hline & $\mathbf{T}_{s 0}$ & predicted active layer temperature & ${ }^{\circ} \mathrm{C}$ \\
\hline & $\mathbf{T}_{s l}$ & predicted lower layer temperature & ${ }^{\circ} \mathrm{C}$ \\
\hline & $\mathbf{T}_{s}$ & predicted average snow temperature & ${ }^{\circ} \mathrm{C}$ \\
\hline & $\mathbf{z}_{s l}$ & predicted lower layer depth & $\mathrm{m}$ \\
\hline & $\mathbf{h}_{2} \mathbf{O}_{\text {sat }}$ & predicted liquid water saturation & $\%$ \\
\hline \multirow[b]{2}{*}{$\begin{array}{l}\text { (d) Restart/Update } \\
\text { initialization (state } \\
\text { variables) }\end{array}$} & $\begin{array}{c}\mathbf{z} \\
\mathbf{z}_{0} \\
\mathbf{z}_{s}\end{array}$ & $\begin{array}{c}\text { elevation } \\
\text { roughness length } \\
\text { ASO-updated snow depths }\end{array}$ & $\begin{array}{l}\mathrm{m} \\
\mathrm{m} \\
\mathrm{m}\end{array}$ \\
\hline & $\begin{array}{c}\boldsymbol{\rho} \\
\mathbf{T}_{s 0} \\
\mathbf{T}_{s l} \\
\mathbf{T}_{s} \\
\mathbf{h}_{2} \mathbf{O}_{s a t}\end{array}$ & $\begin{array}{l}\text { average snow density } \\
\text { active layer temperature } \\
\text { lower layer temperature } \\
\text { average snow temperature } \\
\text { liquid water saturation }\end{array}$ & $\begin{array}{c}\mathrm{kg} / \mathrm{m}^{3} \\
{ }^{\circ} \mathrm{C} \\
{ }^{\circ} \mathrm{C} \\
{ }^{\circ} \mathrm{C} \\
\%\end{array}$ \\
\hline
\end{tabular}

Table 2.2: a) Hourly energy input forcing grids required by iSnobal. b) Hourly mass input forcing grids that are only required when precipitation is measured by one or more meteorological stations within the modeling domain. c) Output grids of snow mass and temperature (energetics are written into a separate file not shown here) from the time step prior to the ASO snow depth update. d) Initialization grids for the iSnobal restart. Highlighted variables in c) and d) indicate parameters that must be adjusted when incorporating the new snow depth measurements from the ASO. 
These two variables require gridded interpolation methods that are appropriate for representing the differing physical processes at work.

Forcing grids were constructed at a $50 \mathrm{~m}$ spatial and hourly temporal resolution. In mountain basins it has been shown that the typical length-scale of hydrologic variability is between 50-100 m (Deems et al., 2006; Pomeroy et al., 2006; Shook \& Gray, 1996; Trujillo et al., 2007; Winstral \& Marks, 2014), particularly for windexposed terrain where snow redistribution dominates the snowpack spatial variability. Therefore, at $50 \mathrm{~m}$ resolution, the model is expected to explicitly capture many of the physical processes that control the spatial distribution of the snowpack.

A crucial energy input to iSnobal is net shortwave radiation $\left(\mathbf{S}_{n}\right)$, which is the difference between incoming $\left(\mathbf{S}_{\text {in }}\right)$ and outgoing $\left(\mathbf{S}_{\text {out }}\right)$ solar radiation. $\mathbf{S}_{n}$ is seldom measured, but $\mathbf{S}_{\text {in }}$ is more often available. To estimate $\mathbf{S}_{\text {out }}$, snow albedo $(\boldsymbol{\alpha})$ is simulated based on the elapsed time since the last snowfall for each model pixel and an assumed dust or debris content (Marks \& Dozier, 1992; Marshall \& Warren, 1987). Parameterizing surface albedo has been found to be difficult in mountainous regions (Guan et al., 2013; Molotch, 2004). Since accurate in situ measurements of snow albedo are only available at a few sites in the western United States, spatially distributed estimates of surface reflectance add a significant source of uncertainty into the model forcings. ASO is able to produce an albedo product from the onboard spectrometer and ongoing research is investigating the nontrivial problem of assimilating the ASO albedo product into the model data stream. Since $\boldsymbol{\alpha}$ is used to derive $\mathbf{S}_{n}$ for each time step, it is not a state variable of $i$ Snobal.

Clear-sky, terrain corrected solar radiation is computed from Dozier (1980) and Essery \& Marks (2007) using the ASO 50 m snow-free DEM grid. Canopy shading is 
computed from the National Land Cover Database (NLCD) using methods described by Link et al. (2004) and Essery et al. (2008). Incoming longwave radiation $\left(\mathbf{I}_{L W}\right)$ is rarely measured so it is modeled from a combination of empirical relationships of clear-sky emissivity adjusted for terrain from Marks \& Dozier (1979), and vegetation canopy cover and estimated cloud cover from available $\mathbf{S}_{\text {in }}$ measurements similar to Link \& Marks (1999) and Reba et al. (2011a). Wind speeds are distributed using the maximum upwind slope terrain parameter, $\mathbf{S}_{x}$ (Winstral et al., 2002), and methods described by Winstral et al. (2009). The calculations of energy transfer between the snow surface and the atmosphere used a surface roughness length of $1 \mathrm{~mm}$ for cells below the canopy and $5 \mathrm{~mm}$ in forest openings and above treeline.

For this modeling exercise soil temperatures $\left(\mathbf{T}_{g}\right)$ were set to a uniform $-2.5^{\circ} \mathrm{C}$ at a depth of $10 \mathrm{~cm}$ below the snow-soil interface, which is cold enough to allow the initiation of the snowpack, but not so cold as to retain snow on the ground late in the ablation season. Bair et al. (2018) showed that the ground temperatures at the nearby Mammoth Mountain CUES study plot fluctuated around $-0.5^{\circ} \mathrm{C}$ throughout the winter. Future studies will examine the impact of spatially and temporally representative soil temperature approximations.

Precipitation is by far the most critical input parameter for any snow or hydrologic model. Prior to model execution and through empirical relationships with the average precipitation temperature $\left(\mathbf{T}_{p p}\right.$, approximated by the distributed dew point temperature), precipitation mass $\left(\mathbf{m}_{p p}\right)$ is parsed into percent snow versus rain $\left(\mathbf{P}_{\text {snow }}\right)$ while the density of new fallen snow $\left(\boldsymbol{\rho}_{n s}\right)$ is calculated on an individual storm basis. Storm snow densification is computed similar to Table 1 in Marks et al. (1999), but is augmented in this work to consider compaction effects during storms from the changing 
overburden pressure. Before, during, and after the ASO snow depth acquisitions, the precipitation distribution and phase are approximated based on the limited number of precipitation measurement sites in and around the modeling domain. For these stations we estimate the elevation trend and distribute the undercatch-adjusted precipitation volume and phase across the modeling domain. A storm event is defined spatially and can extend either over all or a localized subset of the modeling domain. Within an event region, precipitation phase varies according to dew point temperature, so each storm event can be spatially subdivided into rain, mixed phase, and snow pixels for each storm hour. A more rigorous description of the computations involved for all spatial forcing fields - both energetics and mass - is detailed in Havens et al. (2017).

The primary objective of $i$ Snobal in the context of ASO is to produce spatial snow density estimates. The mechanisms within a snowpack that influence bulk density are energy fluxes due to temperature gradients, liquid water content, compaction due to overburden, and time since accumulation (Kojima, 1967). Previous versions of iSnobal simply generalized the effects of temperature and overburden compaction into an empirical formulation dependent only upon time. Recent modifications to the model now permit distinct consideration of bulk compaction and temperature metamorphism and are detailed in Marks et al. (2018). These modifications were included in the model results presented in this work.

\subsubsection{Modeling and Direct Insertion}

Each year during the accumulation period (typically October-February), the process of preparing data for running iSnobal begins with a thorough analysis of available meteorological station data in order to update the meteorological database with any 
stations that may have come online or malfunctioned. After constructing the spatial forcing grids described in Section 2.3.2, iSnobal is then executed from the previous October 1, the beginning of the water year, up to the date of the first ASO flight.

ASO derives gridded estimates of SWE by multiplying the lidar-derived snow depths and the snow density estimates given by iSnobal (Painter et al., 2016). This study focuses on the methods for assimilating the measured ASO snow depths into iSnobal and the effects of this integration on subsequent model results. Vögeli et al. (2016) and Brauchli et al. (2017) demonstrated the value of redefining the spatial snow depth distribution for input to a physically based model using remote sensing information. Over the four water years presented here, a modified direct insertion technique was developed to create the functional initialization files required to restart iSnobal after each survey (Table 2.2d). We refer to the method as 'modified' because additional model state variables besides snow depth must be adapted to match the spatial extent and depth of the snow cover measured by the ASO lidar surveys.

Four scenarios are possible when modeled snow depths from the previous day are discarded in favor of the lidar-derived measurements. The first case is trivial, in which both the ASO and the model agree that a cell is snow-free so no change is made to the model states. The second scenario occurs when both the model and the ASO agree that a cell is snow-covered but disagree on the height of the snow. In this case, the ASO snow depth is inserted into the model, and the remaining state variables (density, layer temperature, and liquid water content) are unchanged. A third case is when iSnobal predicts a snow cover whereas the ASO measures a snow-free grid cell. When such discrepancy occurs, all other state variables are changed to represent a grid cell with no snow. On the other hand, it can be the case that the ASO measures 
snow and iSnobal has estimated the cell to be snow-free. In this fourth scenario, the snow density, layer temperatures, and liquid water saturation must be interpolated to match the perceived ASO snow cover.

To create reasonable values for each of the state variables that are required to restart iSnobal- those highlighted in Table $2.2 \mathrm{~d}$ - an expanding window is applied where a minimum of 10 nearby snow-covered cells must be found before averaging and moving on to the next cell. For these cells, the interpolated values are used for the new initialization of the model (Table 2.2c, following time step) so that cells with lidar-derived snow also contain estimates of bulk density, layer temperature, and liquid water content. In this way we resolve fringe effects from the discrepancies between model results and the remote sensing product in areas of patchy snow cover. Even so, the vast majority of these discrepancies in spatial extent occur within low elevation pixels that contain very little snow and therefore have a minimal effect on the total basin water storage.

\subsection{Results}

Over the course of the 2012-2015 drought, snowfall in the Tuolumne Basin was substantially lower than average. The 2015 snowpack, in particular, was the lowest in recorded history and determined to have the lowest April 1 SWE in over 500 years through tree ring peak SWE reconstruction (Belmecheri et al., 2016). Water year 2016 provided some relief from the drought with a snowpack that was $\approx 85 \%$ of aver-

age. Some basic modeled hydrologic conditions derived by iSnobal during the study period (2013-2016) are presented in Table 2.3. These metrics were derived from the pre-processed precipitation forcing grids used as iSnobal input and described in Section 2.3.2. The average rain-snow transition elevation was determined by finding the 


\begin{tabular}{ccccc}
\hline Year & $\begin{array}{c}\text { Snow proportion of } \\
\text { annual precipitation }\end{array}$ & $\begin{array}{c}\text { Average rain-snow } \\
\text { transition elevation }[\mathrm{m}]\end{array}$ & $\begin{array}{c}\text { Peak } \\
\text { SWE date }\end{array}$ & $\begin{array}{c}\text { Mean peak } \\
\text { SWE }[\mathrm{mm}]\end{array}$ \\
\hline 2013 & $83.0 \%$ & 2,016 & Mar. 11 & 323 \\
2014 & $81.8 \%$ & 1,918 & Apr. 6 & 253 \\
2015 & $71.3 \%$ & 2,394 & Feb. 10 & 124 \\
2016 & $83.9 \%$ & 1,828 & Mar. 22 & 557 \\
\hline
\end{tabular}

Table 2.3: Hydrologic metrics derived from the precipitation model forcing grids and the ASO-updated iSnobal SWE estimates.

hourly median elevation of the pixels that were designated as mixed phase during each storm and computing a mass-weighted average over the water year.

The distribution of mountain SWE accumulation and ablation is governed by elevation gradients, vegetation, aspect, and slope. To investigate the impact of the ASO updates on the model, three elevation bands of the lowest $40 \%$, middle $40 \%-70 \%$, and upper 30\% of the basin area were delineated from the iSnobal results for 2013 to 2016 (Figure 2.3). The first ASO update adds SWE in the upper 30\% of the basin in each of the four years, possibly due to precipitation measurement stations at higher elevations exhibiting greater undercatch than those at lower elevations (Rasmussen et al., 2012). At the same time, the ASO updates throughout the ablation season cause iSnobal to melt the snowpack earlier for elevations below 2,900 m. Also, it is apparent that the lower $40 \%$ of the basin was rain-dominated in 2013-2015 since the cumulative $S W I$ curve is greater than the SWE curve throughout each full water year. The average water year (2016) received a more substantial snowpack at lower elevations. Above 2,700 m, which comprises $60 \%$ of the land area within the basin, snow storage dominated the system in all four years for the primary accumulation period of December through April. 

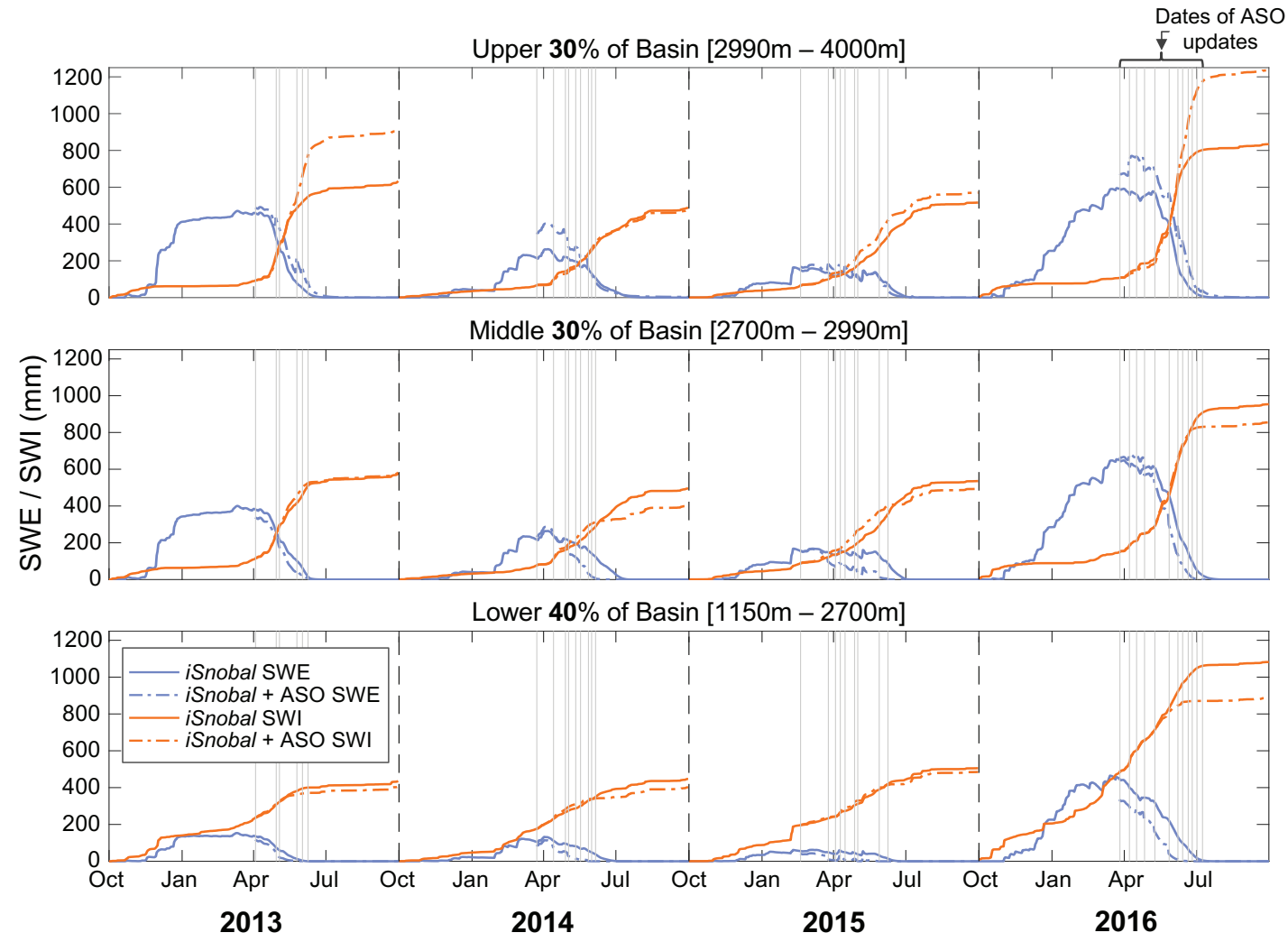

Figure 2.3: Basin-averaged iSnobal snow water equivalent (SWE) and surface water input ( $S W I$ ) over three elevation bands for both the unmodified and ASO-updated predictions. The three bands, delineated by area, reveal elevations most sensitive to direct insertion of the lidar-derived snow depths. From the initial ASO update SWE is added at upper elevations for all four years, while complete melt out occurs earlier at mid to lower elevations. 
(i) iSnobal only

(ii) ASO+iSnobal

$\triangle$ SWE $(\mathbf{i i}-\mathbf{i})$
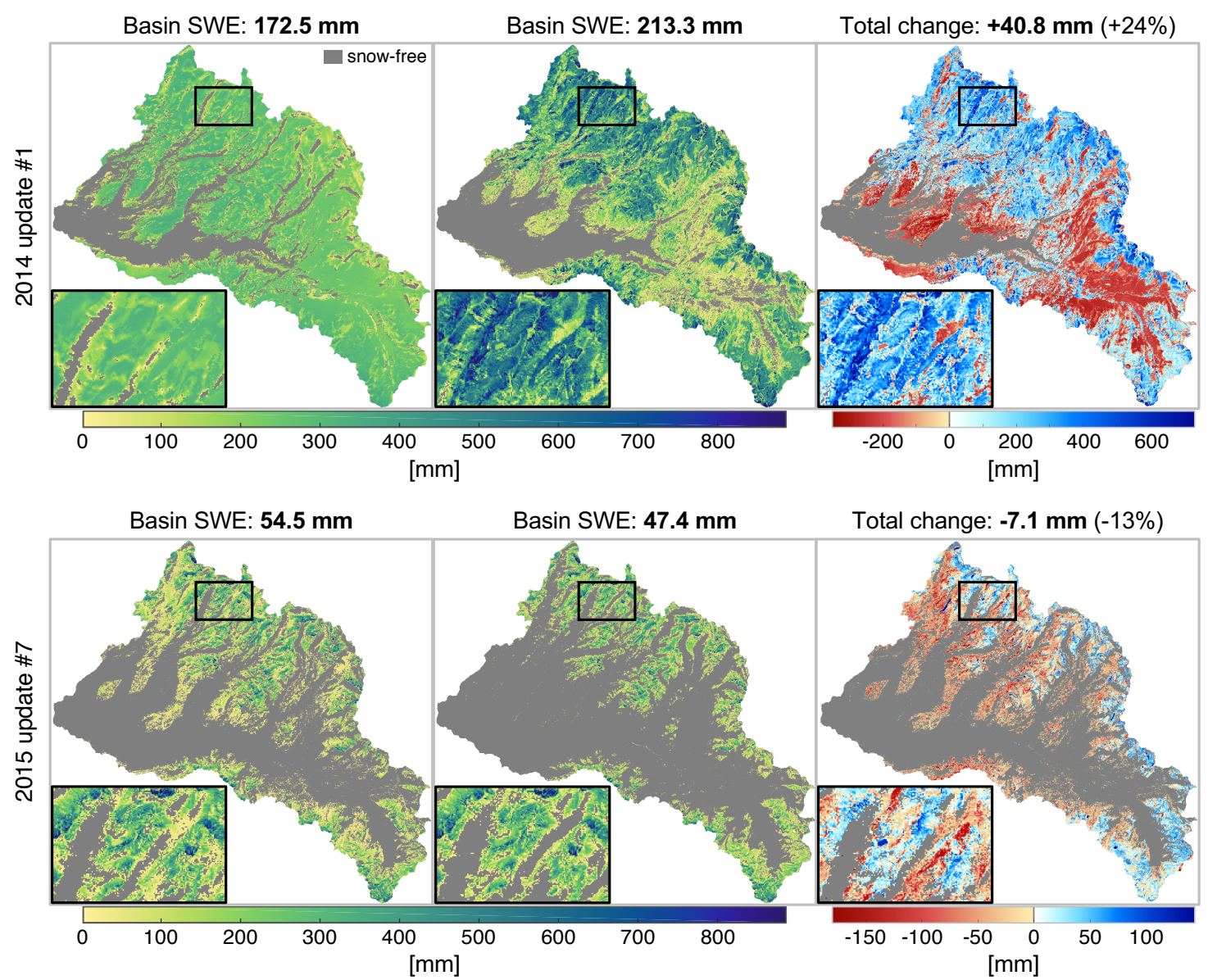

Figure 2.4: Spatial iSnobal SWE distribution both without the lidar update (i) and with (ii) the update applied for two surveys from water years 2014 and 2015, and the change in SWE resulting from the direct insertion of snow depths into the model. Inset areas $(5.0$ by $7.5 \mathrm{~km})$ reveal the enhanced detail of the change in modeled SWE distribution from the ASO updates. The spatial distribution is most refined for the first update of the year (update \#1, top row) and results in a much larger change in SWE than the updates later in the ablation season (update \#2, bottom row) which benefit from prior snow depth updates. Updates correspond to those also shown in Figure 2.5. 
In order to more specifically detail the spatial effects of the ASO updates, two individual updates were chosen from 2014 and 2015 that portrayed a large dynamic range in the basin-averaged change in water storage $(\Delta \mathrm{SWE})$ (Figure 2.4$)$. The March 23, 2014 update represented the largest positive $\Delta \mathrm{SWE}(+40.8 \mathrm{~mm})$ from any of the 36 updates applied over the study period, whereas the May 1, 2015 update had a much smaller effect on the basin-averaged $\triangle \mathrm{SWE}(-7.1 \mathrm{~mm})$. To delve into the qualitative change in spatial distribution from the ASO updates, Figure 2.4 shows the SWE from iSnobal alone, iSnobal with the ASO snow depth update, and $\Delta \mathrm{SWE}$ over the entire basin for the same two updates. Insets show the fine scale changes in SWE distribution due to the snow depth update. Moreover, elevation lapse rates play a large role in the DK algorithm for distributing precipitation. For that reason, more refined equal area elevation bands were constructed to further assess how $\triangle \mathrm{SWE}$ from the ASO updates were distributed across elevations (Figure 2.5). For the first update of 2014 , the majority of the change was in the form of a net gain over the upper $50 \%$ of the basin (bands 6-10). On the other hand, the May 1 update spreads the difference across the middle elevations with negative changes in band 3 to band 8 and negligible change in the lower $20 \%$ and a slight increase in SWE over the upper $20 \%$ of the basin. Within some bands in Figure 5 the mean $\triangle \mathrm{SWE}$ is not within the interquartile range meaning that outliers are skewing the distribution. This occurs generally at lower elevations where the sample size of pixels containing snow is relatively small and the influence of outliers is more considerable.

A linear regression analysis was performed between the ASO-derived snow depths from each flight and both the previously updated (for the second survey onwards) and the ordinary non-updated iSnobal control runs. For each grid cell, the previously 

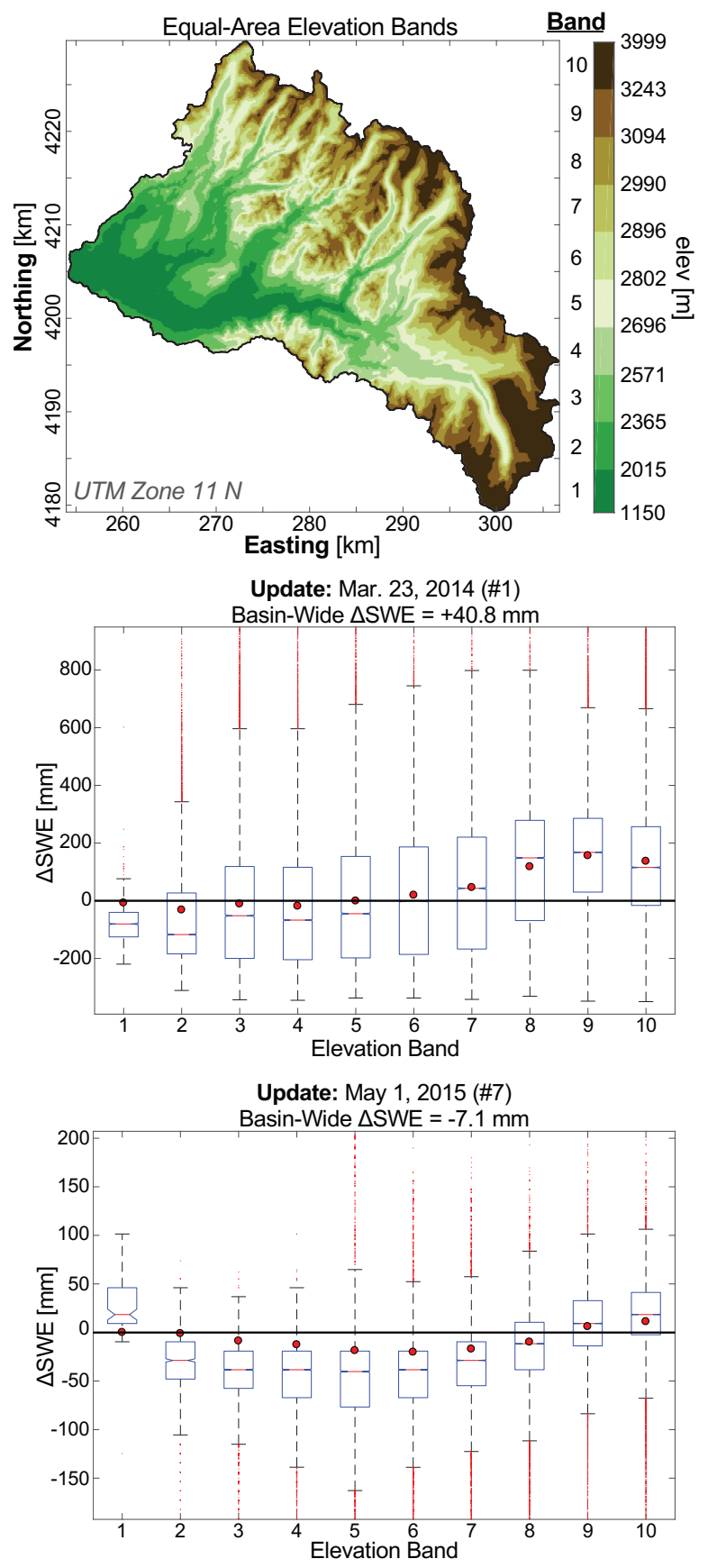

Figure 2.5: iSnobal change in SWE from two ASO updates delineated by equal-area elevation bands. Each band (area $\approx 118 \mathrm{~km}^{2}$ ) makes up $10 \%$ of the total basin area. The $y$-axis of the box plot is the total change in basin SWE resulting from the update, while the elevation bands depicted at top are on the x-axis. Red circles show the mean $\Delta \mathrm{SWE}$ contribution per band, while box plots display $\triangle \mathrm{SWE}$ distributions within bands. Note the significant scale difference on the box plot vertical axes. 
updated iSnobal snow depth estimates were highly correlated with the new depths from the subsequent ASO updates. However, the control run did not benefit from the previously redefined depth distribution and was poorly correlated to the lidar distribution.

Figure 2.6 shows the scatter plot of all grid cells within the basin along with the fitted linear regressions for the seventh seasonal survey of 2015 on May 1 and the same update portrayed in Figure 2.4 and Figure 2.5. Up to that point in 2015 the modeled snow depths never surpassed $1.5 \mathrm{~m}$, but ASO measured depths as high as 4 $m$ in a handful of pixels. At the same time, from the slope of the regression line for the previously non-updated iSnobal results (red line) it is apparent that a large portion of cells saw a decrease in depth from the update. Performing the same analysis on all updates over the four-year study period clearly shows the influence of setting the snowpack spatial distribution with the first update of each year (Figure 2.7). This result is unsurprising since the DK method for distributing precipitation resolves the elevational gradient, yet does not account for aspect, slope, and vegetation, which are the most important controls on local scale variability. Also evident is that the $r^{2}$ decreases occasionally throughout each year for even the updated model. We found this to be caused by two likely factors. First, late season storms that occurred between ASO surveys deposited snow preferentially, which was not accounted for by the DK precipitation distribution. Second, the time duration between subsequent surveys caused the model to drift further from the realistic distribution through uncertainties in the energy balance. For the majority of the ASO survey dates, the $r^{2}$ remained above 0.9 throughout the melt, indicating that iSnobal performs best when provided with a spatially representative snow depth distribution. The mean coefficient of 
determination when considering all 32 updates that had a previous update earlier in the season was $r^{2}=0.889$ with a mean $R M S E$ of $12.5 \mathrm{~cm}$. This is a much higher correlation than for those snow depth distributions that did not benefit from previous ASO updates $\left(r^{2}=0.162, R M S E=41.5 \mathrm{~cm}\right)$.

The full basin-averaged iSnobal simulation results are depicted in Figure 2.8. The timings of the ASO lidar surveys are indicated, and simulation results are shown with and without the lidar-derived snow depth updates. In contrast with the elevationresolved SWE, differences in total basin results between iSnobal estimates with and without the benefit of the ASO lidar updates are generally not large, but as shown previously they are initially spatially erroneous. In other words, the amount of solid precipitation input to the basin agrees with the ASO measurements, but the spatial distribution used to force the model is more uniform and does not account for drift and scour zones. Also shown are the SWI differences before and after adjustment. As mentioned before, $S W I$ includes both snowmelt and rain, and represents liquid water input to the soil. Changes in year-end $S W I$ magnitude are relatively small in all years, with an increase of $14 \%$ in 2013, 2014 and 2015 decreasing $10 \%$ and 1\%, respectively, and 2016 gaining only around $1 \%$.

As a result of the ASO depth updates, the timing of the $S W I$ shifted earlier in 2015 by a few weeks between mid-March and mid-June. Similarly, modeled SWI shifted slightly earlier in 2014, but the shift occurred later in the season and only for the month of May. In 2013 and 2016, the SWI pulse was largely unchanged in timing with the addition of the ASO updates. However, in 2013 the cumulative SWI increased by approximately $80 \mathrm{~mm}$ due to the addition of mass from the last three updates. The SWE and SWI curves for 2016 in Figure 2.8 display reflective 


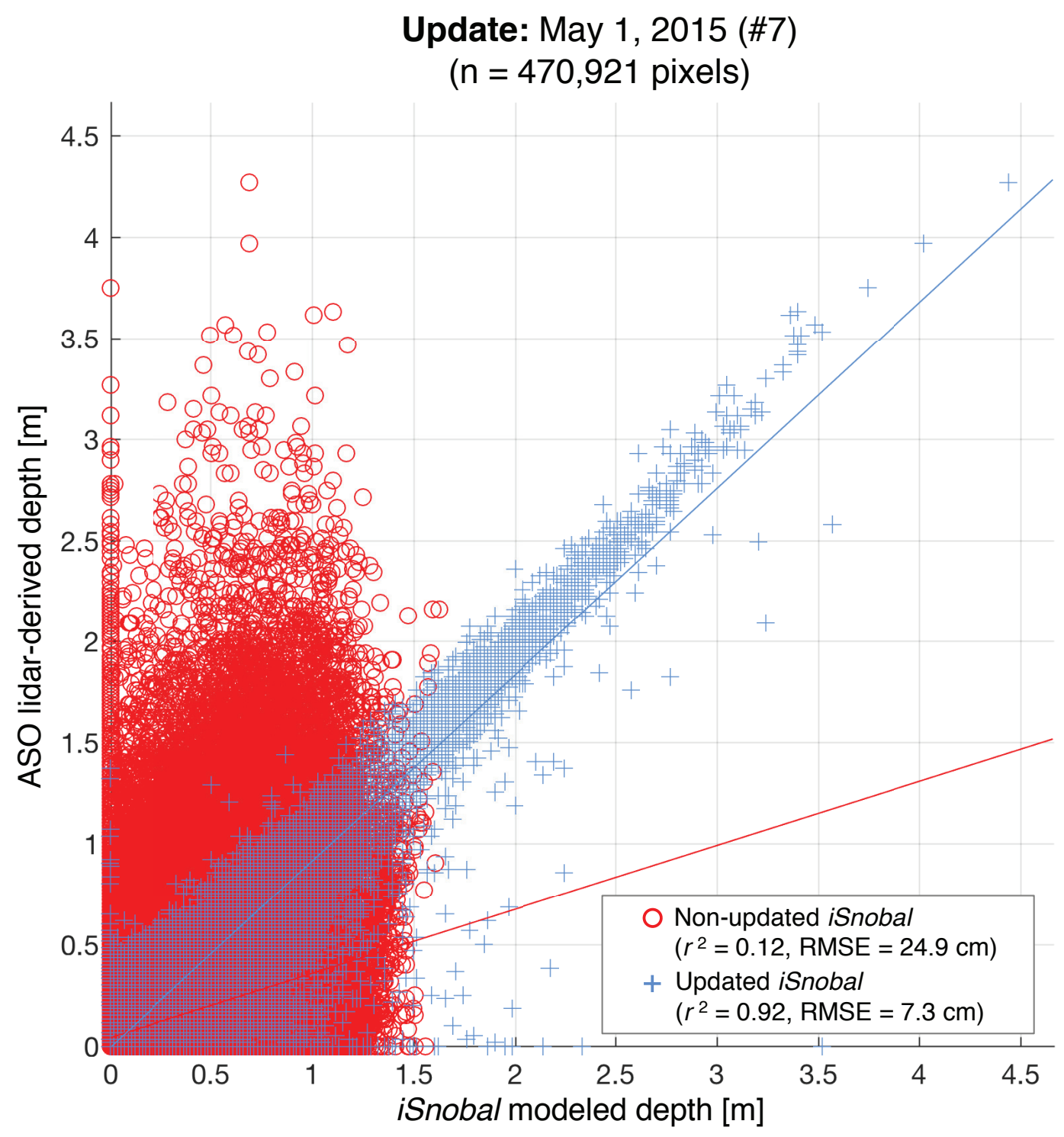

Figure 2.6: Scatter plot of ASO snow depths and both iSnobal snow depths with and without prior ASO updates for the 7th update of the 2015 water year. With previous updates, the spatial distribution is accurately defined and model estimates are highly statistically correlated to the ASO-derived snow depths. 

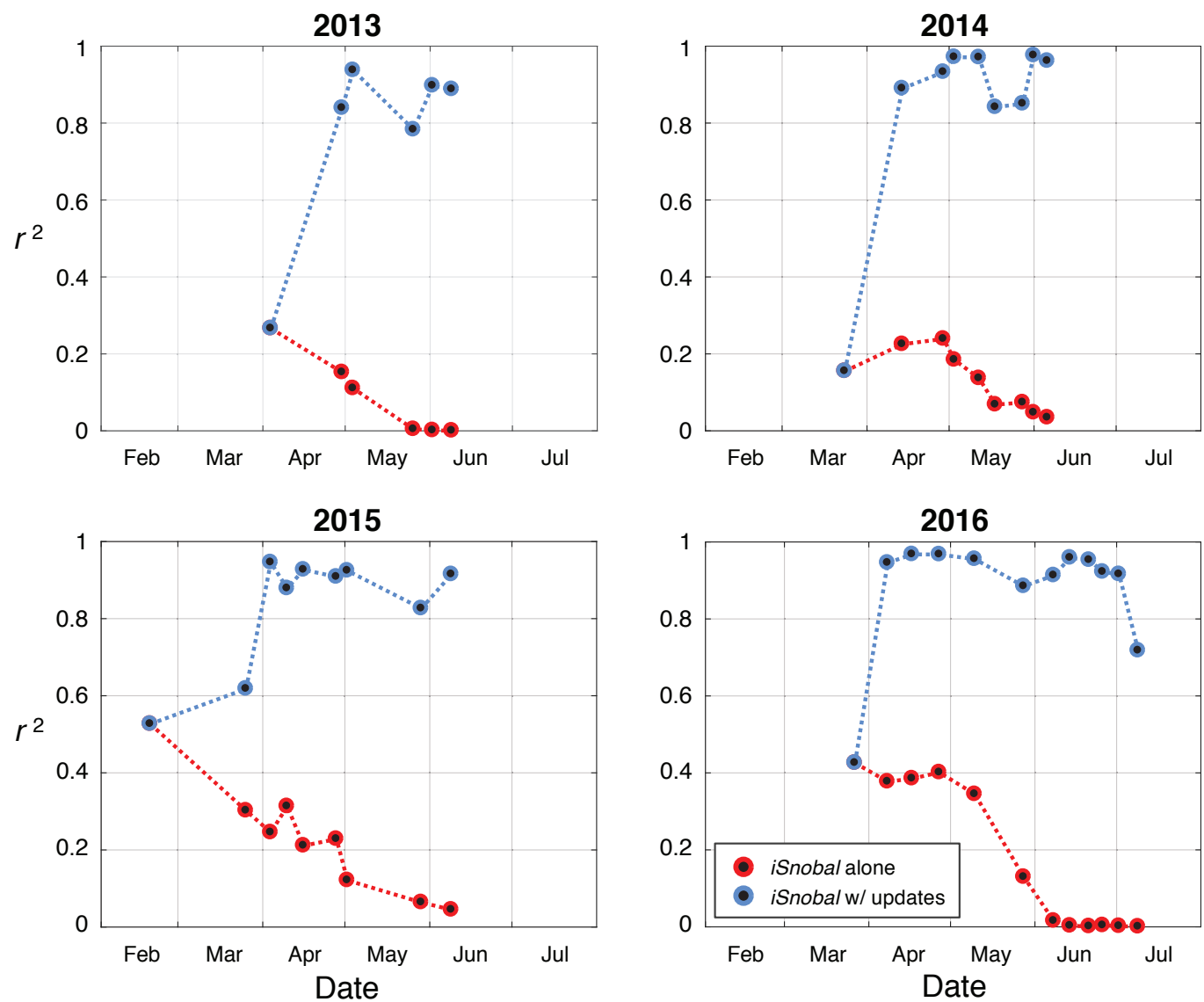

Figure 2.7: Coefficients of determination for each of the ASO-derived snow depth products with respect to iSnobal predicted snow depths on the day of the lidar acquisitions for both the previously updated (blue) and ordinary estimates without ASO (red). Once the spatial distribution is defined by the first update the correlation to subsequent updates drastically increases. 

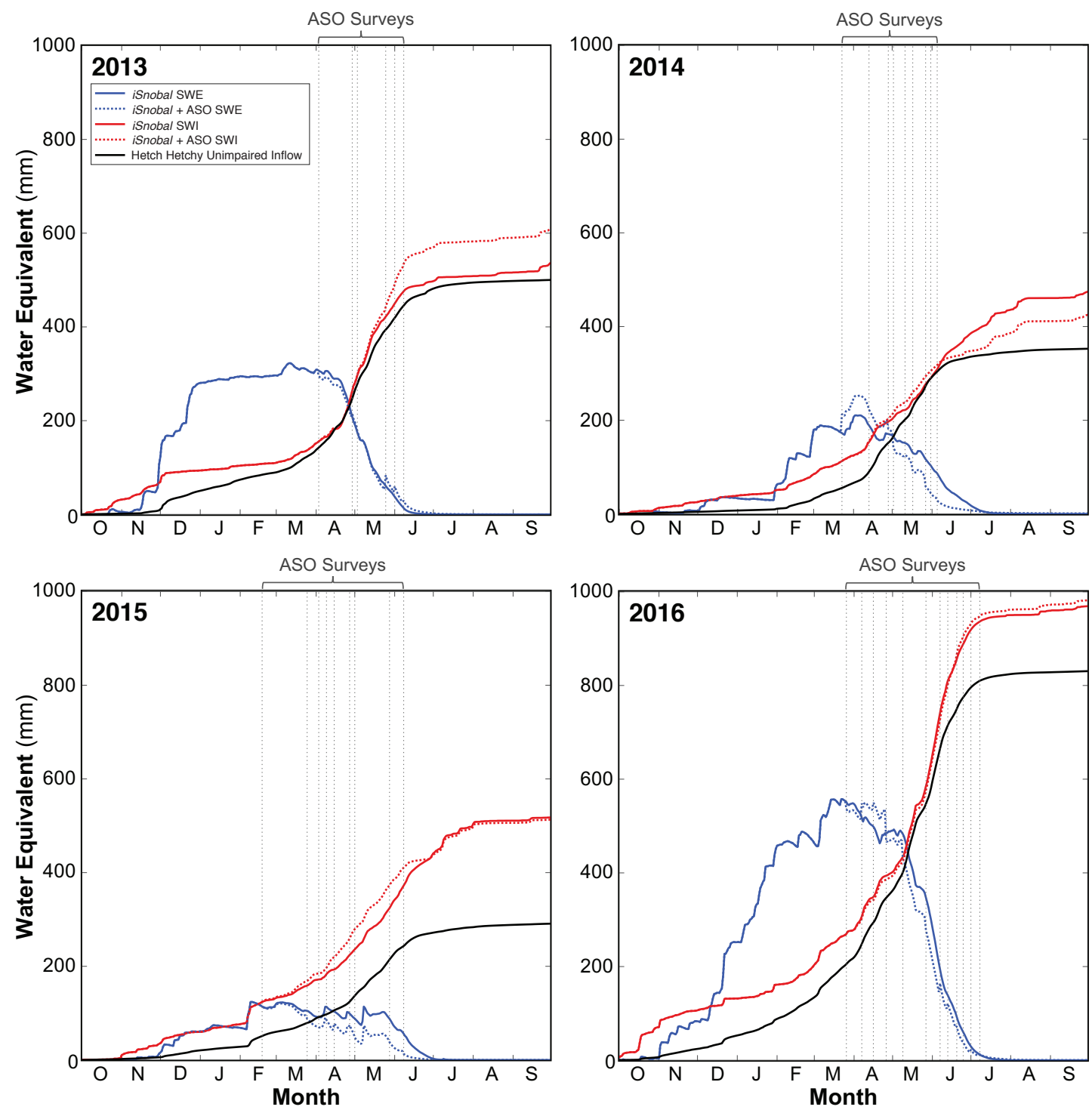

Figure 2.8: Basin-averaged iSnobal model results for both the unmodified predictions and the ASO-derived snow depth updates to the model state. The blue line is SWE and red line is the cumulative $S W I$ from either the base of the snowpack or rain on bare ground. The solid black line is the estimated cumulative inflow to Hetch Hetchy Reservoir (courtesy of the SFPUC). The dashed vertical lines represent the timing of each lidar survey used to update the model. 
symmetry throughout the ablation season since very little spring or summer rain occurred. In 2014 and 2015 substantial spring and summer rain took place after the basin SWE was depleted by the end of June.

\subsection{Discussion}

The first operational season of the ASO (water year 2013) happened to be the second year in what would eventually become a severe four-year drought. Not only was precipitation scarce over the Sierra Nevada, but temperature during storms was also above average resulting in reduced snowfall cold content. The ASO mission was serendipitously timed to facilitate water cycle science and aid water managers in their efforts to maintain reservoir levels during the California drought. The purpose of the analysis presented here was to show the influence from periodically redefining the spatial distribution of snow depth for a physically based snowmelt model. Over all four years, the general net impact of the updates was to initially increase SWE in the upper elevations from the first few updates, and subsequently reduce SWE and melt the snowpack earlier in the middle to lower elevations as the ablation season progressed (Figure 2.3). There are likely several reasons for this behavior, but we believe two factors to be the primary causes.

First, during the winter accumulation period the distribution of precipitation mass from point measurements to a regular grid partially resolved the snowfall elevation gradient but was independent of local terrain and vegetation features. The resulting distribution lacks snow drifts and scour zones, important features of mountain snowpacks that influence storm snow density. The resulting energy budget would add uncertainty to estimates of early season melt before the first ASO survey. Additionally, correspondence with Hetch Hetchy Reservoir managers revealed that the actual 
precipitation undercatch for many of the gauges in and adjacent to the Tuolumne Basin was larger than accounted for in our applied undercatch correction. Rigorous future testing of these sites should evaluate this local knowledge and justify adjusting the precipitation forcing estimates in addition to the gauge undercatch corrections currently being used. Obvious elevational biases were introduced by the precipitation distributing technique used in the pre-processing steps to run iSnobal (Figure 2.3, Figure 2.4, and Figure 2.5). The DK technique effectively reduces bias in the distribution only when point measurements are unbiased themselves. This is because the DK algorithm forces grid cells containing measurement stations to retain those values after the interpolation has been fit. However, the undercatch bias of low elevation measurement sites causes the slope of the precipitation elevational gradient to be reduced.

Second, the acceleration of the spring melt evident from the late season ASO updates could be a result of a lack of proper parameterization of net all-wave radiation. Thermal radiation is altered due to increased sensible heat in areas of patchy snow covers because of advection from exposed rock and soil (Olyphant \& Isard, 1988; Pomeroy \& Brun, 2001), which the ASO data is able to capture and iSnobal does not specifically account for. Without ASO depth updates, the modeled snow cover is more uniform and the model is unable to account for this increase in energy. Furthermore, net shortwave radiation input to iSnobal is a function of gridded spectral albedo, which is calculated from an empirical relationship (Marshall \& Warren, 1987) and adjusted for litter accumulation on the snow surface (Hardy et al., 2004). The albedo decay function used here could lead to a miscalculation of net solar radiation, but we are not able to speculate whether modeled albedo is too high or too low, given that 
albedo is not measured in the basin. In water years 2013 and 2016 the model melted snow faster than ASO (individual updates added SWE late in the season) and in 2014 melted slower (updates removed SWE). Water year 2015 had no discernable trend in the updates themselves, but the updated modeled SWE melted much faster than the case without updates. Future work using the ASO-derived vegetation information and spectral albedo measurements could lead to a new parameterization and more accurate melt timing.

The ASO flights quantify the structure of the spatial distribution of the snowpack, thereby reducing the uncertainty introduced by the more uniform precipitation distribution (Table 2.2b) determined through DK. Figure 2.4 depicts the SWE distributions both before and after two updates in water years 2014 and 2015, along with the $\Delta$ SWE produced by each update. The first update of 2014 added a substantial amount of SWE to the basin, while the seventh update of 2015 had a much smaller effect on the storage. This demonstrates that by the time of the seventh update, the spatial variability of the snowpack was already captured by the previous six ASO acquisitions and the uncertainty due to the pre-processing step of distributing precipitation from point measurements was reduced considerably. Earlier ASO acquisitions in the accumulation season would also be able to characterize the actual distribution of individual snowfall events replacing the more uniform DK point to grid distribution, though this would be challenging due to the rapid densification of new snow and sensitivity to estimated new snow density. However, it is clear that regular updates reduce divergence in simulated SWE distributions when large storms occur across the basin.

Examining the modeled spatial distribution of snow depths over time with respect 
to each ASO-derived distribution verifies that the snow depth updates improve model performance. The modeled depths shown in Figure 2.6 are highly correlated to the ASO depths only when previous updates have redefined the spatial distribution. This redefinition of the snowpack distribution alters the model energetics and the resulting modeled $S W I$ to the soil interface. The high correlations for the previously updated iSnobal estimates to the ASO depths continues throughout the year (Figure 2.7), indicating that the spatial extent of the updated model depths tend to be consistent with the ASO measured snow depths through the final survey of each year. However, the $r^{2}$ drops markedly to $\approx 0.8$ for flights that occurred either after large storms or after greater than three weeks had passed since the prior update. For instance, snowfall events occurred in May for both 2014 and 2015, and a dip in the correlation coefficient can be seen with the updated depths for those years in Figure 2.7. While iSnobal without updates accurately simulates total basin SWE magnitude, this indicates that ASO snow depths are critical for correcting the spatial pattern of snow accumulation. In contrast, iSnobal models melt quite well in the absence of late season storms.

Direct insertion data assimilation (DA) is not usually considered to be a robust technique since model fidelity is sacrificed and error in the assimilated measurement is ignored. A firm understanding of the relative model and lidar uncertainty must be known in order to employ other DA methods such as variational ensemble filter techniques (Auvinen et al., 2010; Houser et al., 2012; Miller et al., 1994). Running iSnobal in a near-real time prediction setting along with computational constraints make it currently impossible to perform robust error analysis using typical ensemble or Monte Carlo methods. Furthermore, studies are numerous in the literature that use point measurements to evaluate gridded model predictions. Though meteorolog- 
ical measurements from cooperator stations and the SNOw TELemetry (SNOTEL) network maintained by the USDA Natural Resources Conservation Service (NRCS) were designed to collect data that most closely represents the local physiography, they have been shown to be biased toward more sheltered sites and can be unrepresentative of the average conditions over an entire grid cell (Molotch \& Bales, 2005).

The ASO lidar measurements, typical of any remote sensing platform, include a certain amount of uncertainty. Previous studies estimated uncertainties of lidarderived snow depths between 15-30 cm using in situ measurement transects (Deems \& Painter, 2006; Tinkham et al., 2014), but these studies were hampered by older lidar technology and GPS co-registration errors. Systematic errors can be introduced by GPS timing, the inertial measurement unit, or in post-processing procedures. However, the snow depth product at the $3 \mathrm{~m}$ grid resolution possesses less accuracy across the study area than the $50 \mathrm{~m}$ product used for iSnobal direct insertion. For instance, the uncertainty in snow depth for the $3 \mathrm{~m} \mathrm{ASO}$ snow depth product is \pm 8 cm (16 cm RMSD) (Painter et al., 2016). For that same survey flight, the average uncertainty over a $50 \mathrm{~m}$ pixel (made up of $\approx 2783 \mathrm{~m}$ cells) is approximately $\pm 0.5 \mathrm{~cm}$ under the assumption of limited bias within the $50 \times 50 \mathrm{~m}$ area of each grid cell.

Nevertheless, the major assumption being made in order to use the direct insertion DA method is that the lidar-derived snow depths are the truth and all uncertainty stems from the modeled SWE estimates when density is unchanged. Deeper snowpacks exhibit higher densities from compaction due to overburden (Sturm et al., 2010), so iSnobal's density algorithm was reformulated to address this process (Marks et al., 2018). The model densifies pixels that receive any additional snow from the ASO update over the course of the next few model time steps. However, an example of 
the limitations of direct insertion DA is evident for water year 2014 in Figure 8. If a more robust DA technique that considered error in ASO snow depths was employed, the sharp increase in SWE magnitude for the first ASO update would perhaps be less abrupt.

Errors in both the lidar processing chain as well as in the model forcing data can be difficult to diagnose in near-real time and are often only apparent in hindsight after subsequent updates, which is not possible within the operational ASO mission structure. In the future, for purposes of modeled SWE accuracy, a filtering mechanism will be developed to locate regions in the lidar snow depth product that depart from previous ASO surveys in ways that are not consistent with measured or modeled precipitation.

The basin-averaged SWE and cumulative SWI as a function of time for all four water years (Figure 2.8) reveal model shortcomings that will be addressed in future near-real time applications. For 2013 and 2014, the cumulative SWI was altered after the inclusion of the updates. The causes for this are large abrupt changes in SWE storage during the ablation period. When ASO added SWE in updates \#4 and \#5 of 2013, the total amount of available melt water was suddenly increased. In 2014, updates \#3, \#4, \#6, and \#7 decreased the SWE storage and available melt water by a combined nearly $80 \mathrm{~mm}$, which is evident in the decreased cumulative $S W I$. A solution to these discrepancies could be more accurate parameterizations of the processes that influence melt, such as albedo decay rates or thermal radiation from snow-free surfaces in areas of patchy snow cover. However, getting the correct precipitation mass into the basin, as either rain or snow, would have the largest impact on cumulative $S W I$. 
The difference between the cumulative $S W I$ (red lines) and inflow to the Hetch Hetchy Reservoir (black line) is the residual to the hydrologic water balance of this basin, which is defined as the sum of total annual ET and ground water losses. Henn et al. (2018b) estimated ET over the ablation period in 2013, 2014, and 2015 to be 168 mm, $161 \mathrm{~mm}$, and $191 \mathrm{~mm}$, respectively, with 2016 not considered. The disagreement of those findings with the residuals in Figure 2.8 are likely due to precipitation inputs to iSnobal, causing the abrupt changes in modeled SWE described above. ASO is able to adjust the modeled SWE but not precipitation that falls as rain, which can be up to a third of the precipitation input annually.

The metrics presented in Table 2.3 show that many aspects of the basin hydrology were adversely affected by the severe snow drought year of 2015. During this year, far more precipitation fell as rain, the average rain-snow transition elevation was higher, and the date of peak SWE was much earlier. Such analyses of the spatial sensitivities of a snowpack are made possible with the use of a high resolution distributed snow model such as iSnobal. Additionally, the ASO proved to be most critical in 2015 given that the model without ASO updates was in diminished agreement. The integration of modeling and remote sensing is far more effective and powerful than either on its own.

The Tuolumne Basin hypsometry is unusual due to the steepness of the lower Tuolumne valley. Small changes in rain snow transition elevation can have large effects on snowpack water storage. The annual cumulative SWI for 2015 (Figure 2.8) was close to 2013 levels and actually higher than 2014 due to monsoonal rainfall in May and June, yet the peak SWE volume was one-third and one-half of those years, respectively. Consequently, a large contributor to the catastrophic snow drought of 
2015 was the $566 \mathrm{~m}$ average upward shift in the rain-snow transition elevation from that of a relatively normal year of 2016 (Table 2.3). The second column of Table 2.3 shows a decrease in annual phase proportion of snowfall of approximately $12-13 \%$ in 2015 from the remaining water years and was likely a contributing factor to the historically meager snowpack. A detailed analysis of the rain-snow transition elevation in the Tuolumne Basin will be addressed in a following study.

\subsection{Conclusions}

The mountain snow cover is heterogeneously distributed across a complex landscape (Jost et al., 2007; Lehning et al., 2011) and is notoriously difficult to characterize. With ASO, the approximated and more uniform modeled snow distribution can be replaced with observations from the airborne lidar. While the total basin storage is not drastically changed by the lidar snow depths, the snow covered area, timing of melt, and the hydrologic system is affected by the redefined snow distribution. The integration of modeling and remote sensing in the ASO program provides a unique opportunity to quantify the volume of water stored in the seasonal snow cover of a large mountain basin. It can also provide a reliable definition of how that SWE is distributed across the basin and show the timing and pattern of surface water input at the snow-soil interface.

Explicitly redefining the spatial snowpack distribution had a similar net effect on the available water from the basin for all four years between 2013-2016. Each winter the first update to the near-real time iSnobal predictions using the ASO lidar-derived snow depths increased the basin averaged SWE estimates at high elevations (above $3000 \mathrm{~m}$ ) where wind redistribution is a major factor, while the subsequent updates throughout the melt season resulted in earlier melt out dates for elevations below 3000 
m. The time-series of ASO overflights provide the first detailed definition of snow distribution and how that distribution changes throughout the snow season. Integration of these into the iSnobal data stream shows us that the first ASO update represents the largest adjustment because it defines the basic distribution. Subsequent updates generally involve much smaller adjustments but are equally important because they define the effect of additional deposition on the snow distribution and validation and adjustment as snowcover depletion progresses during the snow season.

From spatiotemporal analysis of the updated iSnobal SWE product over the four study years, we were able to explicitly derive the average rain-snow transition on a storm-by-storm basis. In 2015, the Tuolumne Basin experienced a reduction of almost $13 \%$ in the snow to rain precipitation ratio and a mean upward shift in rain-snow transition elevation of $566 \mathrm{~m}$ from the average snowpack year of 2016 (Table 2.3).

Future work will include perturbed forcing grids for executing ensemble iSnobal runs in order to better understand model uncertainty. Also, in basins with highly suspect or a complete lack of station measurements, gridded forcing data from sources such as the Modern-Era Retrospective Analysis for Research and Application (MERRA), the North American Land Data Assimilation System (NLDAS), or the High-Resolution Rapid Refresh (HRRR) forecast must be downscaled to the iSnobal/ASO resolution, which will require extensive validation. Likewise, total error propagation (TEP) techniques are being developed by the ASO team to provide a more rigorous uncertainty estimate for the lidar-derived snow depths, the simulated SWE and SWI, and the integrated remote sensing and snow modeling result. With a better understanding of the uncertainty for both the model and the remote sensing measurements, we may move forward with an improved integration of the ASO snow depths into iSnobal 
leading to a more effective overall ASO product. 


\title{
CHAPTER 3:
}

\section{REPRODUCIBLE GRIDDED FORCING DATA FOR A PHYSICALLY BASED SNOW MODEL THROUGHOUT HISTORIC DROUGHT CONDITIONS IN CALIFORNIA (2013-2016)}

\begin{abstract}
Over a four-year period (2013-2016), meteorological station data were used to force simulations of the spatially distributed iSnobal snow model over the Tuolumne River Basin in the California Sierra Nevada. The simulations coincided with multitemporal airborne lidar surveys conducted by the NASA Airborne Snow Observatory (ASO). This paper describes the quality control techniques that were applied to produce the hourly meteorological input time series necessary for a high-resolution energy balance snow model. The meteorological data were downloaded in real time from the California Data Exchange Center (CDEC) and MesoWest. These data included hourly measurements of air temperature, wind speed, wind direction, and precipitation along with derived estimates of vapor pressure and percent cloud cover. The data were rigorously quality controlled with spurious or improbable measurements removed and missing data interpolated in some cases. This paper explains the only subjective and
\end{abstract}


non-reproducible component of the entire modeling stream; from point measurement to gridded snowpack state product. An example application is presented that details how hourly iSnobal spatial forcing data were constructed from cleaned station measurements in an entirely reproducible manner. Since four years of distributed spatial inputs to the $i$ Snobal snow model ultimately result in approximately 3.3 terrabytes of disk storage and are not easily shared with other researchers, the software and configuration files used to produce them are supplied within a Docker container in a separate software repository. Once distributed, the high-resolution gridded forcing dataset is ideal for forcing other energy balance models and validating climate models over complex topography.

\subsection{Introduction}

Over the last decade, a focused effort has been put forth to make meteorological datasets more available to the mountain hydrology research community (Godsey et al., 2018; Kormos et al., 2014b, 2017b, 2018; Lundquist et al., 2016; Reba et al., 2011a). It is increasingly difficult for an experiment to be deemed impactful without the accompanying data from which study conclusions are drawn. Data transparency is crucial for maintaining scientific integrity in this new era of big data and distributed computing. In addition, easily accessible data creates opportunities for more open collaboration between colleagues, intercomparison between studies and facilitates cross-disciplinary research.

The primary aim of this data summary paper is to provide a context for the extent of manual quality control (QC) that must be performed on point measurements in a non-research mountain basin with a sparse measurement network in order to produce near-real time forcing data for a gridded physically based snow model. A secondary 
objective is to show an example of an approach for producing the meteorological forcing grids from the point data, after undergoing QC, that is completely reproducible using recent advancements in operating-system-level virtualization (e.g. Docker).

Energy and mass balance models require accurate representations of meteorological variables in order to satisfy model physics and produce reasonable results. The standard set of variables required by a typical physically based model include air temperature, relative humidity, wind speed and direction, incoming solar radiation, and precipitation mass. Each of these variables can also be simulated using land surface models and climate reanalysis datasets (Daly et al., 1994; Gelaro et al., 2017; Xia et al., 2012), but the coarseness of such model products are unable to capture the gradients present in complex high elevation terrain (Henn et al., 2018a; Strachan et al., 2016). Therefore, the modeling carried out in support of ASO in the Sierra Nevada has been forced using direct measurements from in situ meteorological stations. Numerous studies have shown that station measurements can be effectively used as forcing input to high resolution ( $<100 \mathrm{~m}$ grid resolution) snow models (Hedrick et al., 2018a; Kormos et al., 2014a; Winstral et al., 2013).

Weather stations are sparse in the majority of snow-dominated mountain basins in the Western United States. Measurement sites are often located in wind protected, largely unrepresentative forest clearings at or just above the local rain-snow transition elevation (Molotch \& Bales, 2005). Accurately estimating elevation lapse rates with a sparse network for temperature and precipitation thus remains a challenge for the modeling community. Scientific simulation studies often use one or only a few measurement sites and a predetermined elevation lapse rate to derive spatial forcing fields over the study basin (Winstral et al., 2014). By using all available weather sta- 
tion information, rather than relying on a single well-maintained research site, a more accurate spatial representation of meteorological conditions can be achieved. At the same time, a sparse station network over a large area poses difficulties for maintenance and upkeep of sites and sensors, often prompting dubious measurements. Therefore, the QC process that is described within this paper is necessary when forcing a physically based model with station measurements.

The original modeling application of this dataset was in support of the NASA-JPL ASO, which consists of a coupled airborne lidar and spectrometer currently flying onboard a King Air A90 aircraft (Painter et al., 2016). ASO measures snow depth and reflectance throughout the winter accumulation and spring melt over complex mountain terrain. With snow depths characterized at $3 \mathrm{~m}$ resolution and then coarsened to $50 \mathrm{~m}$ resolution over a large basin, the density of the snowpack must then be modeled to provide a snow water equivalent (SWE) product to interested stakeholders downstream. The snow density component of the ASO product is estimated using the iSnobal physically based gridded snow model (Marks et al., 1999). The process of running iSnobal in near-real time and incorporating the ASO-derived snow depths back into the model over the Tuolumne River Basin in California for years 2013 to 2016 is described in Hedrick et al. (2018a). The dataset presented here contains all of the forcing measurements required by iSnobal, which are described in detail by Marks \& Dozier (1992).

For the application presented in Section 3.5, the model is executed at a $50 \mathrm{~m}$ spatial and hourly temporal resolution, which results in computer disk storage for the meteorological forcing fields over the Tuolumne Basin of $\approx 670$ gigabytes per year. Forcing fields are produced from the input station meteorological data within the 
Spatial Modeling for Resources Framework (SMRF) (Havens et al., 2017). The techniques used to distribute the meteorological variables measured at individual weather stations are based on subjective decisions made by the modeler and the interpolated model forcing grids must be considered modeled estimates themselves. Therefore, the Tuolumne Basin data presented here include only the point measurements both before and after QC, the static grids containing elevation and vegetation information, the periodic ASO $50 \mathrm{~m}$ snow depth products used for the model updating, and model configuration files used to produce the results presented in Hedrick et al. (2018a). The dataset is available in a public data repository (Hedrick et al., 2018b), while a snap shot of the software used to produce the iSnobal forcing grids are available in a separate Git-controlled software repository (Hedrick et al., 2018c). This novel approach for supplying the model software in addition to the edited meteorological measurements necessary to entirely reproduce model forcing data is a significant step forward for data transparency in the hydrologic sciences. At the same time, we recognize that more efficient methods to disseminate similarly large forcing datasets may be devised in the future.

Data records for individual weather stations in the Tuolumne River Basin were rarely temporally continuous throughout all four years due to sensor malfunction and degradation. However, the data presented here are our best estimates of the actual hydrometeorological conditions across the watershed from 2013 to 2016, and can be used to force other hydrologic models or to validate climate models.

The remainder of this data summary is organized in the following manner. Section 3.2 presents a brief overview of the Tuolumne Basin. Section 3.3.1 describes the QC used to arrive at the model-ready vector data for each measured meteoro- 
logical variable. Section 3.4 presents the ASO snow depth rasters for all 36 flights and outgoing daily observed streamflow estimates over the four-year period. Section 3.5 presents an example application where the iSnobal snow model was forced with the data in a completely reproducible manner using the software and dataset openly available from the Zenodo data repository and software library. Section 3.6 describes the availability of the dataset and software. Lastly, Section 3.7 is a short overview of the data and discusses the next steps for reproducible quasi-operational hydrology models.

\subsection{Site Description}

The ASO science definition team chose the Tuolumne River Basin in California's Sierra Nevada (Figure 3.1) to be the initial test basin for the application of airborne surveys for snow depth retrieval at high-resolution. The Tuolumne Basin is a large, snow-dominated, high altitude watershed that is the largest source of fresh water and hydropower for the city and county of San Francisco. Due to its hydrologic significance, the basin has been the subject of numerous scientific studies (Henn et al., 2015; Lundquist et al., 2005; Rice et al., 2011). The basin area is $1181 \mathrm{~km}^{2}$ and the elevation ranges from 1150 to 3999 m.a.s.l. (meters above sea level) with a mean elevation of 2715 m.a.s.l. The basin hypsometry is somewhat unique in that elevations between 1150 and $2000 \mathrm{~m}$ account for only $10 \%$ of the total area, due to the steepness of the Tuolumne River Canyon, and over $80 \%$ of the basin is above $2400 \mathrm{~m}$ (Figure 3.1). With the station elevations plotted on the hypsometric curve it is evident that the upper $30 \%$ of the basin is not represented by in-situ snow measurements. Thus, the ASO snow depth measurements are crucial for estimating snowfall totals in the upper elevations of the basin. 

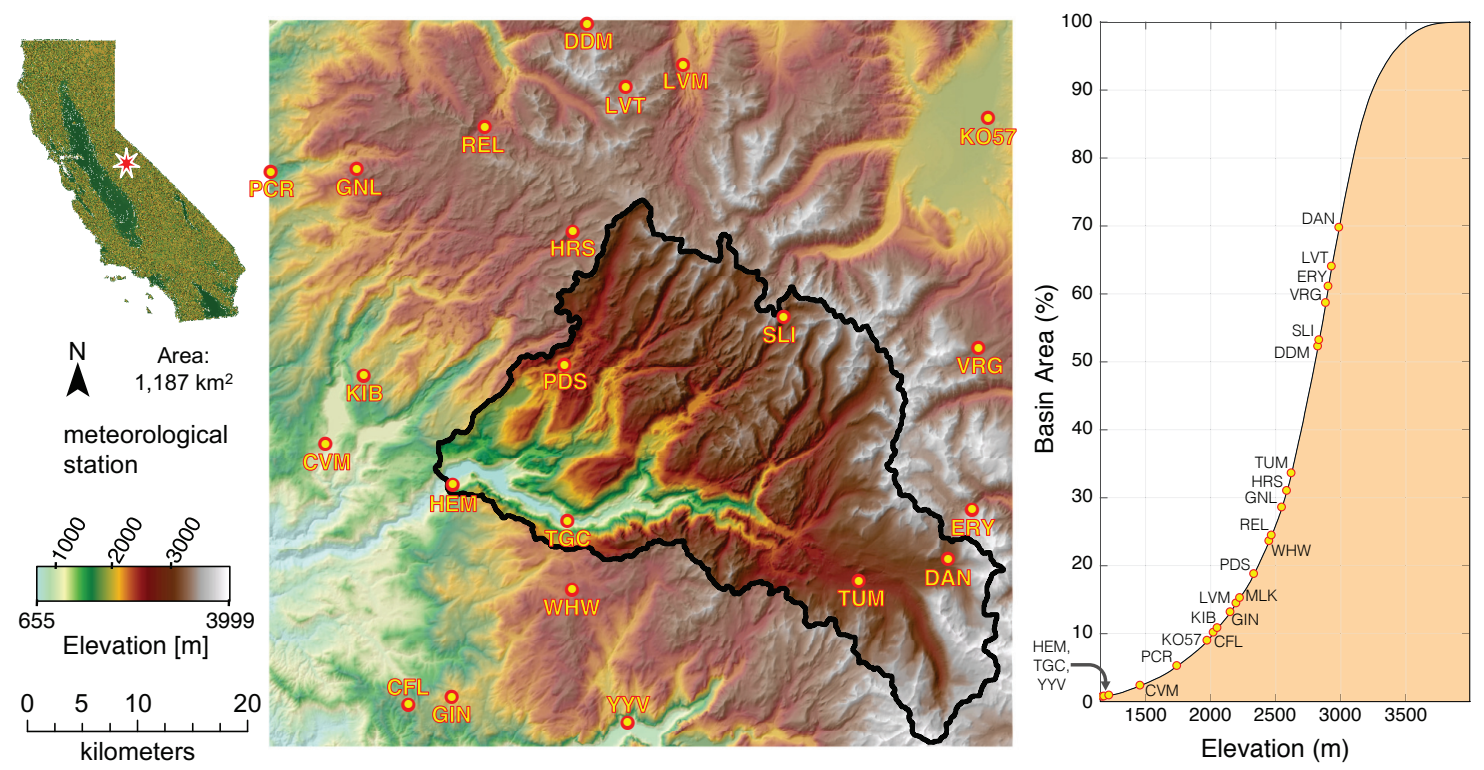

Figure 3.1: Location and relief map of the Tuolumne River Basin above Hetch Hetchy Reservoir within the U.S. State of California. Locations of the stations with measurements presented in this dataset are depicted, along with their site codes according to the CDEC. The lowest elevation within the basin boundary is $\mathbf{1 1 5 0}$ m.a.s.l. at Hetch Hetchy Reservoir just adjacent to the HEM weather station. To the right is the basin hypsometric curve and elevations of all 23 stations included in this dataset. 
Elevation is the dominant control on vegetation in the basin. Precipitation is largely diminished along a northwest to southeast gradient due to a rain shadow effect. The high granitic ridges within the Emigrant Wilderness on the northwestern boundary of Yosemite National Park and the Clark Range that separates the Tuolumne and Merced River Basins to the southwest act as barriers to moisture flowing east from the Pacific Ocean (Feld et al., 2013). From 2004-2017 the annual mean precipitation at the Gianelli Meadow (CDEC site code GNL) site to the northwest of the basin was $1477 \mathrm{~mm}$, while the Tuolumne Meadow (TUM) site in the southeast of the basin received $764 \mathrm{~mm}$ and the Ellery Lake (ERY) site on the east side of the Sierra crest received $494 \mathrm{~mm}$ annually. The basin exhibits a Mediterranean climate with the vast majority of precipitation falling between November and June and peak SWE occurring between March and May.

\subsection{Meteorological Data}

Due to the entirety of the basin lying within the Yosemite Wilderness, the Tuolumne Basin is sparsely instrumented. Many of the monitoring stations lie just within or adjacent to the Wilderness boundary and are not easily accessed for regular instrument maintenance. Automated approaches for meteorological data QC that are commonly used in better-instrumented study basins (Landry et al., 2014; Marty \& Meister, 2012; Morin et al., 2012; Rothwell et al., 2016; Slaughter et al., 2001) were not appropriate for the Tuolumne's sparse measurement network. Instead, the dataset presented here is comprised of manually cleaned hourly measurements where meticulous detail was used to maintain temporal continuity.

Point measurements of air temperature, wind speed and direction, precipitation, vapor pressure computed from relative humidity, and cloud cover fraction derived 
from incoming shortwave irradiance are presented in this dataset. Data were automatically downloaded through the CDEC and MesoWest (Horel et al., 2002) APIs (Application Programming Interfaces) every six hours to a local Structured Query Language (SQL) database server hosted at the NWRC. Station locations reported by CDEC and MesoWest are often hundreds of meters away from the actual sensor sites, so significant effort was put forth to locate actual coordinates and elevations. These updated locations can be found in Figure 3.2 as well as in the included metadata files. Though the data are preliminarily quality controlled by CDEC and MesoWest, a more rigorous procedure is necessary for use in a hydrologic modeling application.

The effect of the QC performed by the NWRC is shown in Figure 3.3, with level 1 (L-1) data being the initially downloaded data and level 2 (L-2) the final model-ready product. Of the six measurement variables in this dataset, four (air temperature, relative humidity, wind speed, and wind direction) are more straightforward to clean and smooth. The approach presented below could be feasibly be applied in a nearly fully-automated fashion, with limited human intervention. However, the other two variables (precipitation and incoming solar radiation) require substantially more intervention based on user-subjective decisions. The procedures for QC vary for each meteorological variable and are described in the following sections in detail.

\subsubsection{Air Temperature and Humidity}

With 23 individual stations measuring air temperature $\left(T_{a}\right)$ at some point over the four years presented here (2013-2016) (Figure 3.2), it is the most common measurement in the Tuolumne modeling domain. An automated procedure could be used to remove the majority of the poor measurements. To smooth noisy data, the MATLAB smoothn function was used. The function employs an iterative spline smoothing 


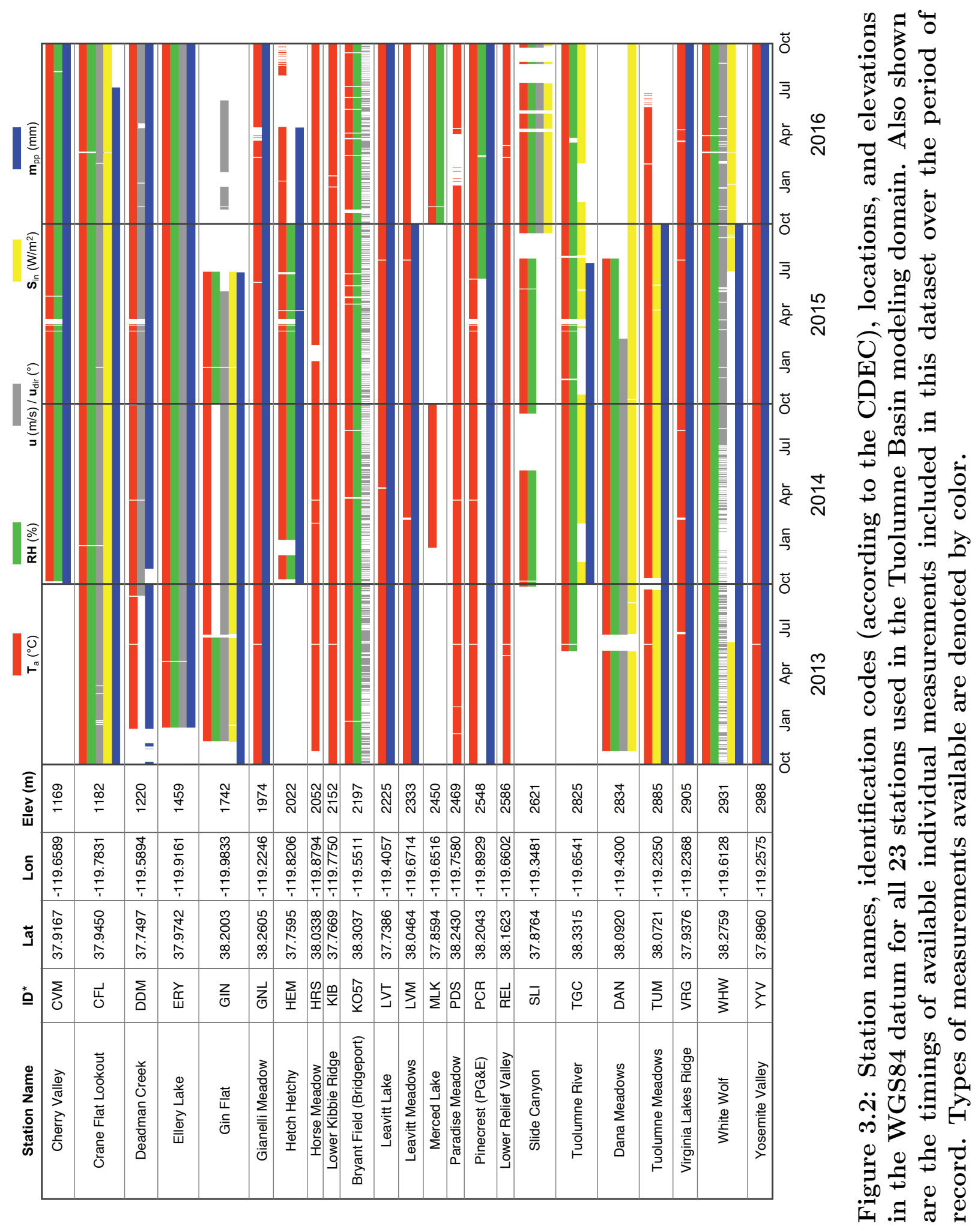


algorithm with various options for how to handle time series data (Garcia, 2010). Through a series of trial and error, the smoothing parameter was set to 0.5 in order to not over or under smooth the data (Figure 3.3a). Additionally, any time periods with missing data were filled using 1-D interpolation. The maximum size of the data gap to interpolate over was set to 6 consecutive hours or less in order to capture diurnal fluctuations in temperature. Any gaps greater than 6 hours were designated as no data.

Relative humidity $(R H)$ measurements were available at a total of 12 sites over the period of record, all of which were co-located with $T_{a}$ sensors. Hourly $R H$ data are used for determining precipitation phase and vapor pressure, which are two crucial inputs to most energy balance models. Strong diurnal fluctuations were observed for many of the site locations due to the large daily fluctuations in $T_{a}$ (Figure 3.3a-b) typical of mountain environments. $R H$ was capped at $100 \%$ and cross-referenced with measured precipitation events in the basin. In some rare cases sensors reported $R H<5 \%$, which would result in extremely low vapor pressures and model instability. Therefore, these hours were removed and interpolated over if less than 6 consecutive hours. Since $R H$ and $T_{a}$ are typically measured by a coupled sensor, the data gaps were mostly coincident. Therefore, the same smoothing algorithm and smoothing parameter that was used for $T_{a}$ was used for $R H$ in order to maintain consistency.

iSnobal does not require direct measurements of relative humidity. Instead, vapor pressure $\left(e_{a}\right)$ was derived from $R H$ using the Clausius-Clapeyron relationship and is provided in this dataset in units of pascals. $R H$ can easily be back-calculated from $T_{a}$ and $e_{a}$, if deemed necessary for other applications. 
a) Air Temperature $\left({ }^{\circ} \mathrm{C}\right)$

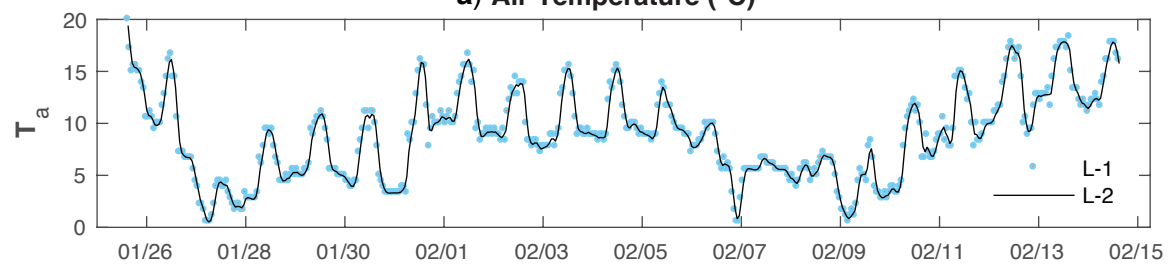

b) Humidity (\%)
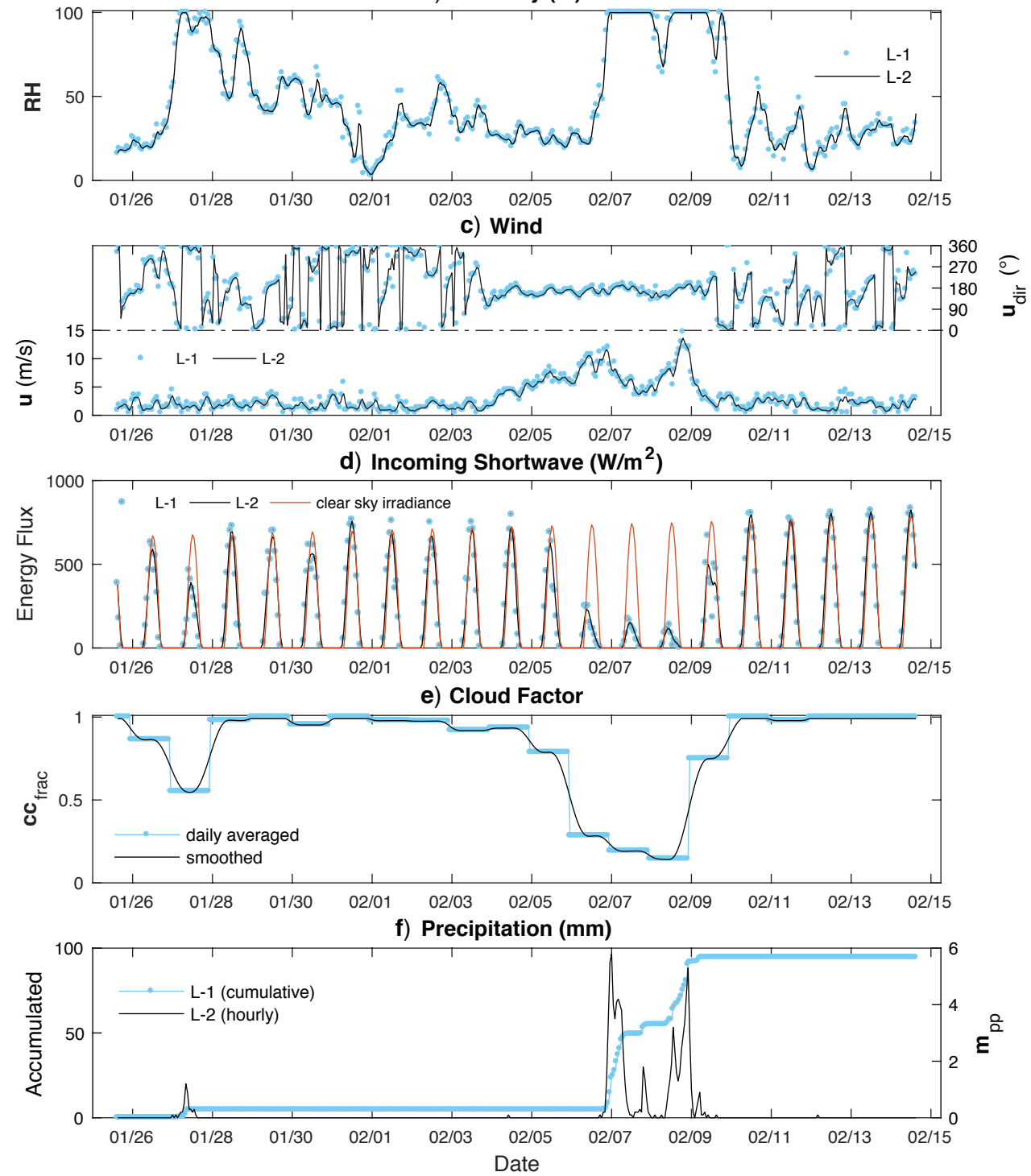

Figure 3.3: Level 1 (L-1) data and smoothed level 2 (L-2) results at the Crane Flat Lookout weather station for the five basic weather measurements plus the derived cloud factor variable over a 20-day period in early 2015. These measurements include a) air temperature, b) relative humidity (back-calculated from vapor pressure), c) wind speed and direction, d) incoming shortwave radiation, e) derived cloud factor, and f) precipitation. This time period depicts a warm, wet mid-winter precipitation event moving across the Tuolumne Basin. 


\subsubsection{Wind}

Measurements of wind speed $(u)$ and direction $\left(u_{\text {dir }}\right)$ are notoriously difficult in mountainous, snow-dominated terrain. Wind data from stations in the Tuolumne were often unavailable during winter storms due to rime build-up on sensors. Sites would also go offline midwinter due to malfunctions and not be available again until technicians could visit for repairs in the summer. Figure 3.2 shows that a total of eight stations were equipped to measure wind over the 2013-2016 time period, with four stations positioned in sheltered forest openings (DAN, DDM, GIN, and WHW) and the other four in exposed locations (CFL, ERY, KO57, and SLI). In order to correct $u_{\text {dir }}$, measurements were separated into their vector components before being smoothed, then converted back into $0^{\circ}-360^{\circ}$ directions (Figure 3.3c). The smoothing parameter was once again set to 0.5 and the wind speeds and directions were interpolated over a maximum of 10 consecutive hours without data to ensure temporal continuity. An interpolating window of this size was used because providing at least one wind estimate was necessary and there were a handful of time periods over the four years where only one site was reporting data.

Also included in this dataset are the distributedMAXimum Upwind Slope (MAXUS) parameters for 72 individual wind directions derived over the $50 \mathrm{~m}$ DEM using a search vector length $\left(d_{\max }\right)$ of $500 \mathrm{~m}$ (described in detail by Winstral \& Marks (2002)). Also known as the $S_{x}$ terrain parameter, MAXUS describes the degree to which a pixel is topographically exposed or sheltered as a function of upwind direction. The hourly value of MAXUS in each pixel is used to scale spatially distributed wind speeds, using relationships developed in other snow-dominated watersheds across the Western United States (Winstral et al., 2009). These scaled wind speeds are then used to 
compute turbulent fluxes over the model domain. In addition, various studies have shown that MAXUS can also be used to distribute precipitation by making use of empirically-derived relationships (Kormos et al., 2014a; Winstral et al., 2013; Winstral \& Marks, 2002). However, Grünewald et al. (2013) points out that statistically based relationships between snow accumulation and wind speed derived in one basin can be difficult to transfer to another basin. For this reason, the example modeling application presented in Section 3.5 only used the MAXUS parameter for the turbulent transfer calculations.

\subsubsection{Incoming Shortwave Irradiance}

Typically, solar irradiance, $S_{i n}$, is the rarest meteorologic measurement found at remote automated weather stations. At the same time, it is the most cumbersome variable to QC, requiring significant human intervention. Over the period of record for this dataset, seven stations in or adjacent to the Tuolumne Basin were equipped with pyranometers to measure $S_{i n}\left(W / m^{2}\right)$. However, only $48.7 \%$ of all possible station hours over the four-year period provided a measurement, highlighting the difficulty of determining net radiation fluxes in sparsely gauged basins.

All stations presented here reported no data for nighttime hours when $S_{\text {in }}=0$ $W / m^{2}$. To retain as many measurements as possible, these data gaps were set to zero and smoothed (smoothing parameter $=0.5$ ). Any negative values after smoothing were then set to zero and any hours reporting zero during daylight hours were manually removed through visual inspection (Figure 3.3d). From the data it was

evident that the TGC site became shaded between November 9 and February 1 of each year, due to the site's location in the bottom of a steep canyon, so that station was discarded for those time periods. 
Since sensor quality varies significantly between stations and calibration in the Tuolumne is not carried out as rigorously as in a closely monitored research basin, a more robust method of estimating actual $S_{\text {in }}$ was necessary. For example, the TGC site consistently reported maximum daily irradiance measurements that were only $40 \%$ of those measured at the WHW site located $8 \mathrm{~km}$ to the south. To overcome such discrepancies we used the solution originally described by Dubayah (1994) and later expanded on by Susong et al. (1999) and Reba et al. (2011b). This approach uses station measurements as a scaling factor for the estimated topographically corrected clear sky incoming shortwave irradiance, $S_{\text {clearsky. }}$. The modeled $S_{\text {clearsky }}$ product is a function of the latitude, longitude, and elevation of the site, hour of the year, and the surrounding terrain and vegetation (Dozier, 1980). A dimensionless 'cloud factor' or cloud cover fraction, $c c_{f r a c}$, is then computed as the ratio

$$
c c_{\text {frac }}=S_{\text {in }} / S_{\text {clearsky }}
$$

The amplitude of the modeled daily maximum $S_{\text {clearsky }}$ is temporarily scaled to approximately match the maximum amplitude of the station measurements over a userdetermined time period where actual clear skies were observed (typically no more than two months for this application). This scaling limits the range of values to $c c_{\text {frac }} \in[0,1]$. Since sensor noise is a higher proportion of the measured irradiance magnitude around dawn and dusk, we calculated a daily $c c_{\text {frac }}$ from each 24-hour irradiance ratio, resulting in a stepped product (Figure 3.3e). The 24-hour stepped values required a different smoothing approach to derive a more continuous representation of cloud cover. The same iterative spline smoothing algorithm described before was used, but this time with a Cauchy weighting function with a termination 
tolerance of $1 \times 10^{-4}$ and a maximum number of 100 iterations. The weighting functions are described more thoroughly in Appendix B of Garcia (2010). The reason for this robust smoothing is to more accurately account for changes in cloud cover over nighttime hours when $S_{i n}=0 \mathrm{Wm}^{-2}$ (see Figure 3.3e).

Using the product of $c c_{\text {frac }}$ and $S_{\text {clearsky }}$ as surrogates for measured $S_{i n}$ adds robustness among stations that report varying irradiance magnitudes due to sensor type and integrating wavelengths. The two primary ways that the iSnobal modeling framework uses point estimates of $c c_{f r a c}$ are discussed in Section 3.5.

\subsubsection{Precipitation}

Measurements of precipitation mass, $m_{p p}$, that fell as either rain or snow were made by a total of 15 stations over the time period (Figure 3.2). $m_{p p}$ is the most important variable in any hydrology model since it represents the primary source water inputs to the system. Automated sensors store precipitation totals as a cumulative depth of water where the initial quality of the data is dependent on the hosting agency. Some factors affecting the measurements include (1) bucket dump and recharge, which occurs when technicians visit sites to drain and refill the bucket with propylene glycol or anti-freeze, (2) signal noise due to diurnal temperature fluctuations in weighing gauge devices, and (3) capping of the bucket orifice due to heavy snowfall. The first two factors can be mitigated through methods such as the APCP (Nayak et al., 2008), but the third is a more insidious problem requiring rigorous manual investigation.

For this dataset the cumulative precipitation was differenced to provide hourly instantaneous precipitation (Figure 3.3f, Figure 3.4). The presented values are not wind undercatch-corrected, which is performed in a SMRF routine at a later step, but the data are corrected for bucket recharge and signal noise using the APCP. To 
a) Deadman Creek (DDM)

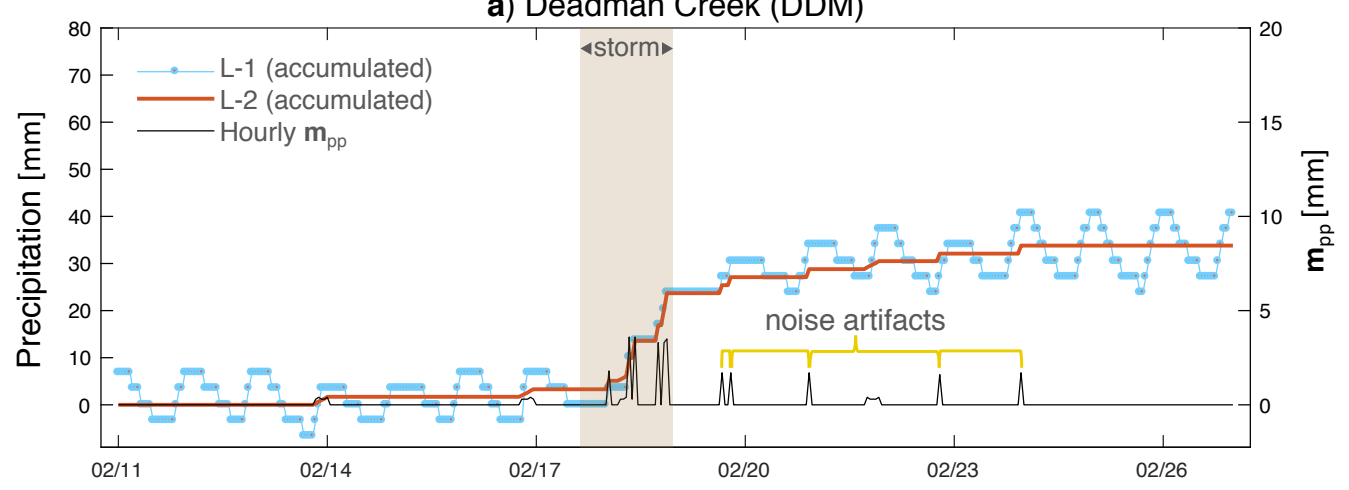

b) Leavitt Lake (LVT)

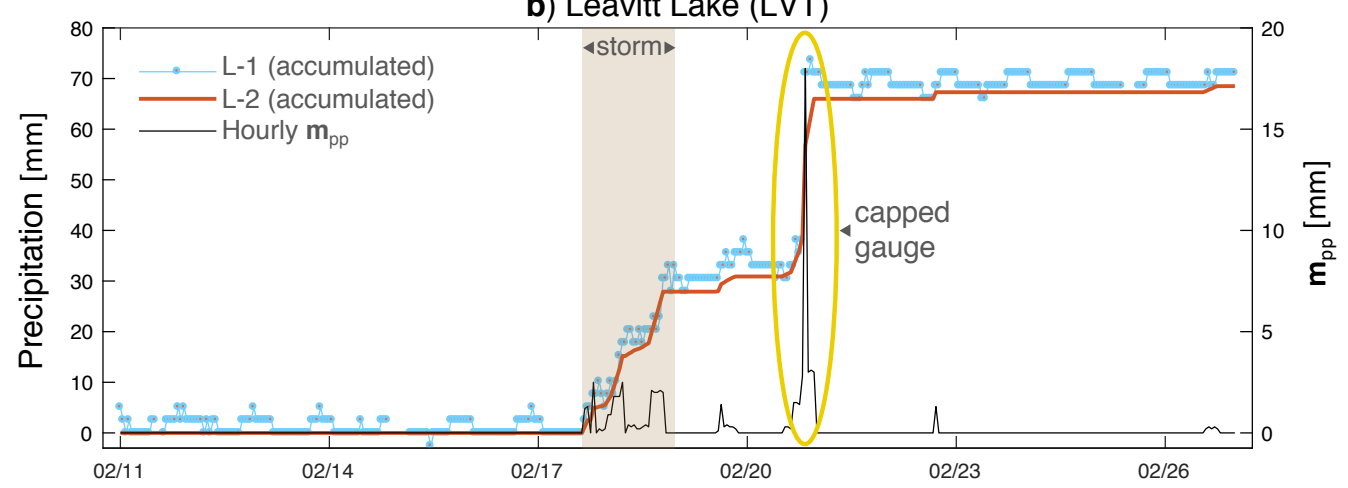

c) Leavitt Meadow (LVM)

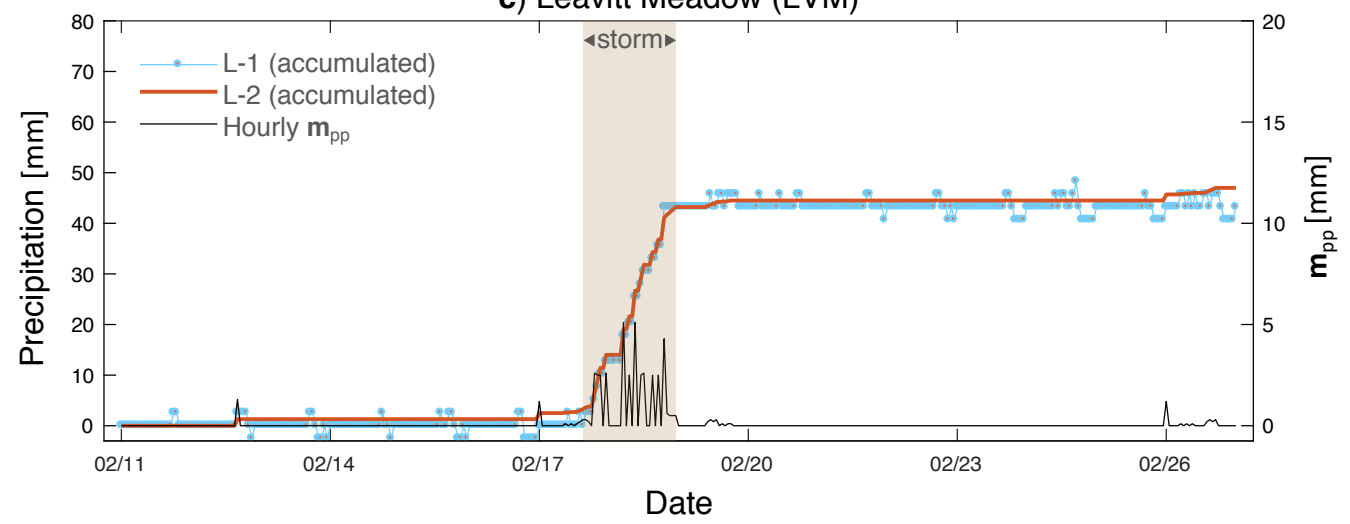

Figure 3.4: Reported precipitation from three stations in the same vicinity for a 16-day period in February 2016. An approximately 32-hour storm began on February 18th and was captured across all three sites. In a), the DDM site experienced significant noise after the storm due to large diurnal fluctuations that were not adequately filtered by the chosen parameters in the APCP. The precipitation gauge at the LVT site (b) was likely capped from the snowfall event, and melted into the gauge two days afterwards. The LVM site (c) reported acceptable measurements throughout the time period. The capped measurements in (b) give a false depiction of the storm characteristics, and should be removed to limit bias in the resulting distributed precipitation grid. 
remove instances when the bucket became capped, manual intervention was required. This was done by comparing the accumulation signals of nearby sensors to determine if storms should have been detected (Figure 3.4). If so, those data were removed from the stations regarded as capped, so that the distributed precipitation was not biased low during the storm and then high when the storm had long been concluded. Figure 3.4a shows a sensor that reported noisy precipitation data for a storm in February 2016, while Figure 3.4b depicts a gauge that was most likely capped from the snowfall during the same storm. When compared to the other nearby sensor in Figure 3.4c, these erroneous precipitation measurements are clearly evident. Depending on sensor type, how often the site is visited, and a host of other uncontrollable factors, the parameters of the APCP smoothing must be adjusted for each station through human intervention.

\subsection{Snow / Streamflow Data}

This dataset also includes 36 ASO snow-on surveys over the time period 2013-2016. These gridded, lidar-derived snow depth products are presented at $50 \mathrm{~m}$ resolution, upscaled using block statistics and bilinear interpolation from the standard $3 \mathrm{~m}$ snow depth product - available from Painter (2018) - in order to match the spatial resolution of the $50 \mathrm{~m}$ density estimates from iSnobal. These snow depth rasters are included in Hedrick et al. (2018a).

Hetch Hetchy Water \& Power, a division of the SFPUC, uses stage height and out-

flow from the O'Shaughnessy Dam to estimate daily inflow to Hetch Hetchy Reservoir. Using the same method since 1970, these daily readings are smoothed to determine the temporal trends in inflow, which is used as the daily streamflow estimate at the outlet of the basin. Lundquist et al. (2016) determined that uncertainty in the daily 
interpolated full natural flow can be around $\pm 10 \%$, which agrees with standard stream gauging uncertainty estimates.

\subsection{Example Application}

Over the water years 2013-2016, iSnobal was run over the Tuolumne Basin to supply ASO with gridded snow density estimates (Hedrick et al., 2018a). The spatially distributed forcing grids required to run iSnobal were constructed from the vector data described above using SMRF. Table 1 of Havens et al. (2017) details the inputs to SMRF, which include point measurements of $T_{a}, u, u_{d i r}$, and $m_{p p}$, along with point estimates of $c c_{f r a c}$ and and $e_{a}$. Atmospheric vapor pressure, $e_{a}$, was derived from $T_{a}$ and $R H$ using the Clausius-Clapeyron relationship.

In SMRF, precipitation was corrected for undercatch as a function of the distributed wind speeds prior to the gridded interpolation step using standardized equations given by Yang et al. (1998). The undercatch correction at each station was dependent on whether the gauges were shielded or unshielded. The phase of each hour of precipitation was then determined based on a modified version of the method described in Marks et al. (1999), which relies on gridded estimates of dew point temperature.

The $i$ Snobal modeling framework requires an estimate of net shortwave radiation flux, $S_{n}$, which is defined as:

$$
S_{n}=S_{i n}(1-\alpha)
$$

where $\alpha$ is a modeled spectral albedo estimate (Wiscombe \& Warren, 1980; Susong et al., 1999; Havens et al., 2017). Throughout the melt season, $\alpha$ was altered using 
a logarithmic decay function. Hourly point estimates of $c c_{\text {frac }}$, described in Section 3.3.3, were distributed to the regular $50 \mathrm{~m}$ grid and then used in conjunction with $\alpha$ and $S_{\text {clearsky }}$ to calculate $S_{n}$ :

$$
S_{n}=\left(c c_{\text {frac }} \times S_{\text {clearsky }}\right)(1-\alpha),
$$

where $S_{\text {clearsky }}$ is computed spatially and is no longer scaled to match maximum $S_{\text {in }}$ measurements as mentioned in Section 3.3.3.

Additionally, $c c_{f r a c}$ is further used within SMRF for developing the spatial estimates of incoming longwave radiation $\left(I_{l w}\right)$. Distributed $I_{l w}$ was modeled using the method presented by Marks \& Dozier (1979) and adjusted for canopy and cloud cover similar to Link \& Marks (1999). A more detailed description of the interpolation methods used to distribute these point measurements to a regular $50 \mathrm{~m}$ grid can be found in Hedrick et al. (2018a) and Havens et al. (2017).

Reproducible results to an experiment are a critical component of the scientific method. Since hydrology experiments typically occur in nature rather than in a controlled laboratory setting, delivering entirely reproducible results is difficult. Only relatively recently have researchers begun to address reproducibility in the hydrologic sciences (Hutton et al., 2016). The dataset in Hedrick et al. (2018b) is presented both as the L-1 station measurements and the quality-controlled L-2 model-ready product. The meteorological station QC process is the only non-reproducible aspect of this dataset, which demands both L-1 and L-2 be included for data transparency. If initiated using the L-2 data and the water year SMRF configuration files located in the data repository (Hedrick et al., 2018b), the SMRF version 0.3 software within its operating system-independent Docker container (Hedrick et al., 2018c) will produce 
the same results as presented in Hedrick et al. (2018a). This extent of reproducibility has never before been possible for a multi-year, near-real time, basin scale modeling experiment.

\subsection{Data Availability}

These data, along with all of the configuration files required by SMRF to produce spatial forcing grids for all four water years, are hosted on a Zenodo research data repository (Hedrick et al., 2018b). A separate code repository that hosts a Docker container file is available from Hedrick et al. (2018c). Within the Docker container can be found a standalone version of the SMRF version 0.3 model code, required dependencies, and instructions for using the software to fully reproduce the results from the example application results (Section 3.5). Once initialized, the software is fully compiled and ready for use within the Docker container.

\subsection{Summary}

This paper presents the Level 2 (L-2) forcing data used by the iSnobal snow model to provide snow density estimates for the ASO operational SWE products across the Tuolumne River Basin for water years 2013-2016. The station measurements of air temperature, relative humidity, wind speed and direction, accumulated precipitation, and solar radiation went through careful QC to remove erroneous data. Without significant near-real time QC, the currently available combination of federal, state, and locally maintained stations should not be used to force operational energy balance models. Additionally, the Level 1 (L-1) station measurements downloaded from CDEC and Mesowest are included in case users would prefer to perform their own $\mathrm{QC}$ on the data. The L-1 data are presented because the QC process is the only 
non-reproducible component of the modeling approach described in Hedrick et al. (2018a).

These data are suitable for any other physically based hydro-ecological model that requires knowledge of hourly meteorological conditions. In addition, the software that created the forcing variables used by iSnobal provides users with an entirely reproducible way to construct gridded meteorological forcing data using the L-2 data. These hourly images can be used to force distributed hydrologic models or for validation and calibration of other coarser gridded forcing datasets (NLDAS-2, MERRA-2, etc.).

This paper presents forcing data used by the iSnobal snow model to provide snow density estimates for the ASO operational SWE products across the Tuolumne River Basin for water years 2013-2016. This data is suitable for any other physically based hydro-ecological model that requires knowledge of hourly meteorological conditions. In addition, the software that created the forcing variables used by iSnobal provides users with an entirely reproducible way to construct gridded meteorological forcing data. These hourly images can be used to force distributed hydrologic models or for validation and calibration of other coarser gridded forcing datasets (NLDAS-2, MERRA-2, etc.). 


\title{
CHAPTER 4:
}

\section{FROM DROUGHT TO FLOOD: EVALUATING EVAPOTRANSPIRATION IN A HIGH-ALTITUDE BASIN DURING EXTREME CONDITIONS}

\begin{abstract}
Over a three-year period, the snowpack in California's Sierra Nevada fluctuated from the lowest in recorded history (2015) to historically large (2017), with a relatively average year in between (2016). This dynamic range in climatic conditions provides an ideal opportunity to investigate the correlation between annual water availability and runoff in a snow-dominated catchment. In this work we will estimate evapotranspiration $(E T)$ using a water balance approach where the water inputs and outputs to the system are accurately constrained using a combined remote sensing and physically based modeling procedure. For all three years of this study, the NASA-JPL Airborne Snow Observatory (ASO) combined snapshot high-resolution snow depths from airborne lidar with snow density estimates from a physically based energy balance model to produce spatial predictions of Snow Water Equivalent (SWE) over the entire Tuolumne River Basin at $50 \mathrm{~m}$ resolution. Using the well-quantified hydrologic
\end{abstract}


inputs from the energy balance calculations with periodic snow depth updates along with measured streamflow from the basin terminus, we can predict the annual ET response to the three dissimilar water years. The modeled annual ET is then compared to independent satellite-derived ET estimates for validation. Results reveal that ET in the Tuolumne does not scale linearly with the amount of available water to the basin, and subsequently runoff efficiency $(R E)$ primarily depends on total annual snowfall precipitation. Lastly, we find that the snow depth updates to the snow model significantly decrease the uncertainty in the ET estimates.

\subsection{Introduction}

Mountain snowpacks respond in various ways to changes in precipitation and temperature regimes. Climate predictions overwhelmingly agree that future temperatures will continue to rise, but future shifts in precipitation are more uncertain in the current literature (Luce et al., 2016; Roderick et al., 2014). Regardless of future precipitation trends, winters are shortening and the likelihood of extreme events is increasing (Jentsch et al., 2007; Seager et al., 2012). A major scientific question for the mountain hydrology community is how this increase in seasonal climate variability will affect runoff ratios and streamflow. Berghuijs et al. (2014) used a data-driven approach to infer that basins which receive a higher proportion of annual precipitation falling as snow experience higher long-term mean streamflow than those basins that are more rain-dominated. Then, by examining multiple basins in the California Sierra Nevada, Godsey et al. (2014) found that summer low flows vary proportionately according to annual variations in peak snow water equivalent (SWE). More recently, Cooper et al. (2018) demonstrated that the annual maximum SWE amount is a primary contribut-

ing factor affecting low flow sensitivity to climate variability in maritime snowpacks 
throughout the western United States.

One way to determine the effect of extreme events on the catchment-scale water cycle is to disaggregate the hydrologic water balance into its constituent components. By constraining one or more of the terms of the water balance equation with better measurements and monitoring techniques, the trends in the more poorly understood terms can be estimated with greater accuracy. This more process-driven approach of closing the water balance has been shown to be useful for assessing processes that are difficult to measure such as evapotranspiration (ET) (Wan et al., 2015; Williams et al., 2012), groundwater recharge (Kendy et al., 2003; Herrmann et al., 2015), and runoff efficiency (RE) (Knowles et al., 2015), which is defined as the ratio of basin discharge to precipitation.

Studies assessing basin-wide $E T$ in particularly snow-dominated catchments where the snow fraction of annual precipitation is greater than $80 \%$ are uncommon but not unprecedented. Leydecker \& Melack (2000) used the Complementary Relationship Areal Evapotranspiration (CRAE) model (Morton, 1983) to estimate areal evaporative losses over various alpine catchments throughout the Sierra Nevada. They found that evaporation was typically low throughout the months of snow cover, and then increased significantly during the late summer and early autumn of each year with an average of $36 \%$ of the water budget being lost to the atmosphere. Kattelmann \& Elder (1991) examined the water balance of the Emerald Lake watershed in Southern Sierra Nevada and found that evaporative losses ranged from 19\% to $32 \%$ of the total water budget in successive years. A water balance approach for quantifying evaporative losses to the atmosphere was carried out by Henn et al. (2018b) over the Tuolumne River Basin. They found that the mean late season residual - defined as 
all water losses to the atmosphere or groundwater recharge - ranged from $30 \%$ to $39 \%$ of the annual water budget for three years (2013-2015) of the recent California Drought.

Subsequently, between 2015 and 2017 California's Sierra Nevada underwent the largest dynamic range of snowpack conditions in recorded history. The winter of 2015 was the final year of the 2012-2015 California drought and it resulted in the lowest total April 1st snowpack in over 500 years according to tree ring SWE reconstruction (Belmecheri et al., 2016). The following winter of 2016 resulted in a near-average snowpack, with April 1st totals around $85 \%$ of the recorded average. Lastly, the winter of 2017 resulted in the 2nd highest SWE on April 1 in recorded history, and the most reservoir inflow on record for many of the large reservoirs along the western slopes of the Sierra Nevada. These three climatically dissimilar years provide a well suited backdrop for examining hydrologic responses to extreme conditions.

The primary question this study aims to answer is How are ET and RE in an alpine or subalpine environment affected by both total water availability as well as the snow fraction of precipitation entering the basin? A secondary question is then To what degree do periodic lidar-derived snow depth measurements decrease uncertainty in the modeled ET and RE estimates? To investigate these questions, we simulate the snowpack at a daily time scale over the duration of an entire water year (October 1 - September 30). This is accomplished by using a physically based, energy and mass balance snow model forced with gridded hourly meteorological estimates derived from both weather station measurements and a downscaled atmospheric forecast model. The snow model is then updated by periodic high spatial resolution measurements of snow depth from airborne lidar, which explicitly defines the spatial distribution of the 
snowpack and has been shown to increase the accuracy in model results throughout the melt season (Hedrick et al., 2018a). Combined with some basic assumptions about the hydrologic behavior of the Tuolumne Basin over an annual time scale, the water balance approach detailed here provides a new perspective on how a snow-dominated basin responds to climate variability.

\subsection{Study Area \& Model Application}

This study was performed over the Tuolumne River Basin in California's Sierra Nevada (Figure 4.1). The outlet of the basin is at the base of O'Shaughnessy Dam, which forms Hetch Hetchy Reservoir and provides the main source of drinking water and hydropower to over 2.7 million residents in the city and county of San Francisco. The total basin area is $1187 \mathrm{~km}^{2}$ and elevations range from 1150-3999 m.a.s.l., with over $90 \%$ of the basin lying above 2000 m.a.s.l., which has been the approximate average rain-snow transition elevation in the basin since 2013 (Hedrick et al., 2018a). Elevations between 2000-2900 m.a.s.l. are mainly comprised of snow-dominated subalpine forests and make up 55\% of the total basin area. The upper $35 \%$ of the basin (2900-3999 m.a.s.l.) is an alpine environment where the snow distribution is heavily influenced by topography and wind. The Tuolumne Basin lithology is comprised of mainly intrusive granodiorite bedrock with soils over much of the basin being less than 1 meter deep (Lundquist et al., 2016). The combination of the lithologic conditions and steepness of the basin result in a smaller fraction of groundwater losses than other more interior continental watersheds. Numerous hydrologic studies have been performed in the Tuolumne Basin (e.g. Henn et al. (2018b); Rice et al. (2011); Raleigh \& Small (2017); Lundquist et al. (2005)) owing to its significance and status as a vital 'water tower' for downstream inhabitants (Viviroli et al., 2007). 


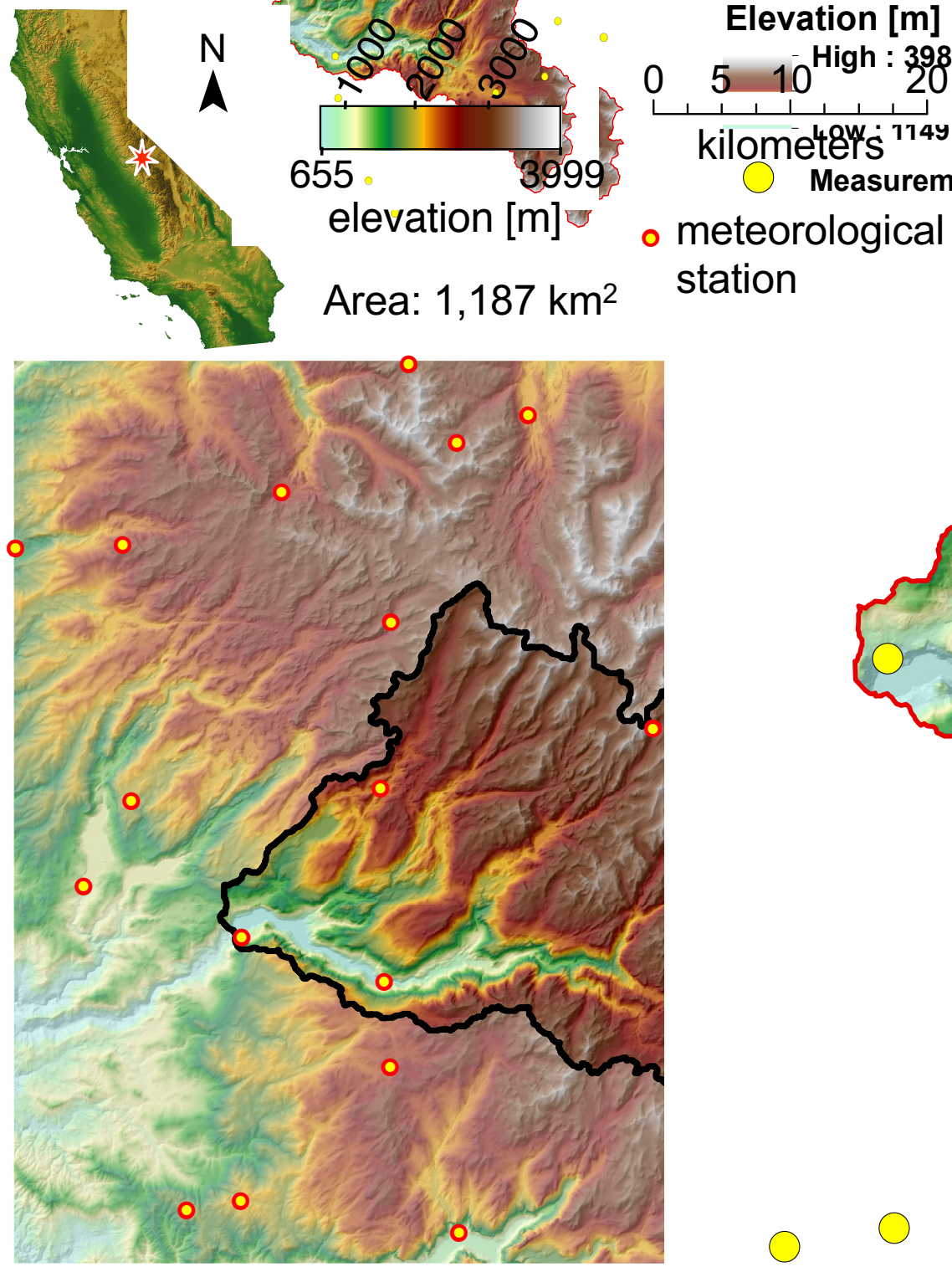

Figure 4.1: Location and relief map of the Tuolumne River Basin above Hetch Hetchy Reservoir within the U.S. State of California. Locations of various measurement stations used to force $i$ Snobal in water year 2015 are depicted as yellow circles. 


\subsection{1 iSnobal \& the Airborne Snow Observatory}

The approach to examining the water balance of the Tuolumne Basin involves estimating the timing and magnitude of snowmelt and rainfall entering the hydrologic system using a physically based snowmelt model. The $i$ Snobal model (Marks et al., 1999) has been tested extensively in previous studies (Erickson et al., 2005; Reba et al., 2011b; Winstral et al., 2013; Kormos et al., 2014a) and has been shown to produce accurate estimates of basin-averaged snowpack mass over annual timescales (Kormos et al., 2017a). In this application, iSnobal provided daily predictions of various energy and mass fluxes at $50 \mathrm{~m}$ spatial resolution over water years 2015-2017. The model was forced with a combination of weather station measurements and downscaled gridded meteorological forecast products from the High-Resolution Rapid Refresh (HRRR) operational model (Benjamin et al., 2016).

In addition to the hourly meteorological forcing fields, the model is also able to be updated by measurements of the snow depth state variable whenever measurements are available. Since 2013, the Airborne Snow Observatory (ASO) has performed snapshot lidar surveys throughout each ablation season in order to periodically determine the spatial distribution of snow depths (Painter et al., 2016) across the Tuolumne River Basin. After they are spatially coarsened from $3 \mathrm{~m}$ to $50 \mathrm{~m}$, these lidar-derived snow depth distributions enable more accurate solutions to the snowpack energy balance and ultimately more accurate estimates of snowpack runoff, here referred to as

surface water input $(S W I)$. The procedure for updating iSnobal using ASO measurements is detailed extensively by Hedrick et al. (2018a). 


\subsection{Background \& Methods}

Over any defined length of time, a closed hydrologic system is subject to the law of conservation of mass. Any water input to the system, whether from precipitation or aquifer-fed springs, must equal the water outputs from the system in the form of streamflow, evaporative losses, aquifer recharge, and changes in basin storage. The hydrologic water balance of any basin, through a given time period, can be represented as

$$
\Delta S=P+\Delta G-(Q+E T)
$$

In this formulation, $\mathrm{P}$ is the input precipitation to the basin, $\mathrm{Q}$ is the cumulative basin runoff at the basin terminus, and ET is the total water lost through the combination of evaporation back to the atmosphere and transpiration by vegetation. The two terms $\Delta G$ and $\Delta S$ represent the groundwater flux and basin storage flux, respectively, and can be either positive or negative over the defined time period.

The mechanisms for delivery of water to streamflow are different for rainfall and snowfall. Within a snow-dominated basin, the water balance input term must be more explicit with respect to the physical processes involved with water stored in a snowpack. The actual water delivery to the hydrologic system can be defined as the surface water input, or SWI, and the water balance can then be written as

$$
\Delta S=S W I+\Delta G-(Q+E T)
$$

SWI is defined as any water that enters the soil as either rain on bare ground, melt water at the snow-soil interface, or rain that percolates through the snowpack. At the same time, a not insignificant amount of $\mathrm{P}$ is evaporated or sublimated from the 
snow surface and is never available to be SWI. The input term to the water balance for snow-dominated catchments can then be written as

$$
S W I=P-E_{s}
$$

where $E_{s}$ is the snowcover evaporation term, which is here treated separately from the ET term. Therefore, the water balance equation can be rewritten as

$$
\Delta S=P+\Delta G-\left(Q+E_{s}+E T\right)
$$

The water balance equation can be significantly simplified by applying two assumptions for snow-dominated mountain catchments. The first assumption is that

$$
\Delta S \approx 0
$$

over the water year time scale. At the beginning and end of a water year, the total snow storage is assumed to be trivial, so that any annual change in snow water storage is zero. Also, in the northern hemisphere soil moisture is the typically at its lowest level around October 1st, meaning overall changes in soil water storage is negligible over an annual time scale.

A second assumption is that annual groundwater flow amounts in and out of the basin are insignificant relative to the other loss terms, ET and Q. Under this assumption, for a steep, granitic basin such as the Tuolumne, the groundwater losses in the high elevations primarily end up in the reservoir, replenishment of a deep aquifer is minimal, and

$$
\Delta G \approx 0
$$


The water balance can then be simplified to

$$
E T=P-\left(Q-E_{s}\right)+\epsilon,
$$

where $\epsilon$ is a residual error term that comprises both measurement uncertainty in $\mathrm{P}$ and $\mathrm{Q}$, along with model uncertainty in $\mathrm{P}$ and $E_{s}$. Below we will explore each variable independently in the context of this study.

\subsubsection{Evapotranspiration in the Sierra Nevada}

Previous work has examined actual ET amounts in the Sierra Nevada using water balance approaches (Henn et al., 2018b; Kattelmann \& Elder, 1991) and regression relationships between eddy covariance flux tower measurements and satellite products (Fellows \& Goulden, 2017; Goulden et al., 2012; Roche et al., 2018). These approaches focused on different applications but concluded that annual ET in the upper elevations of the Sierra Nevada ranged between 150-400 $\mathrm{mm}$ with the majority of the losses occurring below treeline. In fact, the regression-based studies estimated ET only as high as the subalpine environment, since the highest elevation flux tower site used to determine the relationship is at 2700 m.a.s.l. Approximately $50 \%$ of the land area within the Tuolumne Basin is above that elevation and is heavily snow-dominated, shortening the annual duration when ET can occur. Therefore, the actual total ET in the basin is likely toward the lower end of the estimates from the literature, due to the lack of vegetation in the upper reaches of the basin. This study will estimate $E T$, along with uncertainties represented in $\epsilon$ by using measurements of $Q$ and by constraining $P$ and $E_{s}$ using combined remote sensing and modeling results. 


\subsubsection{Precipitation}

Over all three water years in this study, periodic snapshots of lidar-derived snow depths from ASO have been directly inserted into the iSnobal modeling stream to update the depth state variable in near-real time since 2013. These updates allow iSnobal to more accurately simulate the energy balance in each pixel, resulting in more accurate estimates of SWI (Hedrick et al., 2018a). Since SWI is the result of an explicitly solved energy balance, and informed by high-resolution remote sensing measurements, the hydrologic inputs in this study are more spatially representative than other coarser gridded precipitation products. Henn et al. (2018a) described the difficulty and uncertainty involved in estimating spatially distributed precipitation in mountainous terrain using coarse regional-scale models. Snow accumulates preferentially due to wind and topography at the hillslope scale (Musselman et al., 2015; Pomeroy et al., 1993; Winstral et al., 2013), while accumulation at the basin scale is governed by elevational lapse rates (Feld et al., 2013; Lehning et al., 2011) and orographic effects due to atmospheric circulation (Roe \& Baker, 2006). The distribution of rainfall is not measured by the ASO surveys, however, only $20 \%$ of the annual precipitation in an average year falls as rain over the Tuolumne Basin.

A detrended kriging (DK) technique (Garen et al., 1994) was used to distribute station measured precipitation over the 50 m modeling grid (Havens et al., 2017) for the drought and average years (2015 and 2016). In 2017, when single storm totals exceeded $400 \mathrm{~mm}$, many of the precipitation gauges that had been used in prior years became buried or were significantly capped so as not to be useful. Therefore, a new approach was used to distribute precipitation using gridded meteorological forecast

products from the HRRR model (Benjamin et al., 2016). Subsequently, in all three 
years, regardless of the method used for distributing precipitation, the distribution of accumulated snow was redistributed by the lidar-derived snow depths whenever an ASO survey took place.

\subsubsection{Streamflow}

The Tuolumne River flows into Hetchy Hetchy Reservoir, which is managed by the San Francisco Public Utilities Commission (SFPUC). To understand the water balance of the Tuolumne, reconstructed full natural flow FNF at the outlet of O'Shaughnessy Dam are used as a proxy for basin discharge. FNF, sometimes referred to as unimpaired runoff, is defined to be the natural discharge that would have occurred without the presence of any dams or diversions upon the stream course. Using daily observed reservoir stage height and estimates of reservoir releases over the period of record (1970-2017), a mass balance approach yields the daily FNF into the reservoir. Lundquist et al. (2016) estimated the uncertainty in the daily reconstructed flows to be on the order of $\approx 10 \%$, which is the value assigned here to basin discharge $(Q)$. Estimates of cumulative FNF since 1970 and the mean value since 1919 are shown in Figure 4.2. For the three years considered in this study, the large dynamic range of streamflow magnitudes is clear.

\subsubsection{Snow Surface Evaporation and Sublimation}

The amount of atmospheric moisture lost from the snowpack to the atmosphere is a nontrivial portion of the overall water balance and should not be ignored. Evaporation or condensation of liquid water from a surface occurs when the surface's temperature is at or greater than the freezing point $\left(T_{s} \geq 0^{\circ} C\right)$. Conversely, in a snowpack

where $T_{s} \leq 0^{\circ} C$, ice crystals are able to sublimate into water vapor, resulting in a net loss in snowpack mass. For a melting snowpack, or $T_{s}=0^{\circ} \mathrm{C}$, the atmospheric 


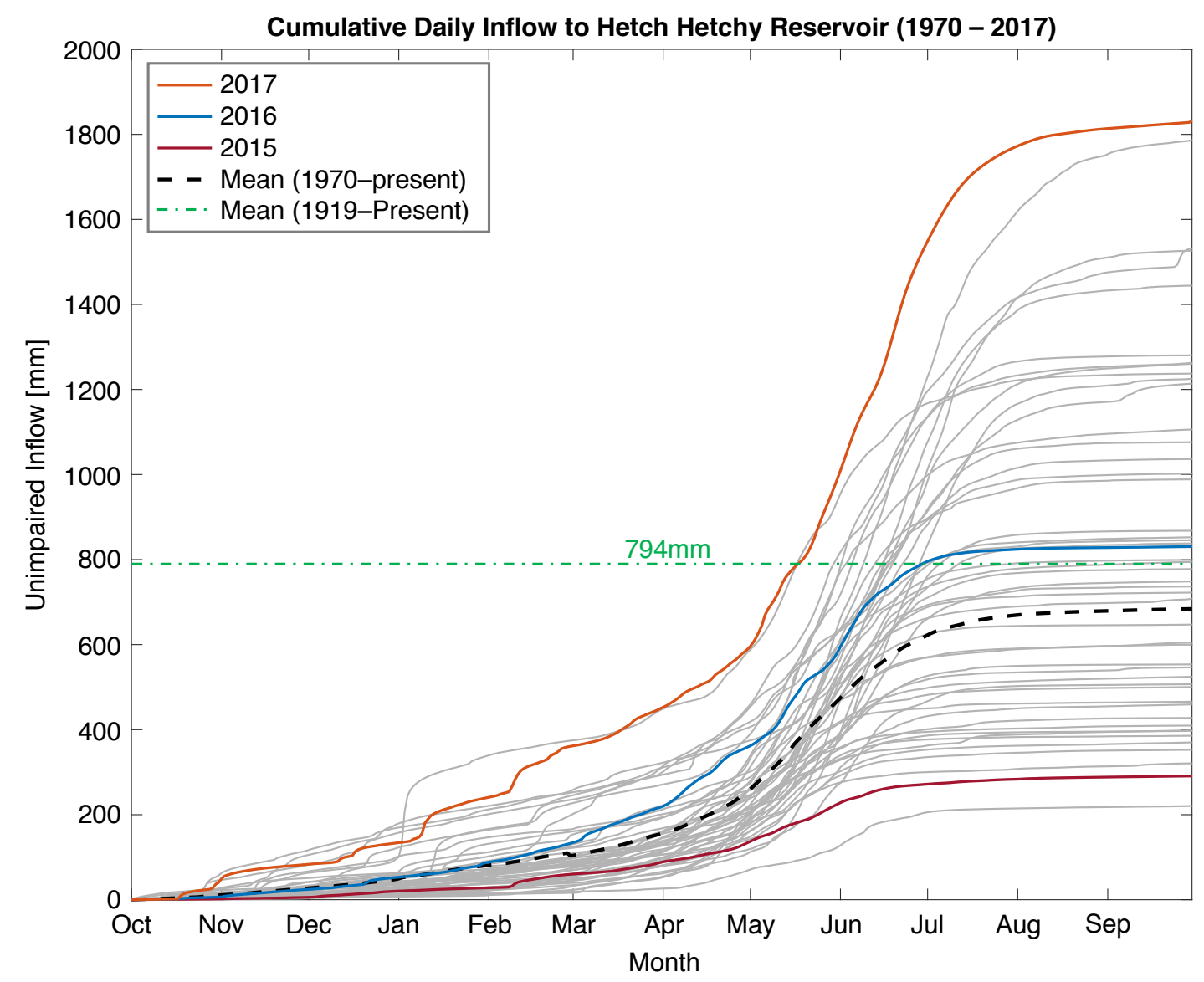

Figure 4.2: Cumulative estimated daily FNF into Hetch Hetchy Reservoir from daily measurements that began in 1970. From 1919-1970 mean inflow estimates were kept by hand and the mean inflow since the dam construction is shown as the dash-dotted horizontal line. Lundquist et al. (2016) estimated the uncertainty in these daily estimates to be approximately $\pm 10 \%$. 
moisture loss formulation in the iSnobal model is a combination of both sublimation and evaporation and is scaled by the average of the latent heats of vaporization and sublimation. In the process of computing the latent heat flux term of the snow energy balance, iSnobal iteratively solves for the evaporative mass flux, $E_{s}$, which is provided as model output. The mathematical representation of the set of nonlinear equations required for computing sublimation and condensation from a snowpack is described by Marks \& Dozier (1992) and Marks et al. (2008), and is based on the stability functions found in Brutsaert (1982).

\subsubsection{Uncertainty Considerations}

The final term of the water balance in equation 4.1 is the residual, $\epsilon$, containing the error terms in this particular estimation of ET. The error can be divided into both measurement and model uncertainty, each of which can be considered separately.

The measurement uncertainty is the difference in actual conditions and reported values over the three years for $P$ and $Q$. As mentioned in Section 4.3.3, a $\pm 10 \%$ uncertainty can be attributed to the reconstructed measurements of $Q$. Measuring snowfall in mountain environments is often very difficult due to high wind speeds during storms (Rasmussen et al., 2012). Even though the precipitation measurements used in this study are corrected for wind undercatch, a conservative estimate of uncertainty in $P$ is $\pm 20 \%$. Additionally, no estimate of error in the HRRR precipitation product used in 2017 is presently available.

Sources of model uncertainty stem from many different aspects in this study. First, error is introduced by the assumptions made in equation 4.5 and equation 4.6 , as the actual changes in storage and groundwater fluxes on annual time scales are

nonzero. Secondly, the distribution of precipitation from both point measurements 
and $3 \mathrm{~km}$ gridded forecast products to the $50 \mathrm{~m}$ grid both use a modeling approach that contains error. Finally, there are model errors in the parameterization of the nonlinear differential equations used to estimate $E_{s}$ in the $i$ Snobal model.

Once all of the measurement and model uncertainty has been taken into consideration, a bulk residual value can be estimated by comparing the distributions of ASO measured snow depths with the iSnobal modeled snow depths. As shown in Figure 6 of Hedrick et al. (2018a) and Figure 2.6 in Chapter 2 of this dissertation, the root-mean square error (RMSE) between modeled and measured snow depths decreased by a factor of three when prior ASO updates had occurred earlier in the season. The trend in RMSE reduction was similar when the entire set of ASO surveys from 2015-2017 was examined. Therefore, barring uncertainties in the energy balance formulation in $i S n o b a l$, the accuracy in estimated $S W I$ to the system is increased threefold when the ASO updates are available.

\subsection{Results \& Discussion}

Accurate estimates of precipitation, as the lone input term to the hydrologic system, are essential for closing the water balance of the Tuolumne. To test the relative accuracy of the precipitation distribution routine in SMRF, Figure 4.3 depicts the results of two methods for deriving gridded precipitation data. Figure 4.3a depicts the 2016 annual cumulative precipitation at $50 \mathrm{~m}$ resolution using the DK distribution method (Garen et al., 1994). The DK distribution is derived from station measurements and is representative of both local elevation gradients and larger scale rain shadow effects. Figure $4.3 \mathrm{~b}$ shows the cumulative precipitation for the same year at $4 \mathrm{~km}$ resolution estimated by the PRISM (Daly et al., 1994). Within the Tuolumne Basin the difference between the two methods is just over $1 \%$ of the annual total precipitation, 


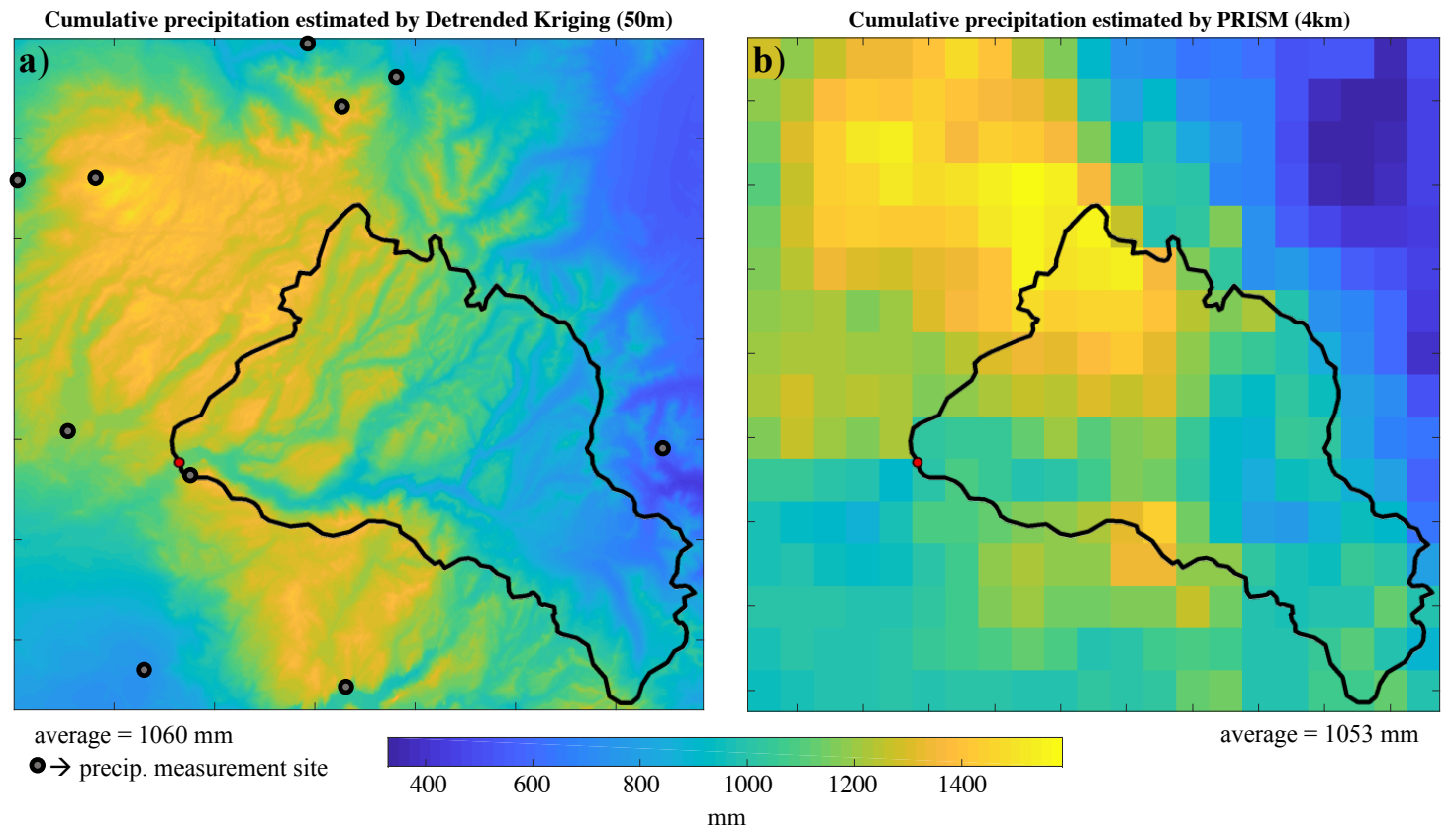

Figure 4.3: Cumulative precipitation from (a) station measurements of precipitation interpolated to a $50 \mathrm{~m}$ grid using DK and (b) the $4 \mathrm{~km}$ PRISM product for water year 2016. Locations of stations used by the DK method are depicted as circles in (a).

yet the spatial structure of where precipitation falls is much more defined by the DK method.

However, the ASO is not able to measure precipitation that falls in the Basin as rain, therefore introducing uncertainty in an annual water balance. Over the course of the ASO campaign (2013-2018) rain has accounted for approximately only $22 \%$ of the total precipitation that has fallen over the Tuolumne, indicating that the basin was significantly snow-dominated even during the California Drought.

Prior to the first ASO update to the model, iSnobal is forced with DK precipitation grids, resulting in a more uniform SWE estimate relative to realistic mountain snowpacks. At the time of the first update, the resulting snow distribution is redefined 
and SWE is altered throughout the basin. The spatial structure of the ASO-defined distribution is maintained throughout the rest of the year, yet still benefits from each subsequent ASO update. For water years 2015 through 2017, iSnobal was run with and without the ASO updates to demonstrate the basin-averaged impact of redefining the snow distribution (Figure 4.4).

As a physically based energy balance model, iSnobal requires its model forcing inputs to keep track of all energy and mass fluxes within the snowpack for every time step of a simulation. Thus, one of the outputs from the model is the evaporation from the snow surface in the form of actual liquid water evaporation or sublimation due to the vapor pressure gradient. The estimated annual cumulative evaporation, $E_{s}$, depicted in Figure 4.4 is a measure of mass that is lost to the atmosphere, and must be considered in the water balance along with ET.

In water years 2015 and 2016, the overall basin-averaged magnitude of cumulative SWI from the base of the snowpack was not sensitive to the redistribution of the snowpack from the ASO updates, though importantly the timing of that input pulse to the system was advanced by 2 to 4 weeks during the timing of peak streamflow in 2015. The impact of the ASO updates can be seen in the basin-averaged SWE from 2015, where the more realistic spatial distribution caused the snowpack to disappear a full three weeks earlier than the modeled SWE without the updates. This result is important for water management agencies that rely on exact melt timing for power generation.

Water year 2017 was a difficult year for energy balance modeling in the Tuolumne Basin. The main reason was due to a lack of precipitation station data at higher elevations. Discussed in Section 4.3.2, the Hybrid-HRRR distribution approach more 


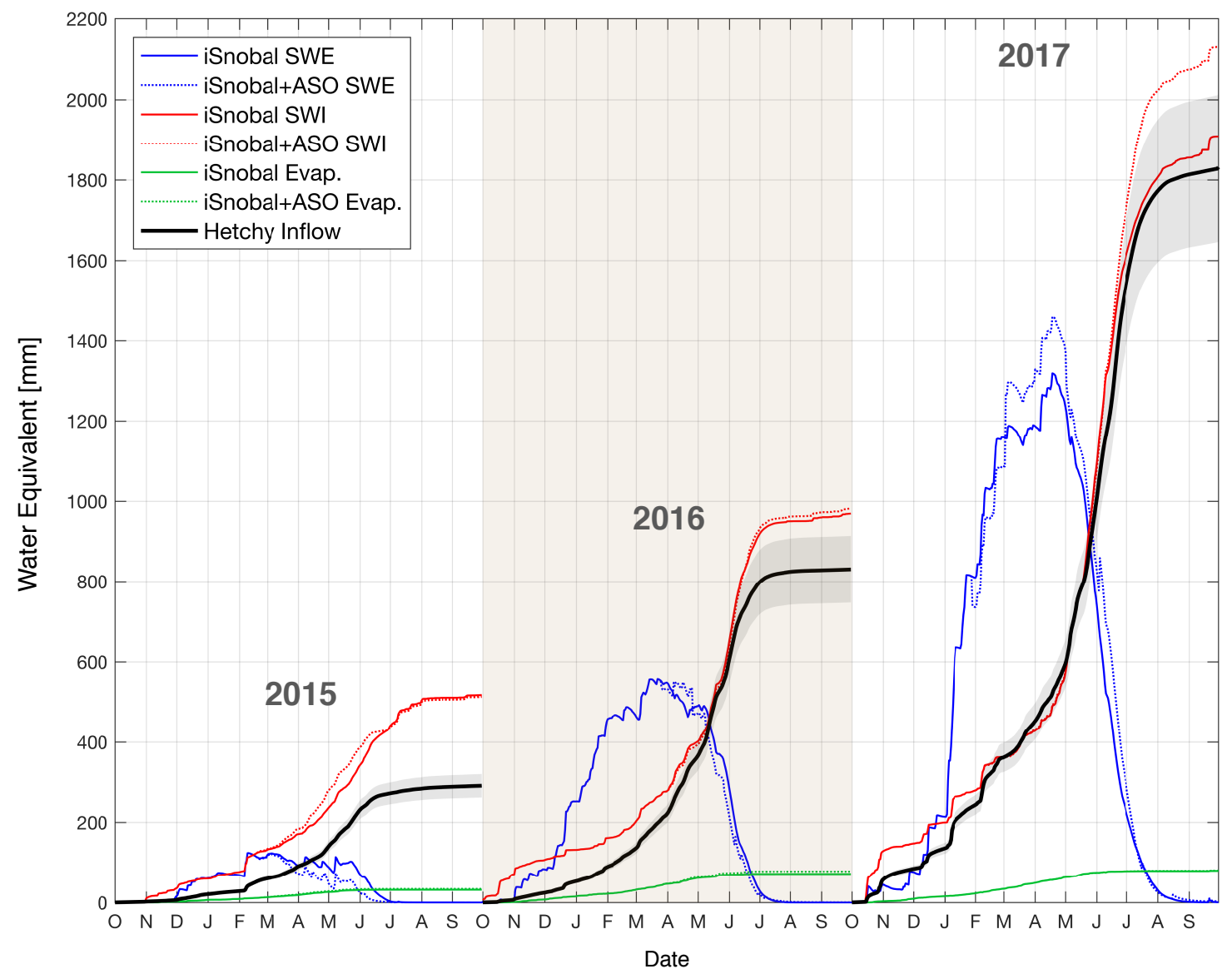

Figure 4.4: Basin-averaged products for the Tuolumne Basin (2015-2017). Solid lines represent iSnobal estimated SWE (blue), SWI (red), cumulative evaporative losses $\left.\left(E_{s}\right)\right)$ from the snow surface (green), as well as the estimated FNF at the outlet at Hetch Hetchy Reservoir (black). Dotted lines show the ASO-updated iSnobal results for each variable. The grey shaded area is the $\pm 10 \%$ uncertainty in the FNF estimates (Lundquist et al., 2016). 
accurately captured the large atmospheric river (AR) events that occurred in January and February of that year, relative to station measurements alone. The first ASO update of 2017 (January 29) had the effect of slightly decreasing SWE in the basin, signifying that Hybrid-HRRR added slightly too much precipitation mass from the two AR events earlier in the month. However, the second update (March 1) added approximately $18 \%$ of SWE storage to the basin. This was likely because the mass inputs from the February 7-10 AR event, the same storm which caused the 2017 Oroville Dam spillway disaster in Northern California, were actually much larger than that predicted by HRRR or captured by station measurements. Lastly, the June 3 update increased SWE storage by $75 \mathrm{~mm}$, likely due to the modeled albedo decay within SMRF melting snow too quickly throughout the month of May.

The ASO updates to iSnobal in 2017 were also important for the cumulative $S W I$. The lidar-derived snow depth distribution added an additional $200 \mathrm{~mm}$ in total available water. The residuals for all three years are shown in Table 4.1. These modeled residual results are in relative agreement with the findings of Henn et al. (2018b), which estimated the residual for 2013 to 2015 to be between $118 \mathrm{~mm}$ and $231 \mathrm{~mm}$. This result of our approach is encouraging for estimating $E T$ from similar water balance approaches.

It appears that the iSnobal cumulative evaporation product, $E_{i}$, was not sensitive to the ASO updates. At the same time, evaporation can be seen to be directly proportional to snow covered area and persistence. Since the Tuolumne Basin was snow-free for much of 2015, the modeled $E_{i}$ from the snow surface was less than half of that in 2016 and 2017, in which snow covered a greater extent of the basin area for much longer. 


\begin{tabular}{ccccccc}
\hline \multirow{2}{*}{ Year } & $\begin{array}{c}\text { iSnobal+ASO } \\
\text { basin inputs }\end{array}$ & $\begin{array}{c}\text { iSnobal+ASO } \\
\text { cumulative } \\
\text { Evaporation }\end{array}$ & $\begin{array}{c}\text { Cumulative } \\
\text { FNF }\end{array}$ & $\begin{array}{c}\text { Modeled } \\
\text { evapotran- } \\
\text { spiration }\end{array}$ & $\begin{array}{c}\text { MOD16 } \\
\text { cumulative } \\
\text { 8-day } E T\end{array}$ & $\begin{array}{c}\text { Sum of } \\
\text { Losses }\end{array}$ \\
\cline { 2 - 7 } & $(P)$ & $(E)$ & $(Q)$ & $(E T)$ & $\left(E T_{M O D}\right)$ & $\begin{array}{c}\left(Q+E_{s}+\right. \\
E T_{M O D}\end{array}$ \\
\hline 2015 & 547 & 34 & $291 \pm 10 \%$ & $222 \pm 29$ & 157 & $482 \pm 29$ \\
2016 & 1,060 & 78 & $831 \pm 10 \%$ & $151 \pm 83$ & 101 & $1,010 \pm 83$ \\
2017 & 2,211 & 81 & $1,832 \pm 10 \%$ & $299 \pm 183$ & 94 & $2,007 \pm 183$ \\
\hline
\end{tabular}

Table 4.1: End of year cumulative sums for water balance terms. $P$ is the basin input term, $E_{s}$ is the modeled evaporative loss from the snow surface to the atmosphere, and $Q$ is the basin discharge. ET is computed from the water balance equation 4.7 and $E T_{M O D}$ is the evapotranspiration estimate from the MOD16 algorithm. The final column is the annual estimated total sum of the loss terms in the Tuolumne Basin.

It appears that the $i S n o b a l$ cumulative evaporation product, $E_{s}$, was not sensitive to the ASO updates. At the same time, evaporation can be seen to be directly proportional to snow covered area and persistence. Since the Tuolumne Basin was snow-free for much of 2015 , the modeled $E_{s}$ from the snow surface was less than half of that in 2016 and 2017, in which snow covered a greater extent of the basin area for much longer.

\subsubsection{Evapotranspiration Validation}

In addition to the flux tower transects, optical satellite products, and water balance approximations mentioned in Section 4.3.1, satellite retrieval algorithms can be used as independent validation sources for estimating actual ET. The MOD16 Global ET Product was first described by Mu et al. (2007) and based on algorithms from Cleugh et al. (2007), with an improved algorithm described by Mu et al. (2011). MOD16 is derived from MODIS-derived land cover type, leaf area index (LAI), and albedo, and 
is used in this study as a comparison data set for the estimated water balance ET. MOD16 provides estimates of terrestrial ET every 8 days at $500 \mathrm{~m}$ spatial resolution. MODIS Tile H08V05 was downloaded from the NASA Land Processes Distributed Active Archive Center (LPDAAC) for time period of October 1, 2014 to October 12017 (Running et al., 2017). Screening of clouds and aerosols is already included in the most recent Version 6 products, but snow cover masking was performed in a post-processing step using the ASO-updated iSnobal model product upscaled to 500 m. Additionally, we used the snow-free ASO lidar returns to further characterize the $500 \mathrm{~m}$ MODIS pixels as containing vegetation or vegetation-free. This decision was made because we assumed $E T$ to be negligible over exposed granite, which comprises a significant portion of the Tuolumne Basin.

The estimated cumulative and 8-day ET totals from the MOD16 Global ET Product, masked to cells within the Tuolumne Basin, is shown in Figure 4.5. Even though this satellite product was corrected for occlusion by snow, cloud, cloud shadow, and bare rock surfaces, the effect of the snowpack persistence can be seen in the data. Since complete melt out occurred extremely early in 2015, the MOD16 algorithm predicted a much earlier increase in plant transpiration than in 2016 and 2017 . Cumulative 8-day ET ranged from $157 \mathrm{~mm}$ in 2015, $101 \mathrm{~mm}$ in 2016, and just $94 \mathrm{~mm}$ in 2017 (Table 4.1).

The resulting MOD16 ET estimates were certainly lower than estimates put forth by previous studies (Fellows \& Goulden, 2017; Henn et al., 2018b; Kattelmann \& Elder, 1991; Leydecker \& Melack, 2000). This result is somewhat unsurprising, though, since the Tuolumne Basin in water year 2017 was snow-covered from early December to mid-July. This meant that there was not as much time for the existing vegetation 


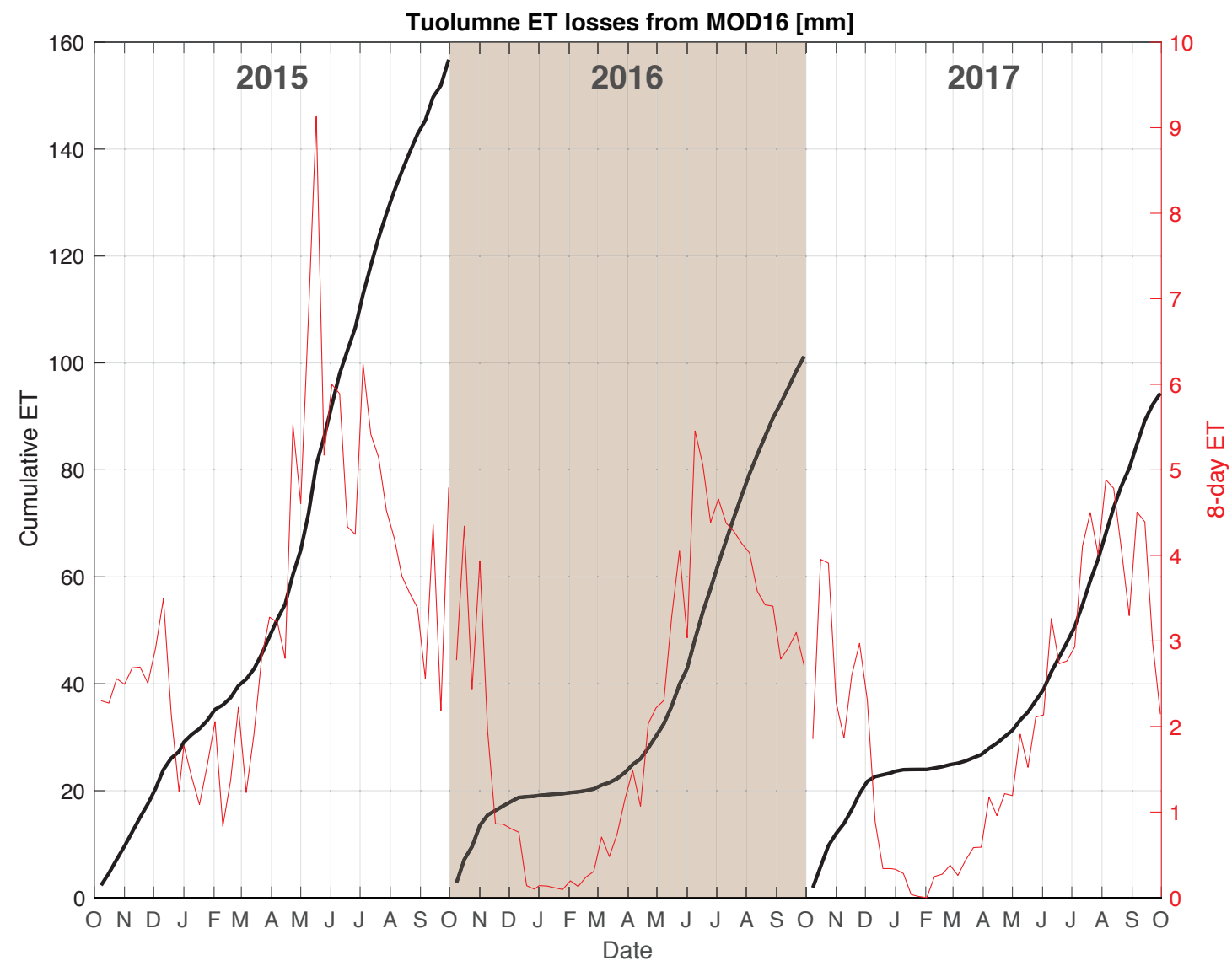

Figure 4.5: Basin-averaged ET losses estimated by the cloud and snowcover corrected MOD16 $500 \mathrm{~m}$ gridded product for water years 2015-2017 over the Tuolumne River Basin. The left-hand side y-axis and the black curves represent cumulative totals over each year, while the right-hand side $y$-axis and the red curves are the 8-day sum totals. Evaporative losses (e.g. sublimation) from snow-covered surfaces are not considered in this MOD16 product and are instead accounted for by iSnobal. 
to transpire when compared to the drought year of 2015. In this respect, the vegetation in this high-altitude basin can be considered buffered against drastic swings in climate variability, at least over the course of a few years.

\subsubsection{Estimating Runoff Efficiency from the Water Balance}

The modeled ET from the water balance approach and defined by equation 4.7, was determined to be $222 \mathrm{~mm}$ in 2015, $151 \mathrm{~mm}$ in 2016, and $299 \mathrm{~mm}$ in 2017 (Table 4.1). The sums of the loss terms that were quantified by $Q, E T_{M O D}$, and $E_{s}$ from $i$ Snobal were $482 \mathrm{~mm}$ in 2015, $1010 \mathrm{~mm}$ in 2016, and $2007 \mathrm{~mm}$ in 2017 (Figure 4.6). The cumulative losses from the basin - as derived from manual observations, a model, and a remote sensing product - were lower than the basin input mass, $P$, in all three years.

A hydrologic metric of a basin often used by water managers to describe a basin is the annual runoff effiency, $R E$, which is defined as the ratio of runoff to input precipitation. In the three years of this study, the runoff efficiency (as a percentage) varied widely from $53 \%$ in $2015,78 \%$ in 2016 , and $82 \%$ in 2017 . These values of $R E$, especially in 2016 and 2017, are much higher than typical values reported for watersheds located in more continental locations, and are traits of the unique lithology of the Tuolumne Basin. Also, RE increases as the input precipitation increases throughout all three years. Future work will examine more years using this water balance approach to attempt to determine this relationship between $R E$ and $P$ and how it might be affected by temperature, precipitation, or even second order processes such as tree mortality or forest fires. 


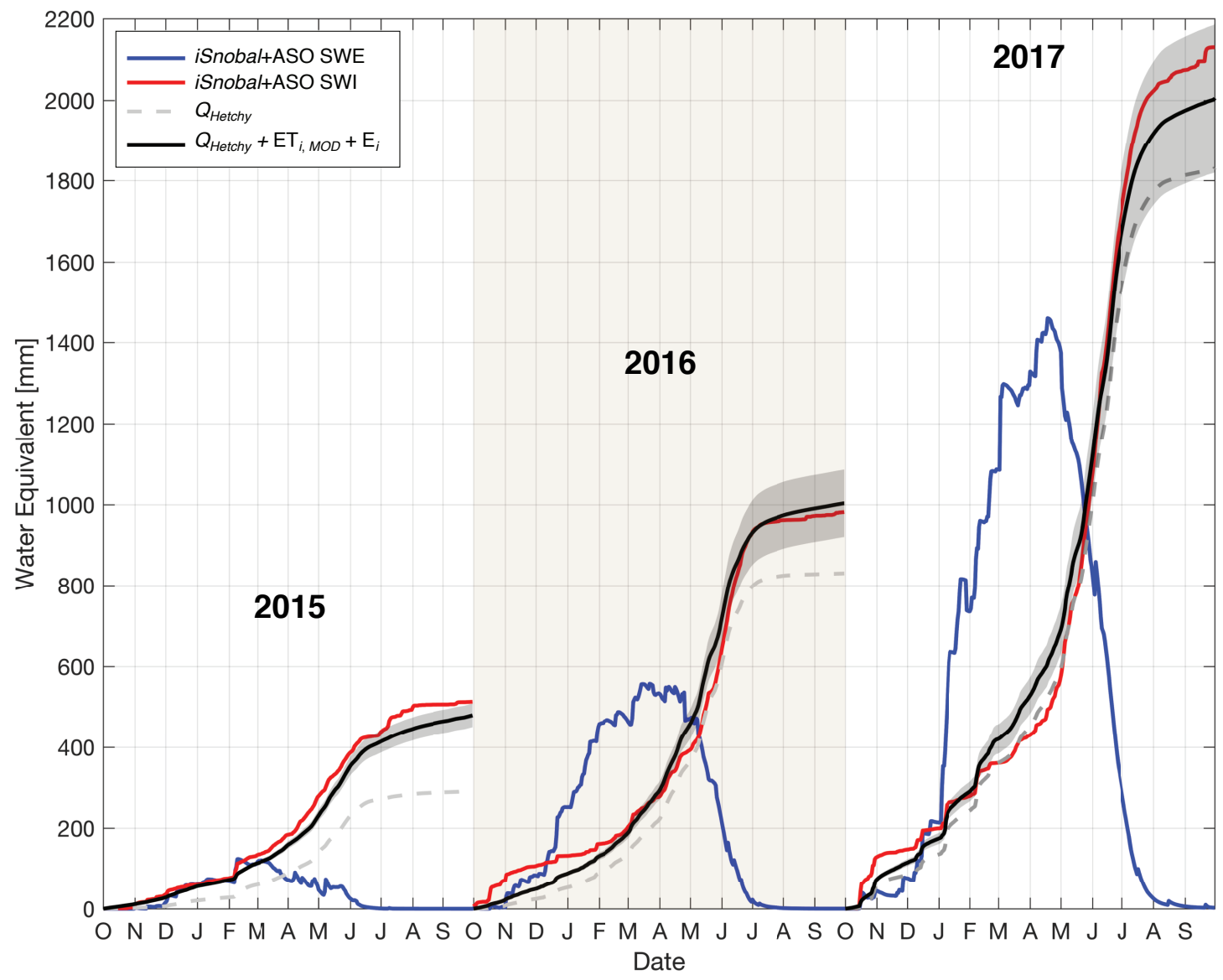

Figure 4.6: Basin-averaged daily SWE storage (blue) and cumulative $S W I$ (red) estimated by the ASO-updated iSnobal model. The dashed grey line is the previously reported cumulative estimated FNF (i.e. basin discharge). The black line is the sum of the cumulative discharge $(Q), E T_{M O D}$ from the MOD16 product, and the iSnobal estimated evaporation $\left(E_{s}\right)$ from the snow surface. The error bounds on the losses are derived from the $\pm 10 \%$ streamflow uncertainty. 


\subsection{Conclusions}

This study used a combination of remote sensing and physically based modeling within a snow-dominated basin to examine responses of the hydrologic loss terms of the water balance over varying climatic conditions. Over three extremely dissimilar water years, the residual term in the water balance equation was determined by accurately accounting for the magnitude and timing of precipitation inputs to the basin. The major conclusions are as follows:

1. Remote sensing-improved estimates of basin precipitation input, in this case represented by daily $S W I$, permit a more accurate estimate of the water balance residual. Under the assumption that the residual value is primarily comprised of evaporative losses to the atmosphere, this subsequently results in a more accurate depiction of ET.

2. The annual ET totals estimated through the water balance approach did not vary as much as the precipitation inputs into the basin between these three years (2015-2017). This means that over the course of just a few years, evaporative losses remain relatively constant compared to total water availability.

3. Basin-averaged annual ET estimates over the three years from the MOD16 satellite-derived product was somewhat lower than expected from the existing literature. However, when combined with evaporative losses from the snow surface estimated by iSnobal, the summed evaporation agreed with the residual of the water balance and was within the uncertainty of the basin discharge measurements into Hetch Hetchy Reservoir. 
4. The annual runoff efficiency, $R E$, of a watershed is not a static descriptive parameter. Rather, this work shows that $R E$ increases proportionally with the total amount of input precipitation. Future work will attempt to derive a functional relationship between input precipitation and $R E$ by analyzing more years, and then expand to other basins in the Sierra Nevada that benefit from the ASO program. 


\section{CHAPTER 5:}

\section{CONCLUSIONS}

In the coming decades, as previous climate trends shift, the legacy hydrologic prediction methods employed throughout the Western United States will become strained beyond their limits. It is the responsibility of the snow hydrology research community to take advantage of computing resources and technological advancements to develop new models and techniques that are robust to non-stationarity. This dissertation introduces a new paradigm for mountain hydrologic prediction. By integrating new techniques for modeling, monitoring, and remote sensing, a more accurate and reliable depiction of the mountain snow cover has been achieved.

Chapter 2 detailed the methodological approach for direct integration of measured snow depths from the Airborne Snow Observatory into the iSnobal physics-based energy balance model. Within the $1200 \mathrm{~km}^{2}$ Tuolumne River Basin and over four consecutive winter seasons, 36 snapshots of the snow distribution were periodically inserted as a state variable into the model. These updates guided the model to more accurate simulations of the snowpack state, and changed timings of the surface water input into the hydrologic system. Also, since the model was forced with station measurements, the ASO updates constrained the elevational gradient in the highest

$30 \%$ of the basin where measurements were lacking. The results of the four-year study reveal that the first update of each season was the most crucial for setting the actual 
spatial distribution. Subsequent updates were more important when significant time had elapsed between updates as well as when large storms occurred.

All of the forcing data, model simulation results, and model code from Chapter 2 were made available in public repositories. Such data transparency allows for complete reproducibility by any person examining the results and conclusions of the study. The only subjective component of the modeling framework was the quality control performed on the meteorological station data. Chapter 3 details how that QC process was undertaken. For each variable required to force iSnobal, the fundamental decisions made in order to provide a continuous data record were described in turn. A major finding of this section was that weather station data should never be used to force high resolution snow models without considerable QC procedures. In addition, the shear effort involved in making meteorological measurements model-ready is not sustainable for continued model applications in other basins. Work has already begun to investigate the functionality of using gridded forecast products such as the High-Resolution Rapid Refresh to produce iSnobal forcing data in lieu of station measurements. This approach would facilitate a more automated modeling procedure and allow expansion to larger modeling domains.

Chapters 2 and 3 dealt specifically with the setup and structure of a near-real time, quasi-operational modeling framework. In contrast, Chapter 4 described a research application of the ASO project. In this section, the evapotranspiration component of the hydrologic water balance over the Tuolumne Basin was examined over three widely dissimilar water years. Under the assumptions that the total annual groundwater flux in the basin was small relative to the total evaporative losses and that the annual change in basin storage was negligible, the annual evapotranspiration loss could be 
estimated. The three examined water years included the most significant drought season in nearly 500 years (2015), an average water year (2016), and a year of the second largest April 1 snowpack in over 45 years (2017). The ASO snow depth updates to the iSnobal precipitation input fields constrained the surface water input $(S W I)$ term by a threefold increase in accuracy compared to model results with no ASO updates. Combined with streamflow estimates from the basin terminus, this allowed a more accurate estimate of evapotranspiration on an annual time scale. A major conclusion from the final section was that evapotranspiration varied much less than the precipitation inputs across all three years. This finding indicates that the annual runoff efficiency in the Tuolumne Basin is primarily a function of the annual precipitation amount.

Future efforts will use the spatial distributions measured by the ASO to construct spatial accumulation fields for interpolating either point measurements or coarse gridded forecast products. Also, any precipitation bias in gridded forecasts will be inferred by examining individual storms captured by the lidar surveys. In addition, an investigation into the effect of vegetation on spatial variability will be conducted that will make use of reflectance measurements from the ASO imaging spectrometer. The future research possibilities utilizing the spatial data provided by the ASO in the Tuolumne Basin are nearly limitless. Never before have researchers had this degree of detailed information about the snowpack spatial distribution within a basin. In the short span of five years the ASO has assembled a dataset that will continue to beg new scientific questions for many years to come. 


\section{ACKNOWLEDGMENT}

I would like to thank Aaron Fellows, Jim Roche, Ned Bair, Jeff Dozier, Jessica Lundquist, McKenzie Skiles, Michele Reba, and two anonymous reviewers for their very insightful comments and suggestions for Chapters 2 and 3. The data and analysis presented in this dissertation were funded in part by USDA-ARS CRIS Understanding Snow and Hydrologic Processes in Mountainous Terrain with a Changing Climate (5362-13610-008-00D), USDA-ARS Pathways Program, NASA Terrestrial Hydrology Program, NRCS Water and Climate Center, Bureau of Reclamation Pacific Northwest Region, California Department of Water Resources, and the NASA Applied Sciences Western Water Applications Office. USDA is an equal opportunity provider

and employer. The data set is available in an openly accessible online repository at https://doi.org/10.5281/zenodo.1343653, while the SMRF software (version 0.3) for producing gridded model forcing data is available as a standalone Docker container in a software repository at https://doi.org/10.5281/zenodo.1343647. The MODIS MOD16A2.006 product was retrieved from the online EarthData Search tool, courtesy of the NASA EOSDIS Land Processes Distributed Active Archive Center (LP DAAC), USGS/Earth Resources Observation and Science (EROS) Center, Sioux Falls, South Dakota, https://Ipdaac.usgs.gov/node/1191. 


\section{REFERENCES}

Anderson, Eric A. 1976. A point energy and mass balance model of a snow cover. Tech. rept. NOAA Technical Report NWS 19.

Anderton, S P, White, S M, \& Alvera, B. 2004. Evaluation of spatial variability in snow water equivalent for a high mountain catchment. Hydrological Processes, 18(3), 435-453.

Auvinen, H, Bardsley, J M, Haario, H, \& Kauranne, T. 2010. The variational Kalman filter and an efficient implementation using limited memory BFGS. International Journal for Numerical Methods in Fluids, 64(3), 314-335.

Bair, Edward H., Davis, Robert E., \& Dozier, Jeff. 2018. Hourly mass and snow energy balance measurements from Mammoth Mountain, CA USA, 20112017. Earth System Science Data, 10(1), 549-563.

Belmecheri, Soumaya, Babst, Flurin, Wahl, Eugene R., Stahle, David W., \& Trouet, Valerie. 2016. Multi-century evaluation of Sierra Nevada snowpack. Nature Climate Change, 6(1), 2-3.

Benjamin, Stanley G., Weygandt, Stephen S., Brown, John M., Hu, Ming, Alexander, Curtis R., Smirnova, Tatiana G., Olson, Joseph B., James, Eric P., Dowell, David C., Grell, Georg A., Lin, Haidao, Peckham, Steven E., Smith, Tracy Lorraine, Moninger, William R., Kenyon, Jaymes S., \& Manikin, Geoffrey S. 2016. 
A North American Hourly Assimilation and Model Forecast Cycle: The Rapid Refresh. Monthly Weather Review, 144(4), 1669-1694.

Berghuijs, Wouter R, Woods, Ross A, \& Hrachowitz, M. 2014. A precipitation shift from snow towards rain leads to a decrease in streamflow. Nature Climate Change, 4(7), 583-586.

Brauchli, Tristan, Trujillo, Ernesto, Huwald, Hendrik, \& Lehning, Michael. 2017. Influence of Slope-Scale Snowmelt on Catchment Response Simulated With the Alpine3D Model. Water Resources Research, 53(12), 10723-10739.

Brutsaert, Wilfried. 1982. Evaporation into the Atmosphere: Theory, History, and Applications. Reidel.

Cleugh, Helen A., Leuning, Ray, Mu, Qiaozhen, \& Running, Steven W. 2007. Regional evaporation estimates from flux tower and MODIS satellite data. Remote Sensing of Environment, 106(3), 285-304.

Colbeck, S. C. 1974. Water Flow Through Snow Overlying an Impermeable Boundary. Water Resources Research, 10(1), 119-123.

Conway, H., \& Abrahamson, J. 1984. Snow Stability Index. Journal of Glaciology, 30(106), 321-327.

Cooper, M. G., Schaperow, J. R., Cooley, S. W., Alam, S., Smith, L. C., \& Lettenmaier, D. P. 2018. Climate Elasticity of Low Flows in the Maritime Western U.S. Mountains. Water Resources Research, 54(8), 5602-5619. 
Daly, Christopher, Neilson, Ronald P, \& Phillips, Donald L. 1994. A StatisticalTopographic Model for Mapping Climatological Precipitation over Mountainous Terrain. Journal of Applied Meteorology, 33(2), 140-158.

Day, Gerald N. 1990. A methodology for updating a conceptual snow model with snow measurements. Tech. rept. NOAA Technical Report NWS 43.

Deems, Jeffrey S., \& Painter, Thomas H. 2006. Lidar measurement of snow depth: accuracy and error sources. Pages 330-338 of: Proceedings, 2006 International Snow Science Workshop, Telluride, CO, vol. 330.

Deems, Jeffrey S., Fassnacht, Steven R., \& Elder, Kelly J. 2006. Fractal Distribution of Snow Depth from Lidar Data. Journal of Hydrometeorology, 7(2), 285-297.

Deems, Jeffrey S., Painter, Thomas H., \& Finnegan, David C. 2013. Lidar measurement of snow depth: a review. Journal of Glaciology, 59(215), 467-479.

Derksen, C, \& Brown, R. 2012. Spring snow cover extent reductions in the 2008-2012 period exceeding climate model projections. Geophysical Research Letters, 39(19).

Dettinger, Michael D, \& Anderson, Michael L. 2015. Storage in California's Reservois and Snowpack in this Time of Drought. San Francisco Estuary and Watershed Science, 13(2).

Dozier, Jeff. 1980. A clear-sky spectral solar radiation model for snow-covered mountainous terrain. Water Resources Research, 16(4), 709-718.

Dozier, Jeff. 1990. Looking Ahead to EOS: The Earth Observing System. Computers in Physics, 4(3), 248. 
Dozier, Jeff. 2011. Mountain hydrology, snow color, and the fourth paradigm. Eos, Transactions American Geophysical Union, 92(43), 373-374.

Dubayah, Ralph C. 1994. Modeling a solar radiation topoclimatology for the Rio Grande River Basin. Journal of Vegetation Science, 5(5), 627-640.

Erickson, Tyler A, Williams, Mark W, \& Winstral, Adam H. 2005. Persistence of topographic controls on the spatial distribution of snow in rugged mountain terrain, Colorado, United States. Water Resources Research, 41(4).

Essery, Richard, \& Marks, Danny. 2007. Scaling and parametrization of clear-sky solar radiation over complex topography. Journal of Geophysical Research: Atmospheres, $112(\mathrm{D} 10)$

Essery, Richard, \& Pomeroy, John W. 2004. Implications of spatial distributions of snow mass and melt rate for snow-cover depletion: theoretical considerations. Annals of Glaciology, 38(1), 261-265.

Essery, Richard, Pomeroy, John, Ellis, Chad, \& Link, Tim. 2008. Modelling longwave radiation to snow beneath forest canopies using hemispherical photography or linear regression. Hydrological Processes, 22(15), 2788-2800.

Feld, Shara I., Cristea, Nicoleta C., \& Lundquist, Jessica D. 2013. Representing atmospheric moisture content along mountain slopes: Examination using distributed sensors in the Sierra Nevada, California. Water Resources Research, 49(7), 44244441.

Fellows, Aaron W., \& Goulden, Michael L. 2017. Mapping and understanding dry 
season soil water drawdown by California montane vegetation. Ecohydrology, 10(1), e1772.

Ferguson, Ian M, \& Maxwell, Reed M. 2012. Human impacts on terrestrial hydrology: climate change versus pumping and irrigation. Environmental Research Letters, $7(4), 044022$.

Foster, Lauren M., Bearup, Lindsay A., Molotch, Noah P., Brooks, Paul D., \& Maxwell, Reed M. 2016. Energy budget increases reduce mean streamflow more than snowrain transitions: using integrated modeling to isolate climate change impacts on Rocky Mountain hydrology. Environmental Research Letters, 11(4), 044015 .

Franz, Kristie J, Hogue, Terri S, \& Sorooshian, Soroosh. 2008. Operational snow modeling: Addressing the challenges of an energy balance model for National Weather Service forecasts. Journal of Hydrology, 360(1-4), 48-66.

Garcia, Damien. 2010. Robust smoothing of gridded data in one and higher dimensions with missing values. Computational Statistics \& Data Analysis, 54(4), $1167-1178$.

Garen, David C., \& Marks, Danny. 2005. Spatially distributed energy balance snowmelt modelling in a mountainous river basin: estimation of meteorological inputs and verification of model results. Journal of Hydrology, 315(1-4), 126-153.

Garen, David C., Johnson, Gregory L., \& Hanson, Clayton L. 1994. Mean Areal Precipitation for Daily Hydrologic Modeling in Mountainous Regions. JAWRA Journal of the American Water Resources Association, 30(3), 481-491. 
Garen, David C., Geyer, Joachim, Schumann, Andreas H., \& Marks, Danny. 2001. Spatially-distributed snowmelt, water balance and streamflow modelling for a large mountainous catchment: Boise River, Idaho, USA. Pages 199-207 of: SoilVegetation-Atmosphere Transfer Schemes and Large-Scale Hydrological Models, vol. 270. Maastricht, The Netherlands: Sixth IAHS Scientific Assembly.

Gelaro, Ronald, McCarty, Will, Suárez, Max J., Todling, Ricardo, Molod, Andrea, Takacs, Lawrence, Randles, Cynthia A., Darmenov, Anton, Bosilovich, Michael G., Reichle, Rolf, Wargan, Krzysztof, Coy, Lawrence, Cullather, Richard, Draper, Clara, Akella, Santha, Buchard, Virginie, Conaty, Austin, da Silva, Arlindo M., Gu, Wei, Kim, Gi-Kong, Koster, Randal, Lucchesi, Robert, Merkova, Dagmar, Nielsen, Jon Eric, Partyka, Gary, Pawson, Steven, Putman, William, Rienecker, Michele, Schubert, Siegfried D., Sienkiewicz, Meta, \& Zhao, Bin. 2017. The Modern-Era Retrospective Analysis for Research and Applications, Version 2 (MERRA-2). Journal of Climate, 30(14), 5419-5454.

Godsey, S. E., Kirchner, J. W., \& Tague, C. L. 2014. Effects of changes in winter snowpacks on summer low flows: Case studies in the Sierra Nevada, California, USA. Hydrological Processes, 28(19), 5048-5064.

Godsey, Sarah E., Marks, Danny, Kormos, Patrick R., Seyfried, Mark S., Enslin, Clarissa L., Winstral, Adam H., McNamara, James P., \& Link, Timothy E. 2018. Eleven years of mountain weather, snow, soil moisture and streamflow data from the rainsnow transition zone the Johnston Draw catchment, Reynolds Creek Experimental Watershed and Critical Zone Observatory, USA. Earth System Science Data, 10(3), 1207-1216. 
Goovaerts, P. 2000. Geostatistical approaches for incorporating elevation into the spatial interpolation of rainfall. Journal of Hydrology, 228(1-2), 113-129.

Goulden, Michael L., Anderson, R. G., Bales, Roger C., Kelly, Anne E., Meadows, M., \& Winston, G. C. 2012. Evapotranspiration along an elevation gradient in California's Sierra Nevada. Journal of Geophysical Research: Biogeosciences, 117(G3).

Griffin, Daniel, \& Anchukaitis, Kevin J. 2014. How unusual is the 2012-2014 California drought? Geophysical Research Letters, 41(24), 9017-9023.

Groisman, Pavel Ya, Karl, Thomas R., Easterling, David R., Knight, Richard W., Jamason, Paul F., Hennessy, Kevin J., Suppiah, Ramasamy, Page, Cher M., Wibig, Joanna, Fortuniak, Krzysztof, Razuvaev, Vyacheslav N., Douglas, Arthur, Førland, Eirik, \& Zhai, Pan-Mao. 1999. Changes in the Probability of Heavy Precipitation: Important Indicators of Climatic Change. Climatic Change, 42(1), 243-283.

Grünewald, T., Schirmer, M., Mott, R., \& Lehning, M. 2010. Spatial and temporal variability of snow depth and ablation rates in a small mountain catchment. The Cryosphere, 4(2), 215-225.

Grünewald, T., Stötter, J., Pomeroy, J. W., Dadic, R., Moreno Baños, I., Marturià, J., Spross, M., Hopkinson, C., Burlando, P., \& Lehning, M. 2013. Statistical modelling of the snow depth distribution in open alpine terrain. Hydrology and Earth System Sciences, $17(8), 3005-3021$.

Guan, Bin, Molotch, Noah P, Waliser, Duane E, Jepsen, Steven M, Painter, Thomas H, \& Dozier, Jeff. 2013. Snow water equivalent in the Sierra Nevada: 
Blending snow sensor observations with snowmelt model simulations. Water Resources Research, 49(8), 5029-5046.

Hardy, J.P., Melloh, Rae, Koenig, G., Marks, Danny, Winstral, Adam, Pomeroy, J.W., \& Link, Tim. 2004. Solar radiation transmission through conifer canopies. Agricultural and Forest Meteorology, 126(3-4), 257-270.

Havens, Scott C., Marks, Danny, Winstral, Adam, \& Rothwell, Eric. 2015. Application of a Physically-Based Distributed Snowmelt Model in Support of Reservoir Operations and Water Management, $\{$ ST-2015-2264\}. Tech. rept. September. U.S. Bureau of Reclamation, Boise.

Havens, Scott C., Marks, Danny, Kormos, Patrick R., \& Hedrick, Andrew R. 2017. Spatial Modeling for Resources Framework (SMRF): A modular framework for developing spatial forcing data for snow modeling in mountain basins. Computers $\&$ Geosciences, 109(September 2016), 295-304.

Hedrick, Andrew R., Marks, Danny, Havens, Scott, Robertson, Mark, Johnson, Micah, Sandusky, Micah, Marshall, Hans-Peter, Kormos, Patrick R., Bormann, Kathryn J., \& Painter, Thomas H. 2018a. Direct insertion of NASA Airborne Snow Observatory-derived snow depth time-series into the iSnobal energy balance snow model. Water Resources Research, aug.

Hedrick, Andrew R., Marks, Danny, Havens, Scott, Robertson, Mark, Johnson, Micah, Sandusky, Micah, Marshall, Hans-Peter, Kormos, Patrick R., Bormann, Kathryn J., \& Painter, Thomas H. 2018b. Direct insertion of NASA Airborne Snow Observatory-derived snow depth time-series into the iSnobal energy balance snow model [Data set]. 
Hedrick, Andrew R., Marks, Danny, Havens, Scott, Robertson, Mark, Johnson, Micah, Sandusky, Micah, Marshall, Hans-Peter, Kormos, Patrick R., Bormann, Kathryn J., \& Painter, Thomas H. 2018c. Direct insertion of NASA Airborne Snow Observatory-derived snow depth time-series into the iSnobal energy balance snow model [Software version 0.1].

Henn, Brian, Clark, Martyn P., Kavetski, Dmitri, \& Lundquist, Jessica D. 2015. Estimating mountain basin-mean precipitation from streamflow using Bayesian inference. Water Resources Research, 51(10), 8012-8033.

Henn, Brian, Newman, Andrew J., Livneh, Ben, Daly, Christopher, \& Lundquist, Jessica D. 2018a. An assessment of differences in gridded precipitation datasets in complex terrain. Journal of Hydrology, 556, 1205-1219.

Henn, Brian, Painter, Thomas H., Bormann, Kat J., McGurk, Bruce, Flint, Alan L., Flint, Lorraine E., White, Vince, \& Lundquist, Jessica D. 2018b. High-Elevation Evapotranspiration Estimates During Drought: Using Streamflow and NASA Airborne Snow Observatory SWE Observations to Close the Upper Tuolumne River Basin Water Balance. Water Resources Research, 54(2), 746-766.

Herrmann, Frank, Keller, Luise, Kunkel, Ralf, Vereecken, Harry, \& Wendland, Frank. 2015. Determination of spatially differentiated water balance components including groundwater recharge on the Federal State level A case study using the mGROWA model in North Rhine-Westphalia (Germany). Journal of Hydrology: Regional Studies, 4(sep), 294-312.

Horel, J, Splitt, M, Dunn, L, Pechmann, J, White, B, Ciliberti, C, Lazarus, S, Slem- 
mer, J, Zaff, D, \& Burks, J. 2002. Mesowest: Cooperative Mesonets in the Western United States. Bulletin of the American Meteorological Society, 83(2), 211-225.

Houser, Paul R, De Lannoy, Gabrielle J M, \& Walker, Jeffrey P. 2012. Hydrologic Data Assimilation. Pages 41-64 of: Approaches to Managing Disaster - Assessing Hazards, Emergencies and Disaster Impacts. InTech.

Hutton, Christopher, Wagener, Thorsten, Freer, Jim, Han, Dawei, Duffy, Chris, \& Arheimer, Berit. 2016. Most computational hydrology is not reproducible, so is it really science? Water Resources Research, 52(10), 7548-7555.

Jentsch, Anke, Kreyling, Jürgen, \& Beierkuhnlein, Carl. 2007. A new generation climate-change experiments: events, not trends. Frontiers in Ecology and the Environment, 5(7), 365-374.

Jost, Georg, Weiler, Markus, Gluns, David R, \& Alila, Younes. 2007. The influence of forest and topography on snow accumulation and melt at the watershed-scale. Journal of Hydrology, 347(1-2), 101-115.

Kattelmann, Richard, \& Elder, Kelly J. 1991. Hydrologic characteristics and water balance of an Alpine Basin in the Sierra Nevada. Water Resources Research, 27(7), $1553-1562$.

Kendy, Eloise, Gérard-Marchant, Pierre, Todd Walter, M., Zhang, Yongqiang, Liu, Changming, \& Steenhuis, Tammo S. 2003. A soil-water-balance approach to quantify groundwater recharge from irrigated cropland in the North China Plain. $H y$ drological Processes, 17(10), 2011-2031. 
Knowles, John F., Harpold, Adrian A., Cowie, Rory, Zeliff, Morgan, Barnard, Holly R., Burns, Sean P., Blanken, Peter D., Morse, Jennifer F., \& Williams, Mark W. 2015. The relative contributions of alpine and subalpine ecosystems to the water balance of a mountainous, headwater catchment. Hydrological Processes, 29(22), 4794-4808.

Kojima, Kenji. 1967. Densification of seasonal snow cover. Low Temperature Science, 799, 929-952.

Kormos, Patrick R., Marks, Danny, McNamara, James P., Marshall, H.P., Winstral, Adam, \& Flores, Alejandro N. 2014a. Snow distribution, melt and surface water inputs to the soil in the mountain rainsnow transition zone. Journal of Hydrology, 519(nov), 190-204.

Kormos, Patrick R., Marks, Danny, Williams, C Jason, Marshall, H. P., Aishlin, Pam, Chandler, David G, \& McNamara, James P. 2014b. Soil, snow, weather, and subsurface storage data from a mountain catchment in the rainsnow transition zone. Earth System Science Data, 6(1), 165-173.

Kormos, Patrick R., Marks, Danny, Pierson, Frederick B., Williams, C Jason, Hardegree, Stuart P., Havens, Scott, Hedrick, Andrew R., Bates, Jonathan D., \& Svejcar, Tony J. 2017a. Ecosystem Water Availability in Juniper versus Sagebrush SnowDominated Rangelands. Rangeland Ecology \&3 Management, 70(1), 116-128.

Kormos, Patrick R., Marks, Danny, Pierson, Frederick B., Williams, C. Jason, Hardegree, Stuart P., Boehm, Alex R., Havens, Scott C., Hedrick, Andrew R., Cram, Zane K., \& Svejcar, Tony J. 2017b. Meteorological, snow, streamflow, topographic, and vegetation height data from four western juniper-dominated experimental 
catchments in southwestern Idaho, USA. Earth System Science Data, 9(1), 9198.

Kormos, Patrick R., Marks, Danny, Seyfried, Mark S., Havens, Scott C., Hedrick, Andrew R., Lohse, Kathleen A., Sandusky, Micah, Kahl, Annelen, \& Garen, David. 2018. 31 years of hourly spatially distributed air temperature, humidity, and precipitation amount and phase from Reynolds Critical Zone Observatory. Earth System Science Data, 10(2), 1197-1205.

Landry, Christopher C., Buck, Kimberly A., Raleigh, Mark S., \& Clark, Martyn P. 2014. Mountain system monitoring at Senator Beck Basin, San Juan Mountains, Colorado: A new integrative data source to develop and evaluate models of snow and hydrologic processes. Water Resources Research, 50(2), 1773-1788.

Lehning, Michael, Grünewald, Thomas, \& Schirmer, Michael. 2011. Mountain snow distribution governed by an altitudinal gradient and terrain roughness. Geophysical Research Letters, 38(19), n/a-n/a.

Leydecker, A., \& Melack, J.M. 2000. Estimating evaporation in seasonally snowcovered catchments in the Sierra Nevada, California. Journal of Hydrology, 236(12), 121-138.

Link, Timothy E, \& Marks, Danny. 1999. Distributed simulation of snowcover massand energy-balance in the boreal forest. Hydrological Processes, 13(14-15), 24392452.

Link, Timothy E, Marks, Danny, \& Hardy, Janet P. 2004. A deterministic method to 
characterize canopy radiative transfer properties. Hydrological Processes, 18(18), 3583-3594.

Livneh, Ben, Deems, Jeff S, Schneider, Dominik, Barsugli, Joseph J, \& Molotch, Noah P. 2014. Filling in the gaps: Inferring spatially distributed precipitation from gauge observations over complex terrain. Water Resources Research, 50(11), 8589-8610.

Luce, Charles H, Tarboton, David G, \& Cooley, Keith R. 1999. Sub-grid parameterization of snow distribution for an energy and mass balance snow cover model. Hydrological Processes, 13(12-13), 1921-1933.

Luce, Charles H., Vose, James M, Pederson, Neil, Campbell, John, Millar, Connie, Kormos, Patrick R., \& Woods, Ross. 2016. Contributing factors for drought in United States forest ecosystems under projected future climates and their uncertainty. Forest Ecology and Management, 380(nov), 299-308.

Lundquist, Jessica D., Dettinger, Michael D., \& Cayan, Daniel R. 2005. Snow-fed streamflow timing at different basin scales: Case study of the Tuolumne River above Hetch Hetchy, Yosemite, California. Water Resources Research, 41(7), n/a-n/a.

Lundquist, Jessica D., Minder, Justin R., Neiman, Paul J., \& Sukovich, Ellen. 2010. Relationships between Barrier Jet Heights, Orographic Precipitation Gradients, and Streamflow in the Northern Sierra Nevada. Journal of Hydrometeorology, 11(5), $1141-1156$.

Lundquist, Jessica D., Roche, James W., Forrester, Harrison, Moore, Courtney, Keenan, Eric, Perry, Gwyneth, Cristea, Nicoleta, Henn, Brian, Lapo, Karl, 
McGurk, Bruce, Cayan, Daniel R., \& Dettinger, Michael D. 2016. Yosemite Hydroclimate Network: Distributed stream and atmospheric data for the Tuolumne River watershed and surroundings. Water Resources Research, 52(9), 7478-7489.

Luo, W, Taylor, M C, \& Parker, S R. 2008. A comparison of spatial interpolation methods to estimate continuous wind speed surfaces using irregularly distributed data from England and Wales. International Journal of Climatology, 28(7), 947959.

Mankin, Justin S., Viviroli, Daniel, Singh, Deepti, Hoekstra, Arjen Y., \& Diffenbaugh, Noah S. 2015. The potential for snow to supply human water demand in the present and future. Environmental Research Letters, 10(11), 114016.

Margulis, Steven A, Cortés, Gonzalo, Girotto, Manuela, Huning, Laurie S, Li, Dongyue, \& Durand, Michael. 2016. Characterizing the extreme 2015 snowpack deficit in the Sierra Nevada (USA) and the implications for drought recovery. Geophysical Research Letters, 43(12), 6341-6349.

Marks, Danny, \& Dozier, Jeff. 1979. A clear-sky longwave radiation model for remote alpine areas. Archiv für Meteorologie, Geophysik und Bioklimatologie Serie B, 27(23), 159-187.

Marks, Danny, \& Dozier, Jeff. 1992. Climate and energy exchange at the snow surface in the Alpine Region of the Sierra Nevada: 2. Snow cover energy balance. Water Resources Research, 28(11), 3043-3054.

Marks, Danny, Domingo, James, Susong, Dave, Link, Tim, \& Garen, David. 1999. A 
spatially distributed energy balance snowmelt model for application in mountain basins. Hydrological Processes, 13(12-13), 1935-1959.

Marks, Danny, Winstral, Adam H., Flerchinger, Gerald N., Reba, Michele L., Pomeroy, John W., Link, Timothy E., \& Elder, Kelly J. 2008. Comparing Simulated and Measured Sensible and Latent Heat Fluxes over Snow under a Pine Canopy to Improve an Energy Balance Snowmelt Model. Journal of Hydrometeorology, 9(6), $1506-1522$.

Marks, Danny, Marshall, Hans-Peter, Kormos, Patrick R., Bormann, Kathryn J., Hedrick, Andrew R., Robertson, Mark, Johnson, Micah, Sandusky, Micah, Havens, Scott C., \& Painter, Thomas H. 2018. A Comprehensive Snow Density Model for Converting Lidar-Measured Snow Depths into Snow Water Equivalent. Water Resources Research.

Marshall, S E, \& Warren, S G. 1987. Parameterization of snow albedo for climate models. Pages 43-50 of: Goodison, B E, Barry, R G, \& Dozier, J (eds), Large Scale Effects of Seasonal Snow Cover. Wallingford, England: International Association of Hydrological Sciences.

Marty, Christoph, \& Meister, Roland. 2012. Long-term snow and weather observations at Weissfluhjoch and its relation to other high-altitude observatories in the Alps. Theoretical and Applied Climatology, 110(4), 573-583.

Miller, Robert N, Ghil, Michael, \& Gauthiez, François. 1994. Advanced Data Assimilation in Strongly Nonlinear Dynamical Systems. Journal of the Atmospheric Sciences, 51(8), 1037-1056. 
Molotch, Noah P. 2004. Incorporating remotely-sensed snow albedo into a spatiallydistributed snowmelt model. Geophysical Research Letters, 31(3), L03501.

Molotch, Noah P., \& Bales, Roger C. 2005. Scaling snow observations from the point to the grid element: Implications for observation network design. Water Resources Research, 41(11).

Monteith, J. L. 1965. Evaporation and Environment. Symposia of the Society for Experimental Biology, 19, 205-234.

Morin, S., Lejeune, Y., Lesaffre, B., Panel, J.-M., Poncet, D., David, P., \& Sudul, M. 2012. An 18-yr long (19932011) snow and meteorological dataset from a midaltitude mountain site (Col de Porte, France, $1325 \mathrm{~m}$ alt.) for driving and evaluating snowpack models. Earth System Science Data, 4(1), 13-21.

Morton, F.I. 1983. Operational estimates of areal evapotranspiration and their significance to the science and practice of hydrology. Journal of Hydrology, 66(1-4), $1-76$.

Mu, Qiaozhen, Heinsch, Faith Ann, Zhao, Maosheng, \& Running, Steven W. 2007. Development of a global evapotranspiration algorithm based on MODIS and global meteorology data. Remote Sensing of Environment, 111(4), 519-536.

Mu, Qiaozhen, Zhao, Maosheng, \& Running, Steven W. 2011. Improvements to a MODIS global terrestrial evapotranspiration algorithm. Remote Sensing of Environment, 115(8), 1781-1800.

Musselman, Keith, Pomeroy, John, Essery, Richard, \& Leroux, Nicolas. 2015. Impact 
of windflow calculations on simulations of alpine snow accumulation, redistribution and ablation. Hydrological Processes, 29(18), 3983-3999.

Nayak, Anurag, Chandler, David G, Marks, Danny, McNamara, James P, \& Seyfried, Mark. 2008. Correction of electronic record for weighing bucket precipitation gauge measurements. Water Resources Research, 44(4), 1-6.

Olyphant, Greg A., \& Isard, Scott A. 1988. The role of advection in the energy balance of late-lying snowfields: Niwot Ridge, Front Range, Colorado. Water Resources Research, 24(11), 1962-1968.

Pagano, Thomas C., Garen, David C., Perkins, Tom R., \& Pasteris, Phillip A. 2009. Daily Updating of Operational Statistical Seasonal Water Supply Forecasts for the western U.S. JAWRA Journal of the American Water Resources Association, 45(3), 767-778.

Painter, Thomas H. 2018. ASO L4 Lidar Snow Depth 3m UTM Grid, Version 1.

Painter, Thomas H., Berisford, Daniel F., Boardman, Joseph W., Bormann, Kathryn J., Deems, Jeffrey S., Gehrke, Frank, Hedrick, Andrew R., Joyce, Michael, Laidlaw, Ross, Marks, Danny, Mattmann, Chris, McGurk, Bruce, Ramirez, Paul, Richardson, Megan, Skiles, S McKenzie, Seidel, Felix C., \& Winstral, Adam. 2016. The Airborne Snow Observatory: Fusion of scanning lidar, imaging spectrometer, and physically-based modeling for mapping snow water equivalent and snow albedo. Remote Sensing of Environment, 184(oct), 139-152.

Pomeroy, J. W., Bewley, D S, Essery, R. L. H., Hedstrom, N R, Link, Tim, Granger, 
R. J., Sicart, J E, Ellis, C. R., \& Janowicz, J R. 2006. Shrub tundra snowmelt. Hydrological Processes, 20(4), 923-941.

Pomeroy, John, \& Brun, Eric. 2001. Physical Properties of Snow. Pages 45-126 of: Jones, H G, Pomeroy, J W, Walker, D A, \& Hoham, R W (eds), Snow Ecology: An Interdisciplinary Examination of Snow-Covered Ecosystems. Cambridge: Cambridge University Press.

Pomeroy, John, Gray, D. M., \& Landine, P. G. 1993. The Prairie Blowing Snow Model: characteristics, validation, operation. Journal of Hydrology, 144(1-4), 165-192.

Prokop, Alexander. 2008. Assessing the applicability of terrestrial laser scanning for spatial snow depth measurements. Cold Regions Science and Technology, 54(3), $155-163$.

Raleigh, Mark S, \& Small, Eric E. 2017. Snowpack density modeling is the primary source of uncertainty when mapping basin-wide SWE with lidar. Geophysical Research Letters, 1-10.

Rasmussen, Roy, Baker, Bruce, Kochendorfer, John, Meyers, Tilden, Landolt, Scott, Fischer, Alexandre P, Black, Jenny, Thériault, Julie M, Kucera, Paul, Gochis, David, Smith, Craig, Nitu, Rodica, Hall, Mark, Ikeda, Kyoko, \& Gutmann, Ethan. 2012. How Well Are We Measuring Snow: The NOAA/FAA/NCAR Winter Precipitation Test Bed. Bulletin of the American Meteorological Society, 93(6), 811-829.

Reba, Michele L., Marks, Danny, Seyfried, Mark, Winstral, Adam, Kumar, Mukesh, \& Flerchinger, Gerald. 2011a. A long-term data set for hydrologic modeling in a snow-dominated mountain catchment. Water Resources Research, 47(7). 
Reba, Michele L., Marks, Danny, Winstral, Adam, Link, Timothy E, \& Kumar, Mukesh. 2011b. Sensitivity of the snowcover energetics in a mountain basin to variations in climate. Hydrological Processes, 25(21), 3312-3321.

Rice, Robert, Bales, Roger C., Painter, Thomas H., \& Dozier, Jeff. 2011. Snow water equivalent along elevation gradients in the Merced and Tuolumne River basins of the Sierra Nevada. Water Resources Research, 47(8), 1-11.

Roche, James W., Goulden, Michael L., \& Bales, Roger C. 2018. Estimating evapotranspiration change due to forest treatment and fire at the basin scale in the Sierra Nevada, California. Ecohydrology, may, e1978.

Roderick, M. L., Sun, F., Lim, W. H., \& Farquhar, G. D. 2014. A general framework for understanding the response of the water cycle to global warming over land and ocean. Hydrology and Earth System Sciences, 18(5), 1575-1589.

Roe, Gerard H., \& Baker, Marcia B. 2006. Microphysical and Geometrical Controls on the Pattern of Orographic Precipitation. Journal of the Atmospheric Sciences, 63(3), 861-880.

Rothwell, Richard, Hillman, Graham, \& Pomeroy, John W. 2016. Marmot Creek Experimental Watershed Study. The Forestry Chronicle, 92(01), 32-36.

Running, Steven W., Mu, Qiaozhen, \& Zhao, Maosheng. 2017. MOD16A2 MODIS/Terra Net Evapotranspiration 8-Day L4 Global 500m SIN Grid V006 [Data set].

Seager, Richard, Naik, Naomi, \& Vogel, Laura. 2012. Does Global Warming Cause 
Intensified Interannual Hydroclimate Variability? Journal of Climate, 25(9), 33553372.

Shook, Kevin, \& Gray, D. M. 1996. Small-Scale Spatial Structure of Shallow Snowcovers. Hydrological Processes, 10(10), 1283-1292.

Slaughter, Charles W, Marks, Danny, Flerchinger, Gerald N, Van Vactor, Steven S, \& Burgess, Mike. 2001. Thirty-five years of research data collection at the Reynolds Creek Experimental Watershed, Idaho, United States. Water Resources Research, $37(11), 2819-2823$.

Strachan, Scotty, Kelsey, Eric P., Brown, Renée F., Dascalu, Sergiu, Harris, Fred, Kent, Graham, Lyles, Bradley, McCurdy, Gregory, Slater, David, \& Smith, Kenneth. 2016. Filling the Data Gaps in Mountain Climate Observatories Through Advanced Technology, Refined Instrument Siting, and a Focus on Gradients. Mountain Research and Development, 36(4), 518-527.

Sturm, Matthew, Taras, Brian, Liston, Glen E., Derksen, Chris, Jonas, Tobias, \& Lea, Jon. 2010. Estimating Snow Water Equivalent Using Snow Depth Data and Climate Classes. Journal of Hydrometeorology, 11(6), 1380-1394.

Susong, David, Marks, Danny, \& Garen, David. 1999. Methods for developing time-series climate surfaces to drive topographically distributed energy- and waterbalance models. Hydrological Processes, 13(12-13), 2003-2021.

Tinkham, Wade T., Smith, Alistair M.S., Marshall, Hans-Peter, Link, Timothy E., Falkowski, Michael J., \& Winstral, Adam H. 2014. Quantifying spatial distribu- 
tion of snow depth errors from LiDAR using Random Forest. Remote Sensing of Environment, 141(feb), 105-115.

Trujillo, Ernesto, Ramírez, Jorge A., \& Elder, Kelly J. 2007. Topographic, meteorologic, and canopy controls on the scaling characteristics of the spatial distribution of snow depth fields. Water Resources Research, 43(7).

Vano, Julie A., Das, Tapash, \& Lettenmaier, Dennis P. 2012. Hydrologic Sensitivities of Colorado River Runoff to Changes in Precipitation and Temperature*. Journal of Hydrometeorology, 13(3), 932-949.

Vaughan, David G, Comiso, Josefino C, Allison, Ian, Carrasco, Jorge, Kaser, Georg, Kwok, Ronald, Mote, Philip, Murray, Tavi, Paul, Frank, Ren, Jiawen, Rignot, Eric, Solomina, Olga, Steffen, Konrad, \& Zhang, Tingjun. 2013. Observations: Cryosphere. Pages 317-382 of: Stocker et al., T F (ed), Climate Change 2013: The Physical Science Basis, Contribution of Working Group I to the Fifth Assessment Report of the Intergovernmental Panel on Climate Change. Cambridge Univ. Press, Cambridge, U.K. and New York, NY, USA.

Viviroli, Daniel, Dürr, Hans H, Messerli, Bruno, Meybeck, Michel, \& Weingartner, Rolf. 2007. Mountains of the world, water towers for humanity: Typology, mapping, and global significance. Water Resources Research, 43(7), n/a-n/a.

Vögeli, Christian, Lehning, Michael, Wever, Nander, \& Bavay, Mathias. 2016. Scaling Precipitation Input to Spatially Distributed Hydrological Models by Measured Snow Distribution. Frontiers in Earth Science, 4(December), 1-15.

Wan, Zhanming, Zhang, Ke, Xue, Xianwu, Hong, Zhen, Hong, Yang, \& Gourley, 
Jonathan J. 2015. Water balance-based actual evapotranspiration reconstruction from ground and satellite observations over the conterminous United States. Water Resources Research, 51(8), 6485-6499.

Williams, Christopher A., Reichstein, Markus, Buchmann, Nina, Baldocchi, Dennis, Beer, Christian, Schwalm, Christopher, Wohlfahrt, Georg, Hasler, Natalia, Bernhofer, Christian, Foken, Thomas, Papale, Dario, Schymanski, Stan, \& Schaefer, Kevin. 2012. Climate and vegetation controls on the surface water balance: Synthesis of evapotranspiration measured across a global network of flux towers. Water Resources Research, 48(6), 1-13.

Wilson, Tamara S, Sleeter, Benjamin M, \& Cameron, D Richard. 2016. Future landuse related water demand in California. Environmental Research Letters, 11(5), 054018 .

Winstral, Adam H., \& Marks, Danny. 2002. Simulating wind fields and snow redistribution using terrain-based parameters to model snow accumulation and melt over a semi-arid mountain catchment. Hydrological Processes, 16, 3585-3603.

Winstral, Adam H., \& Marks, Danny. 2014. Long-term snow distribution observations in a mountain catchment: Assessing variability, time stability, and the representativeness of an index site. Water Resources Research, 50(1), 293-305.

Winstral, Adam H., Elder, Kelly, \& Davis, Robert E. 2002. Spatial Snow Modeling of Wind-Redistributed Snow Using Terrain-Based Parameters. Journal of Hydrometeorology, 3(5), 524-538.

Winstral, Adam H., Marks, Danny, \& Gurney, Robert. 2009. An efficient method 
for distributing wind speeds over heterogeneous terrain. Hydrological Processes, 23(17), 2526-2535.

Winstral, Adam H., Marks, Danny, \& Gurney, Robert. 2013. Simulating wind-affected snow accumulations at catchment to basin scales. Advances in Water Resources, $55,64-79$.

Winstral, Adam H., Marks, Danny, \& Gurney, Robert. 2014. Assessing the Sensitivities of a Distributed Snow Model to Forcing Data Resolution. Journal of Hydrometeorology, 15(4), 1366-1383.

Wiscombe, Warren J., \& Warren, Stephen G. 1980. A Model for the Spectral Albedo of Snow. I: Pure Snow. Journal of the Atmospheric Sciences, 37(12), 2712-2733.

Xia, Youlong, Mitchell, Kenneth, Ek, Michael, Sheffield, Justin, Cosgrove, Brian, Wood, Eric, Luo, Lifeng, Alonge, Charles, Wei, Helin, Meng, Jesse, Livneh, Ben, Lettenmaier, Dennis, Koren, Victor, Duan, Qingyun, Mo, Kingtse, Fan, Yun, \& Mocko, David. 2012. Continental-scale water and energy flux analysis and validation for the North American Land Data Assimilation System project phase 2 (NLDAS-2): 1. Intercomparison and application of model products. Journal of Geophysical Research: Atmospheres, 117(D03109).

Yang, Daqing, Goodison, Barry E., Metcalfe, John R., Golubev, Valentin S., Bates, Roy, Pangburn, Timothy, \& Hanson, Clayton L. 1998. Accuracy of NWS 8" Standard Nonrecording Precipitation Gauge: Results and Application of WMO Intercomparison. Journal of Atmospheric and Oceanic Technology, 15(1), 54-68. 
Yen, YC. 1962. Effective thermal conductivity of ventilated snow. Journal of Geophysical Research, 67(3), 1091-1098. 